\title{
A PANDEMIA A TRAVÉS DE TÁBOAS E GRÁFICOS
}

\author{
CARPente SARdĩ̃a, José ANTONio \\ Profesor de Matemáticas no IES de Fene (1989-2019) \\ jcarpente@edu.xunta.es
}

\section{RESUMO}

Este traballo non ten outra finalidade que compartir táboas e gráficos obtidos a partir de datos oficiais nas distintas vagas da pandemia.

A primeira parte refírese á primeira vaga e céntrase na evolución en España e Galicia. A segunda parte céntrase na incidencia acumulada nas sete cidades galegas e na comarca de Ferrolterra durante a fin da segunda vaga e na terceira.

\section{ABSTRACT}

This work has no other purpose than to share tables and graphs obtained from official data in the various waves of the pandemic. The first part refers to the first wave and focuses on the evolution in Spain and Galicia. The second part focuses on the accumulated incidences in the seven Galician cities and in the region of Ferrolterra towards the end of the second wave and in the third.

\section{INTRODUCIÓN}

As táboas, gráficos e suxestións presentadas neste traballo teñen un afán divulgativo e, se algún docente o considera conveniente, práctico. Penso que poden ser útiles para o traballo na aula no estudo da estatística descritiva, especialmente para ver exemplos dos distintos tipos de gráficos estatísticos; e mesmo na materia de Métodos Estatísticos e Numéricos de $2^{\circ}$ de Bacharelato, para o estudo das series de tempo e o seu axuste mediante as medias móbeis. Nas Ciencias Sociais tamén poden usarse para ver a evolución da pandemia e as distintas vagas mediante a interpretación das gráficas. 
Engádense as táboas e gráficos que fun confeccionando ao longo destes meses, e envío copias das follas de cálculo utilizadas á redacción do Boletín das Ciencias en formato LibreOffice Calc (.ods), por se alguén quere dispor libremente delas.

\section{A PRIMEIRA VAGA EN ESPAÑA E EN GALICIA}

Desde os primeiros momentos da pandemia propúxenme facer un seguimento dos datos oficiais da Covid-19. Despois de buscar un pouco, achei unha páxina web de Europa Press ${ }^{1}$ onde aparecían aqueles con claridade. Elaborei dúas follas de cálculo: unha para España e outra para Galicia.

Os datos que recollín para España foron os de casos novos, mortes e curados (tanto diarios coma acumulados nos tres casos). Engadín á táboa os incrementos diarios de cada serie, os casos pechados (mortos máis curados) e os casos activos (casos acumulados menos casos pechados). Finalmente, agreguei as medias móbeis a sete días para todas as series anteriores, excepto para a dos casos pechados.

A folla correspondente a Galicia amosa as mesmas series de datos agás, por non dispor delas, as de curados e, xa que logo, as de casos pechados e casos activos.

Durante a elaboración das táboas, o Ministerio de Sanidade realizou dous cambios de criterio na elaboración da contabilidade ${ }^{2}$. 0 primeiro deles tivo lugar o 19 de abril cando se pasou a contabilizar como contaxiados por coronavirus só a aqueles que foran confirmados cunha proba PCR, e non os positivos polo test de anticorpos. Posteriormente, o 25 de maio, reduciuse o número de mortos en 1918 para, segundo explicou o Ministerio, axustar os datos cos do Servizo de Vixilancia Epidemiolóxica (SiViEs); ademais informouse de que algunhas comunidades autónomas comunicaran como falecidos casos sospeitosos mais non confirmados. Este axuste tamén se traduciu na contabilidade de casos acumulados, con 372 menos nese día.

Ademais destes cambios de criterio na contabilidade, o 19 de maio deixaron de aparecer o número de casos curados. Por esta razón, as táboas e gráficas de curados e casos activos só alcanzan ata o 18 de maio.

Cada unha das gráficas elaboradas inclúe a serie dos valores reais (en azul) e a das medias móbeis (en vermello), agás a última gráfica que recolle en azul os casos acumulados, en amarelo os curados, en vermello os mortos e en verde os pechados (suma dos dous anteriores).

Os cambios de criterio na contabilidade aprécianse nas gráficas con situacións anómalas, como que descendan series acumulativas ou se produzan un número negativo de mortes ou casos novos.

\section{LENDA}

N: casos novos diarios

MD: mortes diarias

CuD: curados diarios
CA: casos acumulados

MA: mortes acumuladas

CuA: curados acumulados
M+C: casos pechados

CsAc: casos activos

$\% \Delta \mathbf{I}, \mathbf{\%} \Delta \mathbf{M}$ e $\% \Delta \mathbf{C}$ : \% incremento respecto ó día anterior de infectados, mortos e curados, respectivamente.

\footnotetext{
${ }^{1}$ Os datos están tirados de: https://www.epdata.es/datos/coronavirus-china-datos-graficos/498. 0 primeiro caso produciuse o 31 de xaneiro. A primeira morte produciuse o 13 de febreiro. Remátase a recollida de datos o 5 de xuño, cando xa remitira a vaga e os números eran baixos.
}

${ }^{2}$ Véxase a mesma páxina web indicada na nota 1. 
Táboa 1. Datos de casos, mortes e curados en España

\begin{tabular}{|c|c|c|c|c|c|c|c|c|c|c|c|}
\hline & $\mathrm{CN}$ & $\mathrm{CA}$ & $\% \triangle M$ & MD & MA & $\% \triangle M$ & CuD & $\mathrm{CuA}$ & $\% M C$ & $M+C$ & CsAc \\
\hline $27 /$ feb & & & & & & & & & & & \\
\hline$/$ feb & 16 & 34 & $88,9 \%$ & & & & & & & & \\
\hline$/$ feb & 17 & 50 & $47,1 \%$ & & & & & & & & \\
\hline $1 /$ mar & 28 & 73 & $46,0 \%$ & & & & & & & & \\
\hline /mar & 54 & 119 & $63,0 \%$ & & & & & & & & \\
\hline /mar & 56 & 175 & $47,1 \%$ & & & & & & & & \\
\hline 04/mar & 75 & 250 & $42,9 \%$ & 1 & 1 & & & & & & \\
\hline 05/mar & 78 & 348 & $39,2 \%$ & 2 & 3 & & & & & & \\
\hline 06/mar & 188 & 531 & $52,6 \%$ & 2 & 5 & & & & & & \\
\hline 07/mar & 234 & 764 & $43,9 \%$ & 3 & 8 & $60,0 \%$ & & 30 & & & \\
\hline 08/mar & 330 & 1094 & $43,2 \%$ & 7 & 15 & $87,5 \%$ & 0 & 30 & $0,0 \%$ & 45 & 1049 \\
\hline 09/mar & 433 & 1527 & $39,6 \%$ & 13 & 28 & $86,7 \%$ & 0 & 30 & $0,0 \%$ & 58 & 1469 \\
\hline 10/mar & 773 & 2299 & $50,6 \%$ & 7 & 36 & $28,6 \%$ & 105 & 135 & $350,0 \%$ & 171 & 2128 \\
\hline 11/mar & 973 & 3274 & $42,4 \%$ & 13 & 48 & $33,3 \%$ & 3 & 138 & & 186 & 3088 \\
\hline $12 /$ mar & 1163 & 4427 & $35,2 \%$ & 38 & 85 & 77,1 & 51 & 189 & 37, & 274 & 4153 \\
\hline 13 & 1527 & 5958 & $34,6 \%$ & 37 & 124 & $45,9 \%$ & 4 & 193 & 2,1 & 317 & 5641 \\
\hline & 1708 & 7641 & $28,2 \%$ & 18 & 144 & $16,1 \%$ & 351 & 544 & 181, & 688 & 6953 \\
\hline & 2128 & 9785 & $28,1 \%$ & 151 & 296 & $105,6 \%$ & 12 & 556 & & 852 & 8933 \\
\hline 16 & 1707 & 11491 & $17,4 \%$ & 22 & 318 & $7,4 \%$ & 19 & 575 & 3, & 893 & 10598 \\
\hline & 2476 & 13994 & $21,8 \%$ & 182 & 497 & 56 , & 511 & 10 & 88 & 15 & 2411 \\
\hline & 3693 & 17688 & $26,4 \%$ & & 591 & & & & & & \\
\hline & 4045 & 21735 & $22,9 \%$ & 175 & 766 & $29,6 \%$ & 50 & 12 & 4,3 & 1976 & 19759 \\
\hline & 4570 & 26304 & $21,0 \%$ & 228 & 995 & $29,9 \%$ & 332 & 15 & 27 , & 25 & 23767 \\
\hline & 5447 & 31750 & $20,7 \%$ & 333 & 1349 & 35, & 589 & & 38 & 34 & 28270 \\
\hline & 4862 & 36616 & $15,3 \%$ & 346 & 1715 & 27,1 & 541 & & 25 & 4387 & 32229 \\
\hline & 4645 & 41262 & $12,7 \%$ & 464 & 2146 & $25,1 \%$ & 46 & & & & 35976 \\
\hline & 7691 & 48953 & $18,6 \%$ & 571 & 2711 & 26,3 & 55 & 36 & 17 , & 64 & 42545 \\
\hline 25 & 8547 & 57506 & $17,5 \%$ & 596 & 3307 & 22, & 1357 & 50 & 36 & 8361 & 49145 \\
\hline & 8952 & 66460 & $15,6 \%$ & 615 & 3920 & $18,5 \%$ & 127 & & & 10246 & 56214 \\
\hline & 9182 & 75641 & $13,8 \%$ & 745 & 4673 & $19,2 \%$ & 216 & & & & 62477 \\
\hline & 8244 & 83885 & $10,9 \%$ & 839 & 5513 & 18 , & 240 & 5 & & & \\
\hline 2 & 6421 & 90309 & $7,7 \%$ & 715 & 6223 & 12 & 232 & & 21 & 19 & 70867 \\
\hline & 5813 & 96122 & $6,4 \%$ & 696 & 6923 & & & & & & 74376 \\
\hline & & & $8,5 \%$ & 820 & 7744 & & 2103 & & & & \\
\hline 01 & 7412 & 680 & $7,1 \%$ & 941 & 8674 & 12 & 3097 & 20 & 18 , & 28697 & 82983 \\
\hline & 7576 & 9263 & $6,8 \%$ & 875 & 9546 & $10,1 \%$ & 3486 & & & & 86208 \\
\hline & 72 & & $6,1 \%$ & 846 & 10394 & & & & & & 89601 \\
\hline 04 & 6654 & 98 & $5,3 \%$ & 778 & 11171 & $7,5 \%$ & 36 & 3 & $\%$ & 44 & 91854 \\
\hline & 5530 & 38731 & $4,2 \%$ & 669 & 11841 & $6,0 \%$ & 3528 & & $11,7 \%$ & & 93189 \\
\hline & 3666 & 398 & $2,6 \%$ & 629 & 12469 & $5,3 \%$ & 2022 & & & & 94206 \\
\hline 07/abr & 5202 & 07 & $3,7 \%$ & 752 & 13224 & $6,1 \%$ & 2897 & 38 & $8,1 \%$ & 51844 & 95763 \\
\hline 08/abr & 5573 & 53190 & $3,8 \%$ & 818 & 13981 & $5,7 \%$ & 4471 & & $11,6 \%$ & 57072 & 96118 \\
\hline & & & $3,8 \%$ & 782 & & & 4025 & & & 61876 & 97059 \\
\hline $10 / a b r$ & 4530 & 63472 & $2,9 \%$ & 651 & & & & & & & 97205 \\
\hline $11 / a b r$ & 4548 & 68022 & $2,8 \%$ & 511 & 15905 & $3,2 \%$ & 3258 & 54118 & $6,4 \%$ & 70023 & 97999 \\
\hline $12 / a b r$ & 3896 & 71921 & $2,3 \%$ & 606 & 16515 & $3,8 \%$ & 2908 & 57026 & $5,4 \%$ & 73541 & 98380 \\
\hline & 30 & & & 550 & & & 2139 & & & & 98722 \\
\hline 11 & 31 & 067 & $1,8 \%$ & 544 & 17600 & $3,1 \%$ & 2759 & 61924 & $4,7 \%$ & 79524 & 98543 \\
\hline
\end{tabular}




\begin{tabular}{|c|c|c|c|c|c|c|c|c|c|}
\hline $15 / a b r$ & 4410182491 & $2,5 \%$ & 68318282 & $3,9 \%$ & 3758 & 65682 & $6,1 \%$ & 83964 & 98527 \\
\hline 16/abr & 3817186311 & $2,1 \%$ & 62018901 & $3,4 \%$ & 3779 & 69461 & $5,8 \%$ & 88362 & 97949 \\
\hline 17/abr & 3820190129 & $2,0 \%$ & 58519490 & $3,1 \%$ & 3491 & 72952 & $5,0 \%$ & 92442 & 97687 \\
\hline 18/abr & 3833193965 & $2,0 \%$ & 56620046 & $2,9 \%$ & 1710 & 74662 & $2,3 \%$ & 94708 & 99257 \\
\hline 19/abr & 2402193252 & $-0,4 \%$ & 41220454 & $2,0 \%$ & 2695 & 77357 & $3,6 \%$ & 97811 & 95441 \\
\hline 20/abr & 2218195470 & $1,1 \%$ & 40420851 & $1,9 \%$ & 3230 & 80587 & $4,2 \%$ & 101438 & 94032 \\
\hline 21/abr & 2950198421 & $1,5 \%$ & 43121283 & $2,1 \%$ & 1927 & 82514 & $2,4 \%$ & 103797 & 94624 \\
\hline $22 / a b r$ & 2311200733 & $1,2 \%$ & 43821717 & $2,0 \%$ & 3401 & 85915 & $4,1 \%$ & 107632 & 93101 \\
\hline 23/abr & 2919203649 & $1,5 \%$ & 45022156 & $2,0 \%$ & 3335 & 89250 & $3,9 \%$ & 111406 & 92243 \\
\hline $24 / a b r$ & 2106205763 & $1,0 \%$ & 36622521 & $1,6 \%$ & 3105 & 92355 & $3,5 \%$ & 114876 & 90887 \\
\hline 25/abr & 2507208269 & $1,2 \%$ & 38322898 & $1,7 \%$ & 3353 & 95708 & $3,6 \%$ & 118606 & 89663 \\
\hline 26/abr & 1640209910 & $0,8 \%$ & 29223184 & $1,2 \%$ & 3024 & 98732 & $3,2 \%$ & 121916 & 879 \\
\hline $27 / a b r$ & 1662211570 & $0,8 \%$ & 33223516 & $1,4 \%$ & 2143 & 100875 & $2,2 \%$ & 124391 & 8717 \\
\hline 28/abr & 1524213095 & $0,7 \%$ & 30323813 & $1,3 \%$ & 1673 & 102548 & $1,7 \%$ & 126361 & 8673 \\
\hline 29/abr & 836213942 & $0,4 \%$ & 32524272 & $1,9 \%$ & 6399 & 108947 & $6,2 \%$ & 133219 & 80723 \\
\hline $30 / a b r$ & 1240215183 & $0,6 \%$ & 26824537 & $1,1 \%$ & 3103 & 112050 & $2,8 \%$ & 136587 & 78596 \\
\hline 01/mai & 1347216570 & $0,6 \%$ & 28124818 & $1,1 \%$ & 2628 & 114678 & $2,3 \%$ & 139496 & 7707 \\
\hline 02/mai & 1233217804 & $0,6 \%$ & 27625097 & $1,1 \%$ & 2570 & 117248 & $2,2 \%$ & 142345 & 75459 \\
\hline 03/mai & 935218739 & $0,4 \%$ & 16425260 & $0,6 \%$ & 1654 & 118902 & $1,4 \%$ & 144162 & 74577 \\
\hline 04/mai & 465219205 & $0,2 \%$ & 16425424 & $0,6 \%$ & 2441 & 121343 & $2,1 \%$ & 146767 & 72438 \\
\hline 05/mai & 1034220244 & $0,5 \%$ & 18525610 & $0,7 \%$ & 2143 & 123486 & $1,8 \%$ & 149096 & 71148 \\
\hline 06/mai & 876221124 & $0,4 \%$ & 24425854 & $1,0 \%$ & 2516 & 126002 & $2,0 \%$ & 151856 & 6926 \\
\hline 07/mai & 914222045 & $0,4 \%$ & 21326062 & $0,8 \%$ & 2509 & 128511 & $2,0 \%$ & 154573 & 67472 \\
\hline 08/mai & 1160223218 & $0,5 \%$ & 22926291 & $0,9 \%$ & 2637 & 131148 & $2,1 \%$ & 157439 & 65779 \\
\hline 09/mai & 714223961 & $0,3 \%$ & 17926469 & $0,7 \%$ & 2804 & 133952 & $2,1 \%$ & 160421 & 63540 \\
\hline 10/mai & 621227377 & $1,5 \%$ & 14326613 & $0,5 \%$ & 2214 & 136166 & $1,7 \%$ & 162779 & 6459 \\
\hline 11/mai & 373227770 & $0,2 \%$ & 12326737 & $0,5 \%$ & 973 & 137139 & $0,7 \%$ & 163876 & 638 \\
\hline $12 /$ mai & 426228252 & $0,2 \%$ & 17626909 & $0,6 \%$ & 1841 & 138980 & $1,3 \%$ & 165889 & 62363 \\
\hline $13 /$ mai & 439228691 & $0,2 \%$ & 18427091 & $0,7 \%$ & 1843 & 140823 & $1,3 \%$ & 167914 & \\
\hline 14/mai & 506229540 & $0,4 \%$ & 21727308 & $0,8 \%$ & 2551 & 143374 & $1,8 \%$ & 170682 & 5885 \\
\hline 15/mai & 549230183 & $0,3 \%$ & 13827449 & $0,5 \%$ & 1409 & 144783 & $1,0 \%$ & 172232 & $5 / 95$ \\
\hline 16/mai & 539230698 & $0,2 \%$ & 10227549 & $0,4 \%$ & 1663 & 146446 & $1,1 \%$ & 173995 & 567 \\
\hline $17 /$ mai & 421231350 & $0,3 \%$ & 8727634 & $0,3 \%$ & 2719 & 149576 & $2,1 \%$ & 177210 & 5414 \\
\hline 18/mai & 285231606 & $0,1 \%$ & 5927693 & $0,2 \%$ & 800 & 150376 & $0,5 \%$ & 178069 & \\
\hline 19/mai & 295232037 & $0,2 \%$ & 8327793 & $0,4 \%$ & & & & & \\
\hline 20/mai & 416232555 & $0,2 \%$ & 9527892 & $0,4 \%$ & & & & & \\
\hline 21/mai & 344233037 & $0,2 \%$ & 4827940 & $0,2 \%$ & & & & & \\
\hline $22 /$ mai & 446234824 & $0,8 \%$ & 5628628 & $2,5 \%$ & & & & & \\
\hline 23/mai & 361235290 & $0,2 \%$ & 4828678 & $0,2 \%$ & & & & & \\
\hline 24/mai & 246235772 & $0,2 \%$ & 7028752 & $0,3 \%$ & & & & & \\
\hline 25/mai & 132235400 & $-0,2 \%$ & 5026834 & $-6,7 \%$ & & & & & \\
\hline 26/mai & 194236259 & $0,4 \%$ & 3527117 & $1,1 \%$ & & & & & \\
\hline 27/mai & 231236769 & $0,2 \%$ & 3927118 & $0,0 \%$ & & & & & \\
\hline 28/mai & 182237906 & $0,5 \%$ & 3827119 & $0,0 \%$ & & & & & \\
\hline 29/mai & 187238564 & $0,3 \%$ & 3927121 & $0,0 \%$ & & & & & \\
\hline 30/mai & 271239228 & $0,3 \%$ & 4327125 & $0,0 \%$ & & & & & \\
\hline 31/mai & 96239429 & $0,1 \%$ & 3927127 & $0,0 \%$ & & & & & \\
\hline 01/xuñ & 71239638 & $0,1 \%$ & 3527127 & $0,0 \%$ & & & & & \\
\hline 02/xuñ & 137239932 & $0,1 \%$ & 3427127 & $0,0 \%$ & & & & & \\
\hline 03/xuñ & 219240326 & $0,2 \%$ & 6327128 & $0,0 \%$ & & & & & \\
\hline 04/xuñ & 195240660 & $0,1 \%$ & 5627133 & $0,0 \%$ & & & & & \\
\hline 05 & 1772 & $0.1 \%$ & 52 & 0 & & & & & \\
\hline
\end{tabular}




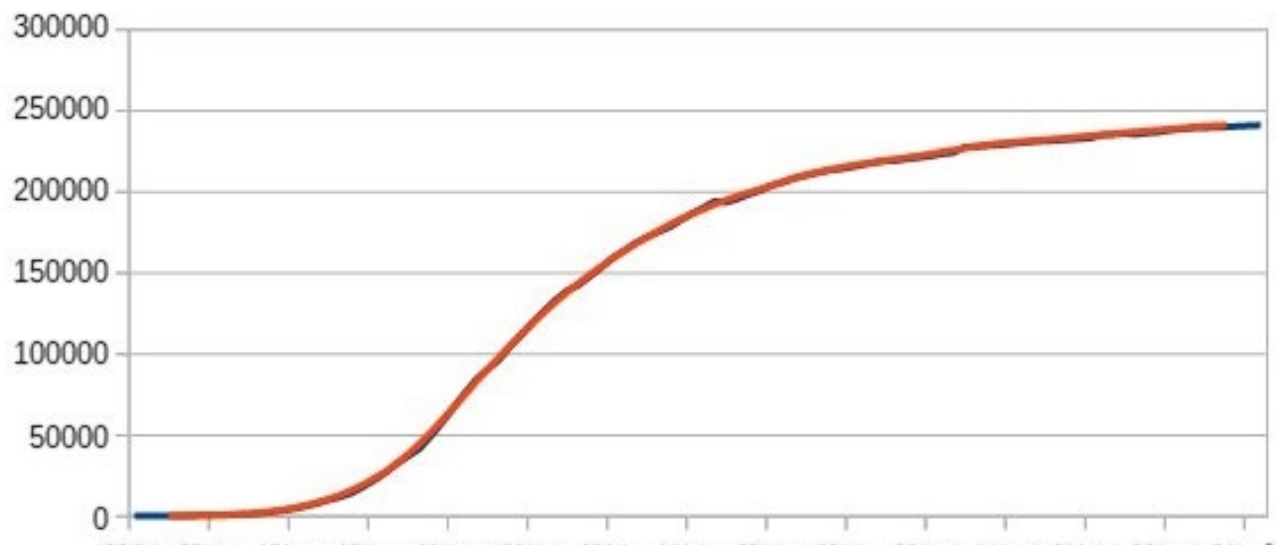

27/feb 05/mar 12/mar 19/mar 26/mar 02/abr 09/abr 16/abr 23/abr 30/abr 07/mai 14/mai 21/mai 28/mai 04/xun

Figura 1. Número total de infectados en España.

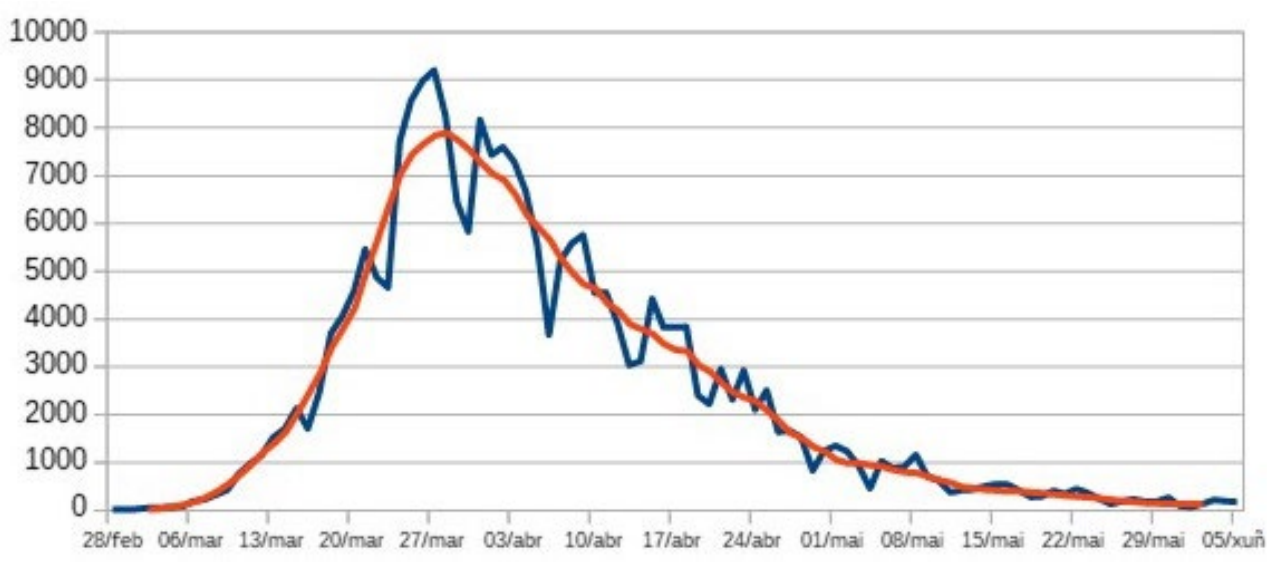

Figura 2. Número de infectados diarios en España.

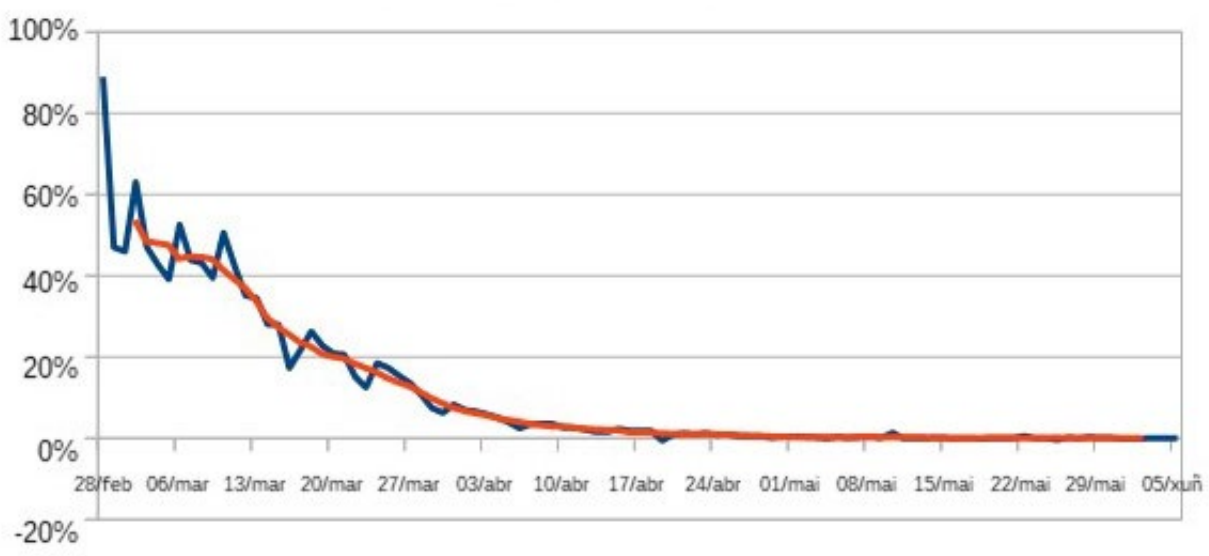

Figura 3. Incremento diario de infectados en España. 


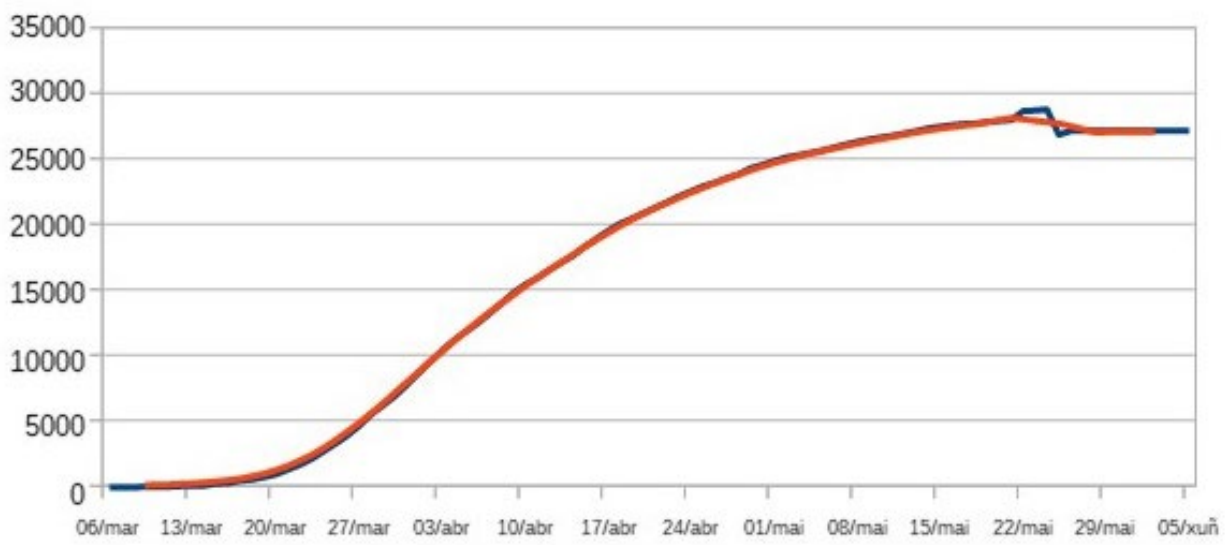

Figura 4. Número total de mortos en España.

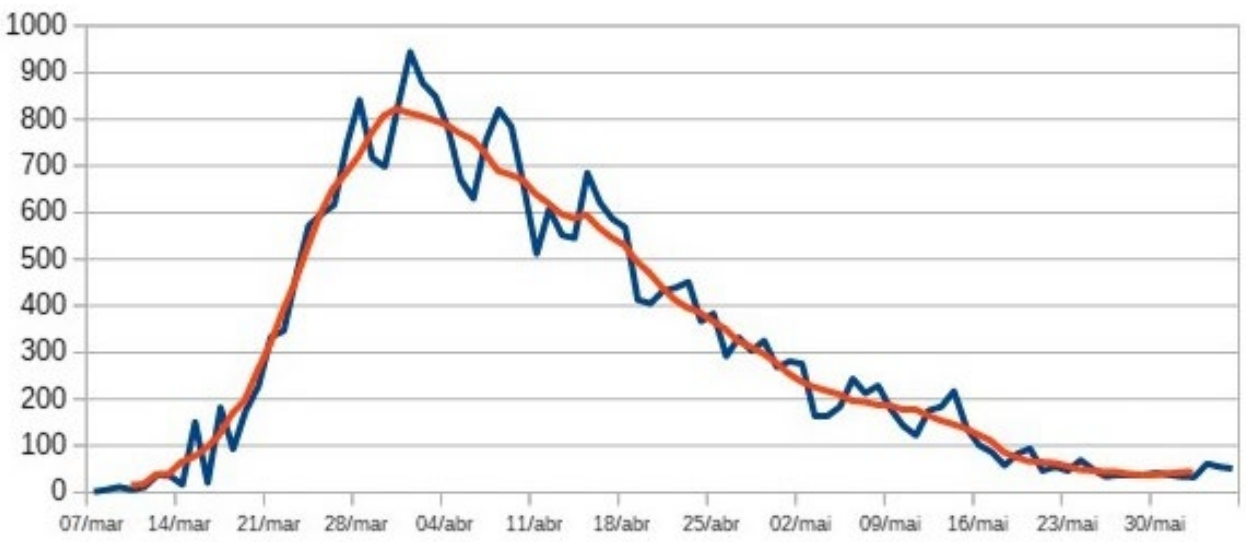

Figura 5. Número de mortos diarios en España.

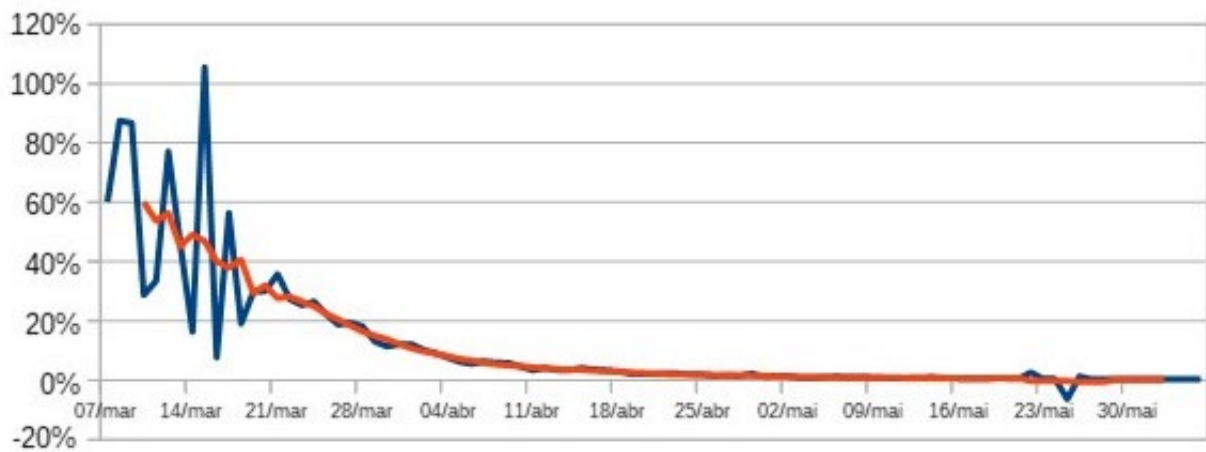

Figura 6. Incremento diario de mortos (desde o 18 de marzo) en España. 


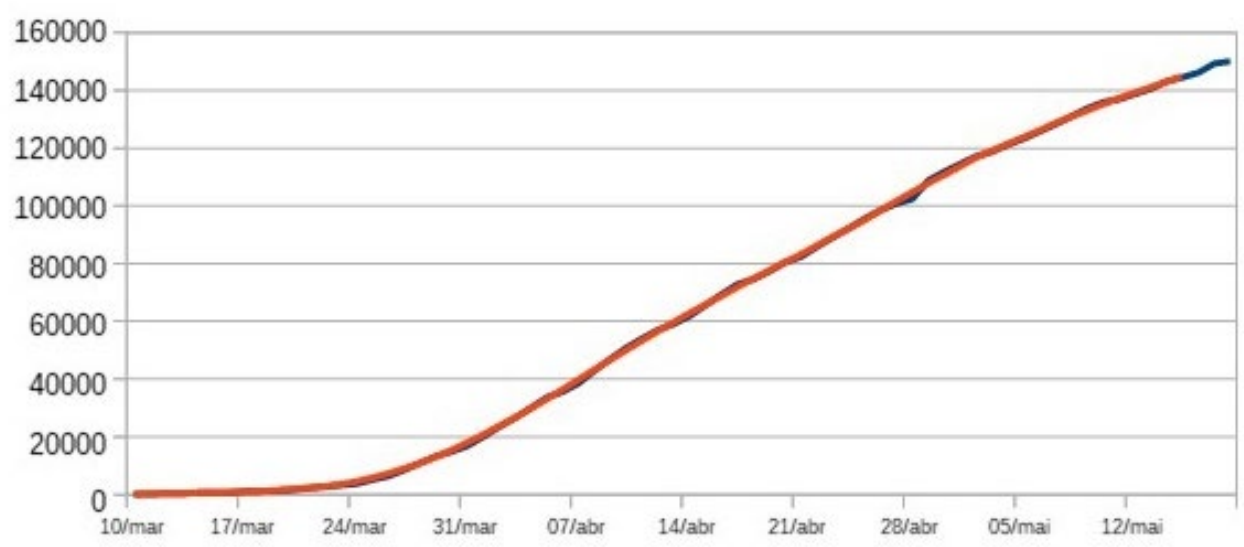

Figura 7. Número total de curados en España.

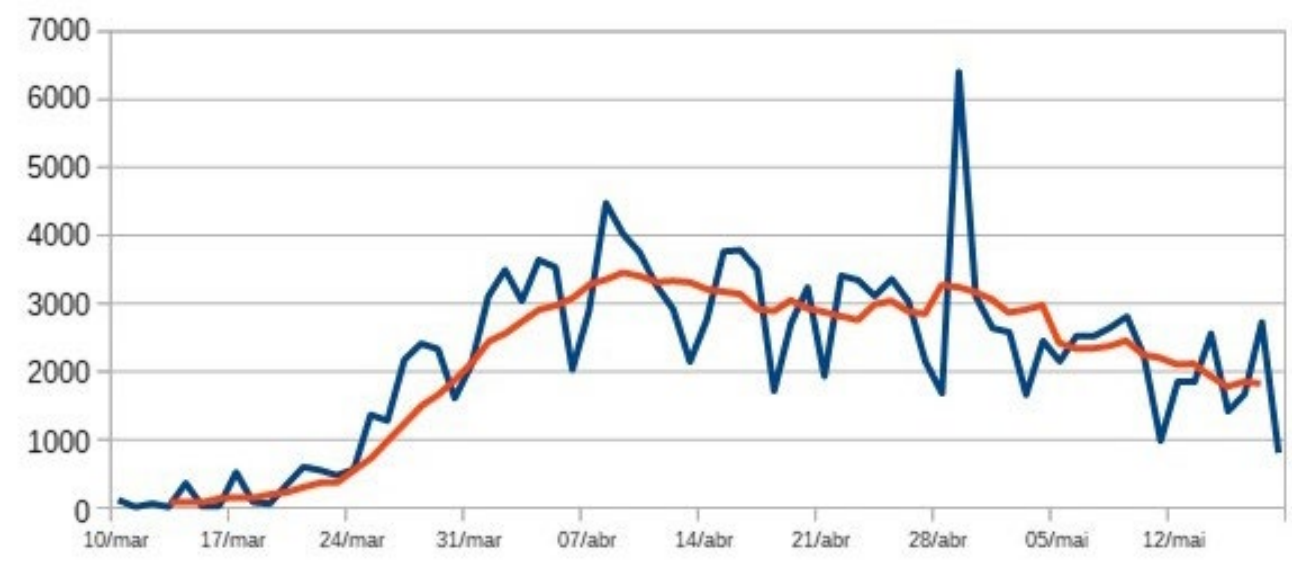

Figura 8. Número de curados diarios en España.

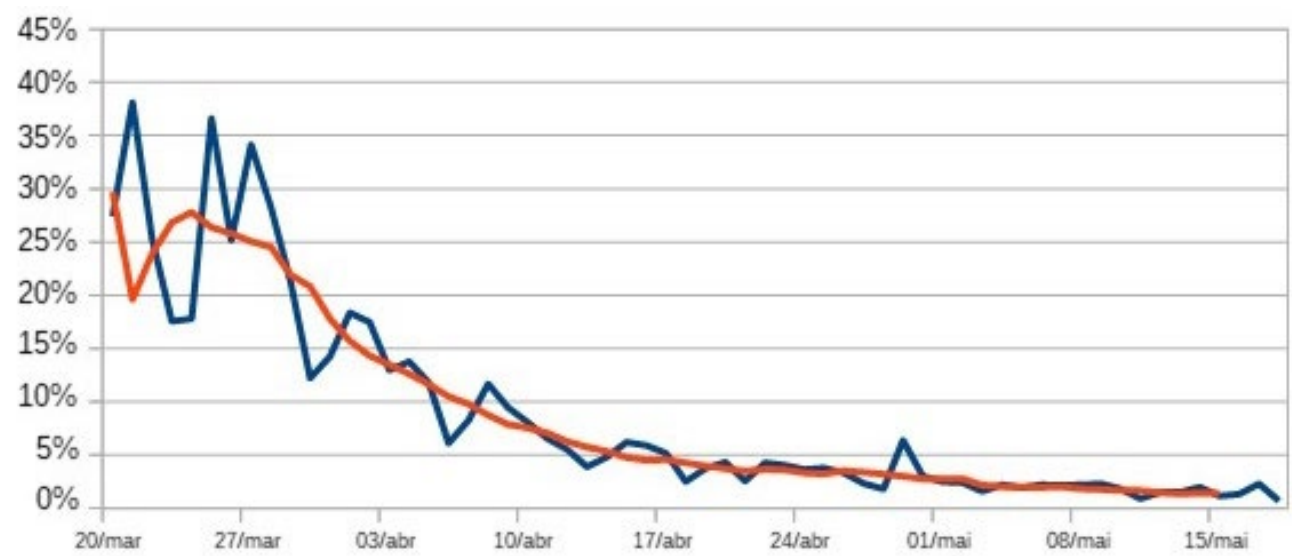

Figura 9. Incremento diario de curados en España. 


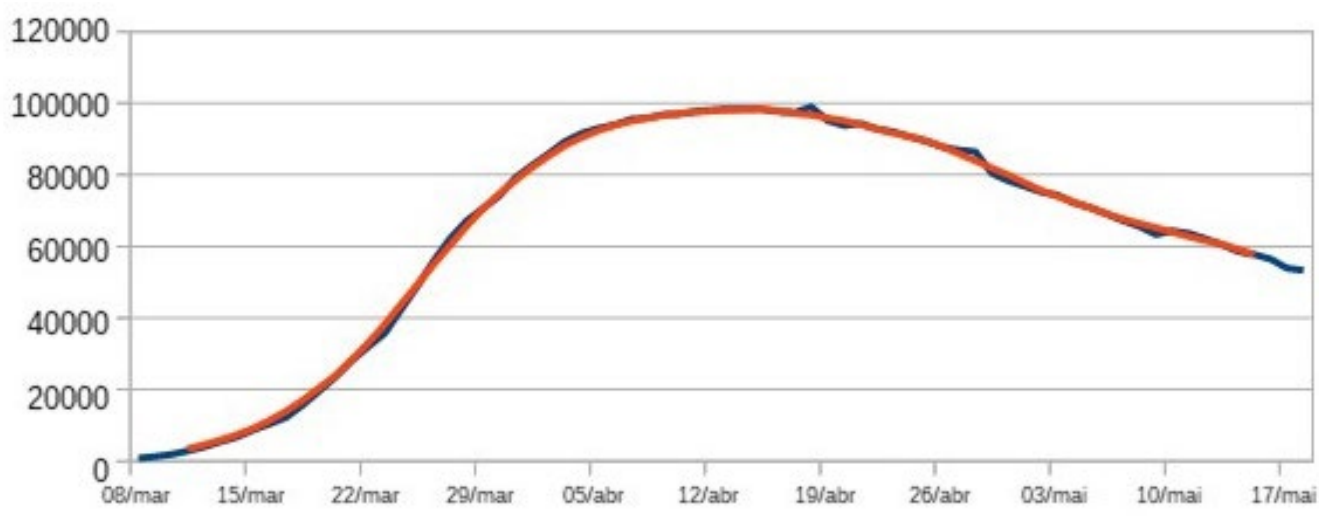

Figura 10. Casos activos (ata o 18 de maio) en España.

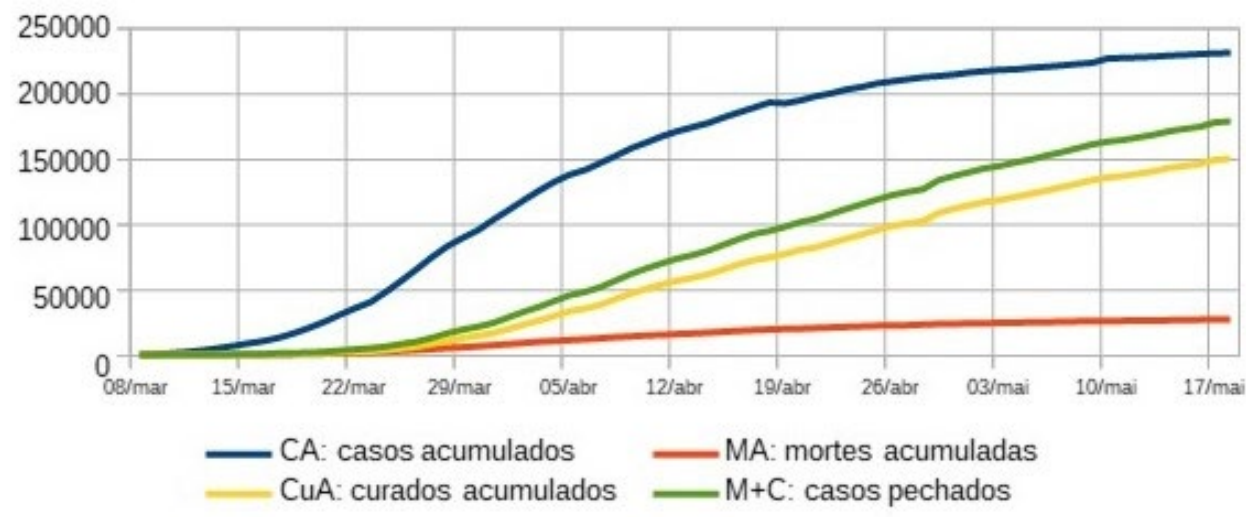

Figura 11. Totais de infectados, curados e mortos en España. 
Táboa 2. Datos de medias móbeis a sete días en España

\begin{tabular}{|c|c|c|c|c|c|c|c|c|c|c|}
\hline & & DIAS $\mathrm{N}$ & BEIS & 7 DIAS & & & & & & \\
\hline & $\mathrm{CN}$ & $\mathrm{CA}_{103}$ & $\% \triangle M$ & MD & MA & $\% \triangle M$ & CuD & $\mathrm{CuA}$ & $\% \triangle M C$ & CsAc \\
\hline 02/mar & 46 & 150 & $53,4 \%$ & & & & & & & \\
\hline 03/mar & 71 & 221 & $48,3 \%$ & & & & & & & \\
\hline $04 /$ mar & 102 & 323 & $47,8 \%$ & & & & & & & \\
\hline 05/mar & 145 & 469 & $47,4 \%$ & & & & & & & \\
\hline $06 /$ mar & 199 & 670 & $44,1 \%$ & & & & & & & \\
\hline $07 /$ mar & 302 & 973 & $44,6 \%$ & & & & & & & \\
\hline 08/mar & 430 & 1405 & $44,5 \%$ & & & & & & & \\
\hline 09/mar & 585 & 1988 & $43,9 \%$ & & 32 & & & & & \\
\hline $10 /$ mar & 776 & 2763 & $41,3 \%$ & 17 & 49 & $59,9 \%$ & & 106 & & \\
\hline $11 /$ mar & 987 & 3746 & $39,1 \%$ & 19 & 69 & $53,6 \%$ & 73 & 180 & $81,9 \%$ & 3497,3 \\
\hline $12 / \mathrm{mar}$ & 1244 & 4987 & $37,0 \%$ & 40 & 109 & $56,2 \%$ & 75 & 255 & $82,2 \%$ & 4623,6 \\
\hline $13 / \mathrm{mar}$ & 1426 & 6411 & $33,8 \%$ & 41 & 150 & $44,9 \%$ & 78 & 333 & $82,7 \%$ & 5927,7 \\
\hline $14 /$ mar & 1669 & 8081 & $29,7 \%$ & 66 & 216 & $48,8 \%$ & 136 & 469 & $45,4 \%$ & 7396,7 \\
\hline $15 /$ mar & 2057 & 10141 & $27,4 \%$ & 77 & 294 & $46,8 \%$ & 146 & 615 & $46,0 \%$ & 9232,3 \\
\hline $16 /$ mar & 2469 & 12613 & $25,6 \%$ & 97 & 391 & $40,0 \%$ & 146 & 761 & $41,4 \%$ & 11462 \\
\hline $17 / \mathrm{mar}$ & 2904 & 15520 & $23,7 \%$ & 124 & 515 & $37,7 \%$ & 193 & 953 & $45,0 \%$ & 14051 \\
\hline $18 / \mathrm{mar}$ & 3438 & 18964 & $22,6 \%$ & 169 & 687 & $40,5 \%$ & 227 & 1180 & $24,5 \%$ & 17096 \\
\hline $19 /$ mar & 3829 & 22797 & $20,8 \%$ & 197 & 890 & $29,3 \%$ & 302 & 1482 & 27,8 & 20424 \\
\hline $20 /$ mar & 4248 & 27050 & $20,1 \%$ & 260 & 1151 & $31,8 \%$ & 366 & 1849 & $29,8 \%$ & 24050 \\
\hline $21 / \mathrm{mar}$ & 4993 & 32044 & $19,7 \%$ & 316 & 1468 & $27,5 \%$ & 373 & 2222 & $19,6 \%$ & 28355 \\
\hline $22 / \mathrm{mar}$ & 5687 & 37732 & $18,4 \%$ & 388 & 1856 & $28,0 \%$ & 556 & 2778 & $23,9 \%$ & 33099 \\
\hline $23 / \mathrm{mar}$ & 6388 & 44122 & $17,3 \%$ & 450 & 2306 & $26,4 \%$ & 731 & 3509 & $26,9 \%$ & 38307 \\
\hline $24 /$ mar & 7047 & 51170 & $16,3 \%$ & 524 & 2832 & $24,8 \%$ & 993 & 4502 & $27,8 \%$ & 43837 \\
\hline $25 /$ mar & 7446 & 58618 & $14,9 \%$ & 597 & 3426 & $22,3 \%$ & 1252 & 5754 & $26,4 \%$ & 49437 \\
\hline $26 /$ mar & 7669 & 66288 & $13,8 \%$ & 649 & 4070 & $20,3 \%$ & 1507 & 7260 & $25,9 \%$ & 54957 \\
\hline $27 / \mathrm{mar}$ & 7836 & 74125 & $12,9 \%$ & 682 & 4753 & $18,3 \%$ & 1669 & 8929 & $25,1 \%$ & 60443 \\
\hline $28 /$ mar & 7901 & 82027 & $11,5 \%$ & 718 & 5472 & $16,2 \%$ & 1890 & 10819 & $24,6 \%$ & 65736 \\
\hline $29 /$ mar & 7739 & 89766 & $10,0 \%$ & 767 & 6239 & $14,8 \%$ & 2138 & 2958 & 22 , & 0570 \\
\hline $30 /$ mar & 7542 & 97310 & $8,7 \%$ & 804 & 7042 & $13,6 \%$ & 2455 & 15412 & 20 , & 74855 \\
\hline $31 / \mathrm{mar}$ & 7268 & 04580 & $7,6 \%$ & 819 & 7860 & $12,1 \%$ & 2578 & 17991 & $17,8 \%$ & 78730 \\
\hline 01/abr & 7041 & 11625 & $6,8 \%$ & 810 & 8668 & $10,6 \%$ & 2754 & 20745 & $15,7 \%$ & 82212 \\
\hline $02 / a b r$ & 6914 & 18542 & $6,3 \%$ & 804 & 9470 & $9,6 \%$ & 2926 & 23671 & $14,3 \%$ & 85401 \\
\hline 03/abr & 6607 & 25153 & $5,8 \%$ & 794 & 10263 & $8,8 \%$ & 2986 & 26656 & $13,5 \%$ & 88234 \\
\hline 04/abr & 6186 & 31345 & $5,1 \%$ & 784 & 11046 & $8,0 \%$ & 3099 & 29756 & $12,6 \%$ & 90543 \\
\hline 05/abr & 5924 & 37275 & $4,6 \%$ & 767 & 11804 & $7,1 \%$ & 3295 & 33051 & 11 , & 92420 \\
\hline 06/abr & 56 & 42942 & $4,2 \%$ & 753 & 12549 & $6,4 \%$ & 3372 & 36423 & $10,5 \%$ & 3970 \\
\hline 07/abr & 5271 & 48219 & $3,7 \%$ & 726 & 13265 & $5,8 \%$ & 3474 & 39898 & $\%$ & 95056 \\
\hline 08/abr & 4970 & 53194 & $3,4 \%$ & 687 & 13941 & $5,2 \%$ & 3421 & 43318 & 8 , & 95934 \\
\hline 09/abr & 4737 & 57935 & $3,1 \%$ & 678 & 14609 & $4,9 \%$ & 3332 & 46651 & $7,8 \%$ & 96676 \\
\hline $10 / a b r$ & 4646 & 62585 & $3,0 \%$ & 667 & 15265 & $4,6 \%$ & 3349 & 49999 & $7,5 \%$ & 97321 \\
\hline 11/abr & 4348 & 66937 & $2,7 \%$ & 637 & 15890 & $4,2 \%$ & 3329 & 53329 & $7,0 \%$ & 97718 \\
\hline $12 / a b r$ & 4182 & .71123 & $2,5 \%$ & 618 & 16505 & $3,9 \%$ & 3227 & 56556 & $6,2 \%$ & 98062 \\
\hline $13 / a b r$ & 3906 & 75034 & $2,3 \%$ & 595 & 17096 & $3,6 \%$ & 3192 & 59748 & $5,7 \%$ & 98189 \\
\hline $14 / a b r$ & 3805 & 78842 & $2,2 \%$ & 586 & 17680 & $3,4 \%$ & 3156 & 62904 & $5,3 \%$ & 98258 \\
\hline 15/abr & 3703 & 82548 & $2,1 \%$ & 593 & 18271 & $3,4 \%$ & 2935 & 65839 & $4,7 \%$ & 98438 \\
\hline $16 / a b r$ & 3489 & 85595 & $1,7 \%$ & 566 & 18834 & $3,1 \%$ & 2904 & 68743 & $4,5 \%$ & 98018 \\
\hline $17 / a b r$ & 3373 & 88526 & $1,6 \%$ & 545 & 19375 & $2,9 \%$ & 3060 & 71804 & $4,5 \%$ & 97348 \\
\hline $18 / a b r$ & 3350 & 91434 & $1,6 \%$ & 529 & 19901 & $2,8 \%$ & 2941 & 74745 & $4,2 \%$ & 96788 \\
\hline 19/abr & 3050 & 94040 & $1,4 \%$ & 494 & 20392 & $2,5 \%$ & 2890 & 77635 & $3,9 \%$ & 96013 \\
\hline $20 / a b r$ & 2922 & 96517 & $1,3 \%$ & 469 & 20857 & $2,3 \%$ & 2827 & 80462 & $3,6 \%$ & 95198 \\
\hline $21 / a b r$ & 2677 & 98750 & $1,1 \%$ & 438 & 21290 & $2,1 \%$ & 2772 & 83234 & $3,4 \%$ & 94226 \\
\hline 22/abr & 2488 & 00794 & $1,0 \%$ & 412 & 21697 & $1,9 \%$ & 3007 & 86241 & $3,6 \%$ & 92856 \\
\hline & 20 & 3174 & $1,2 \%$ & 395 & 22087 & $1,8 \%$ & 3054 & 89294 & $3,5 \%$ & \\
\hline 24/abr & 2299 & 05474 & $1,1 \%$ & 385 & 22468 & $1,7 \%$ & 2898 & 92193 & $3,3 \%$ & 90813 \\
\hline
\end{tabular}




\begin{tabular}{|c|c|c|c|c|c|c|c|}
\hline $25 / a b r$ & 2096207570 & $1,0 \%$ & 36622829 & $1,6 \%$ & 286295055 & $3,2 \%$ & 89686 \\
\hline $26 / a b r$ & 1885209457 & $0,9 \%$ & 35023194 & $1,6 \%$ & $3290 \quad 98345$ & $3,5 \%$ & 87918 \\
\hline $27 / a b r$ & 1645211105 & $0,8 \%$ & 32423534 & $1,5 \%$ & 3257101602 & $3,3 \%$ & 85968 \\
\hline $28 / a b r$ & 1537212648 & $0,7 \%$ & 31223863 & $1,4 \%$ & 3189104791 & $3,2 \%$ & 8399 \\
\hline 29/abr & 1355214011 & $0,6 \%$ & 29724177 & $1,3 \%$ & 3077107868 & $3,0 \%$ & 8196 \\
\hline $30 / a b r$ & 1254215272 & $0,6 \%$ & 27824473 & $1,2 \%$ & 2881110750 & $2,7 \%$ & 8004 \\
\hline 01/mai & 1083216363 & $0,5 \%$ & 25424746 & $1,1 \%$ & 2924113674 & $2,7 \%$ & 7794 \\
\hline $02 /$ mai & 1013217384 & $0,5 \%$ & 23825003 & $1,0 \%$ & 2991116665 & $2,7 \%$ & 7571 \\
\hline 03/mai & 1019218410 & $0,5 \%$ & 22625229 & $0,9 \%$ & 2436119101 & $2,1 \%$ & 7408 \\
\hline 04/mai & 972219390 & $0,4 \%$ & 21825446 & $0,9 \%$ & 2352121453 & $2,0 \%$ & 7249 \\
\hline 05/mai & 945220340 & $0,4 \%$ & 21125657 & $0,8 \%$ & 2353123806 & $1,9 \%$ & 7087 \\
\hline 06/mai & 871221219 & $0,4 \%$ & 19725853 & $0,8 \%$ & 2386126192 & $1,9 \%$ & 6917 \\
\hline 07/mai & 826222453 & $0,6 \%$ & 19426046 & $0,7 \%$ & 2466128658 & $2,0 \%$ & 6774 \\
\hline 08/mai & 813223677 & $0,5 \%$ & 18826234 & $0,7 \%$ & 2257130915 & $1,8 \%$ & 6652 \\
\hline 09/mai & 726224821 & $0,5 \%$ & 18726419 & $0,7 \%$ & 2213133128 & $1,7 \%$ & 6527 \\
\hline $10 /$ mai & 664225902 & $0,5 \%$ & 17826596 & $0,7 \%$ & 2117135246 & $1,6 \%$ & 6406 \\
\hline 11/mai & 606226973 & $0,5 \%$ & 17926774 & $0,7 \%$ & 2123137369 & $1,6 \%$ & 6283 \\
\hline $12 /$ mai & 518227968 & $0,4 \%$ & 16626939 & $0,6 \%$ & 1948139317 & $1,4 \%$ & 6171 \\
\hline 13/mai & 493228930 & $0,4 \%$ & 15527094 & $0,6 \%$ & 1785141102 & $1,3 \%$ & 6073 \\
\hline 14/mai & 465229498 & $0,2 \%$ & 14727240 & $0,5 \%$ & 1857143017 & $1,4 \%$ & 592 \\
\hline 15/mai & 452230046 & $0,2 \%$ & 13827376 & $0,5 \%$ & 1832144908 & $1,3 \%$ & J \\
\hline 16/mai & 433230586 & $0,2 \%$ & 12427502 & $0,5 \%$ & & & \\
\hline $17 /$ mai & 430231138 & $0,2 \%$ & 11227617 & $0,4 \%$ & & & \\
\hline 18/mai & 407231638 & $0,2 \%$ & 8727707 & $0,3 \%$ & & & \\
\hline 19/mai & 392232301 & $0,3 \%$ & 7627876 & $0,6 \%$ & & & \\
\hline 20/mai & 367232957 & $0,3 \%$ & 6828037 & $0,6 \%$ & & & \\
\hline 21/mai & 342233589 & $0,3 \%$ & 6628197 & $0,6 \%$ & & & \\
\hline $22 /$ mai & 320234131 & $0,2 \%$ & 6428074 & $-0,4 \%$ & & & \\
\hline 23/mai & 306234734 & $0,3 \%$ & 5727977 & $-0,3 \%$ & & & \\
\hline 24/mai & 279235336 & $0,3 \%$ & 4927867 & $-0,4 \%$ & & & \\
\hline 25/mai & 256236031 & $0,3 \%$ & 4827749 & $-0,4 \%$ & & & \\
\hline 26/mai & 219236566 & $0,2 \%$ & 4627534 & $-0,7 \%$ & & & \\
\hline $27 /$ mai & 206237128 & $0,2 \%$ & 4527312 & $-0,8 \%$ & & & \\
\hline 28/mai & 185237651 & $0,2 \%$ & 4027080 & $-0,8 \%$ & & & \\
\hline 29/mai & 176238256 & $0,3 \%$ & 3827122 & $0,2 \%$ & & & \\
\hline 30/mai & 168238781 & $0,2 \%$ & 3827123 & $0,0 \%$ & & & \\
\hline 31/mai & 166239289 & $0,2 \%$ & 4227125 & $0,0 \%$ & & & \\
\hline 01/xuñ & 168239682 & $0,2 \%$ & 4427127 & $0,0 \%$ & & & \\
\hline 02/xuñ & 167240027 & $0,1 \%$ & 4627129 & $0,0 \%$ & & & \\
\hline \multicolumn{8}{|l|}{ 03/xuñ } \\
\hline \multicolumn{8}{|l|}{ 04/xuñ } \\
\hline & & & & & & & \\
\hline
\end{tabular}


Táboa 3. Datos de casos, mortes e medias móbeis a sete días para Galicia. Datos tomados de https://www.epdata.es/datos/coronavirus-china-datos-graficos/498. o primeiro caso produciuse o 5 de marzo. A primeira morte produciuse o 15 de marzo.

\section{LENDA}

CN: casos novos diarios

MD: mortes diarias

$\% \Delta \mathbf{I}: \%$ incremento infectados respecto ao día anterior
CA: casos acumulados

MA: mortes acumuladas

$\% \Delta \mathbf{M}$ : \% incremento mortos respecto ao día anterior

\begin{tabular}{|c|c|c|c|c|c|c|c|c|c|c|c|c|}
\hline & & & & & & & & EDIAS I & IOBEIS & (7 D & AS) & \\
\hline & $\mathrm{CN}$ & CA & $\% \mathbf{M}$ & MD & MA & $\% \mathrm{MM}$ & $\mathrm{CN}$ & CA & $\% \mathbb{M}$ & MD & MA & $\%$ MM \\
\hline 05/mar & 1 & 1 & & & & & & & & & & \\
\hline 06/mar & 2 & & $200,0 \%$ & & & & & & & & & \\
\hline 07/mar & 2 & 5 & $66,7 \%$ & & & & & & & & & \\
\hline 08/mar & 2 & 7 & $40,0 \%$ & & & & 7 & 14 & & & & \\
\hline 09/mar & 12 & 19 & $171,4 \%$ & & & & 7 & 19 & $80,1 \%$ & & & \\
\hline 10/mar & 16 & 22 & $15,8 \%$ & & & & 14 & 30 & $72,0 \%$ & & & \\
\hline $11 /$ mar & 13 & 39 & $77,3 \%$ & & & & 18 & 46 & $67,5 \%$ & & & \\
\hline $12 / \mathrm{mar}$ & 0 & 35 & $-10,3 \%$ & & & & 29 & 73 & $71,7 \%$ & & & \\
\hline $13 /$ mar & 50 & 85 & $142,9 \%$ & & & & 34 & 105 & $50,9 \%$ & & & \\
\hline $14 /$ mar & 30 & 115 & $35,3 \%$ & & & & 39 & 144 & $51,4 \%$ & & & \\
\hline $15 /$ mar & 80 & 195 & $69,6 \%$ & 2 & 2 & & 44 & 187 & $42,7 \%$ & & & \\
\hline $16 /$ mar & 50 & 245 & $25,6 \%$ & 0 & 2 & $0,0 \%$ & 60 & 247 & $48,9 \%$ & & & \\
\hline $17 /$ mar & 47 & 292 & $19,2 \%$ & 1 & 3 & $50,0 \%$ & 70 & 317 & $32,4 \%$ & & & \\
\hline 18/mar & 49 & 341 & $16,8 \%$ & 0 & 3 & $0,0 \%$ & 89 & 406 & $31,4 \%$ & 1 & & \\
\hline 19/mar & 112 & 453 & $32,8 \%$ & 1 & 4 & $33,3 \%$ & 103 & 509 & $24,8 \%$ & 1 & 5 & $31,7 \%$ \\
\hline 20/mar & 125 & 578 & $27,6 \%$ & 1 & 5 & $25,0 \%$ & 138 & 647 & $25,7 \%$ & 2 & 8 & $38,8 \%$ \\
\hline $21 / \mathrm{mar}$ & 161 & 739 & $27,9 \%$ & 4 & 9 & $80,0 \%$ & 160 & 807 & $25,4 \%$ & 2 & 10 & $33,3 \%$ \\
\hline $22 /$ mar & 176 & 915 & $23,8 \%$ & 3 & 12 & $33,3 \%$ & 187 & 994 & $25,4 \%$ & 3 & 14 & $38,3 \%$ \\
\hline 23/mar & 293 & 1208 & $32,0 \%$ & 6 & 18 & $50,0 \%$ & 209 & 1203 & $23,0 \%$ & 4 & 18 & $36,1 \%$ \\
\hline $24 / \mathrm{mar}$ & 207 & 1415 & $17,1 \%$ & 2 & 20 & $11,1 \%$ & 249 & 1452 & $22,1 \%$ & 5 & 23 & $37,5 \%$ \\
\hline $25 /$ mar & 238 & 1653 & $16,8 \%$ & 7 & 27 & $35,0 \%$ & 290 & 1743 & $20,9 \%$ & 5 & 28 & $27,4 \%$ \\
\hline 26/mar & 262 & 1915 & $15,8 \%$ & 5 & 32 & $18,5 \%$ & 318 & 2061 & $19,4 \%$ & 7 & 35 & $26,6 \%$ \\
\hline $27 /$ mar & 407 & 2322 & $21,3 \%$ & 11 & 43 & $34,4 \%$ & 359 & 2420 & $17,5 \%$ & 7 & 42 & $20,9 \%$ \\
\hline 28/mar & 450 & 2772 & $19,4 \%$ & 4 & 47 & $9,3 \%$ & 375 & 2795 & $16,2 \%$ & 9 & 51 & $23,2 \%$ \\
\hline 29/mar & 367 & 3139 & $13,2 \%$ & 13 & 60 & $27,7 \%$ & 397 & 3192 & $15,2 \%$ & 13 & 64 & $23,4 \%$ \\
\hline 30/mar & 584 & 3723 & $18,6 \%$ & 6 & 66 & $10,0 \%$ & 418 & 3610 & $14,3 \%$ & 14 & 78 & $22,7 \%$ \\
\hline 31/mar & 316 & 4039 & $8,5 \%$ & 18 & 84 & $27,3 \%$ & 414 & 4024 & $12,4 \%$ & 15 & 93 & $19,8 \%$ \\
\hline $01 / a b r$ & 393 & 4432 & $9,7 \%$ & 31 & 115 & $36,9 \%$ & 408 & 4431 & $10,7 \%$ & 17 & 110 & $20,3 \%$ \\
\hline $02 / a b r$ & 410 & 4842 & $9,3 \%$ & 15 & 130 & $13,0 \%$ & 401 & 4832 & $9,6 \%$ & 17 & 128 & $17,6 \%$ \\
\hline 03/abr & 377 & 5219 & $7,8 \%$ & 19 & 149 & $14,6 \%$ & 347 & 5179 & $7,5 \%$ & 19 & 147 & $17,5 \%$ \\
\hline 04/abr & 406 & 5625 & $7,8 \%$ & 19 & 168 & $12,8 \%$ & 327 & 5506 & $6,7 \%$ & 18 & 164 & $14,2 \%$ \\
\hline 05/abr & 319 & 5944 & $5,7 \%$ & 14 & 182 & $8,3 \%$ & 301 & 5807 & $5,7 \%$ & 23 & 188 & $13,8 \%$ \\
\hline 06/abr & 207 & 6151 & $3,5 \%$ & 17 & 199 & $9,3 \%$ & 274 & 6081 & $4,9 \%$ & 24 & 212 & $12,9 \%$ \\
\hline
\end{tabular}




\begin{tabular}{|c|c|c|c|c|c|c|c|c|c|c|c|c|}
\hline 07/abr & 180 & 6331 & $2,9 \%$ & 9 & 208 & $4,5 \%$ & 247 & 6328 & $4,2 \%$ & 24 & 236 & $11,8 \%$ \\
\hline 08/abr & 207 & 6538 & $3,3 \%$ & 70 & 278 & $33,7 \%$ & 222 & 6549 & $3,5 \%$ & 26 & 261 & 11,3 \\
\hline 09/abr & 220 & 6758 & $3,4 \%$ & 19 & 297 & $6,8 \%$ & 199 & 6748 & $3,1 \%$ & 25 & 287 & 10,6 \\
\hline 10/abr & 188 & 946 & $2,8 \%$ & 21 & 318 & $7,1 \%$ & 192 & 6940 & $9 \%$ & 24 & 311 & \\
\hline 11/abr & 30 & 176 & $3 \%$ & 29 & 347 & $9,1 \%$ & 181 & 7121 & $2,6 \%$ & 25 & 336 & \\
\hline $12 / a b r$ & 60 & 336 & $2 \%$ & 13 & 360 & $3,7 \%$ & 167 & 7288 & $2,4 \%$ & 16 & 352 & \\
\hline & 15 & & & & & & & & & & 368 & \\
\hline $14 / a b r$ & 103 & 597 & $4 \%$ & 15 & 384 & $4,1 \%$ & 152 & 7600 & $2,1 \%$ & 4 & 382 & \\
\hline 15/abr & 111 & 708 & $5 \%$ & 7 & 391 & $1,8 \%$ & 130 & 7729 & & 2 & 393 & \\
\hline 16/abr & 165 & 373 & $1 \%$ & 14 & 405 & $3,6 \%$ & 21 & 7851 & & 2 & 405 & \\
\hline 17/abr & 0 & 13 & $8 \%$ & 10 & 415 & $2.5 \%$ & 15 & 7966 & $1.5 \%$ & 12 & 418 & \\
\hline 18/abr & 71 & 84 & $9 \%$ & 15 & 430 & $3,6 \%$ & 124 & 809 & $1,6 \%$ & 11 & 429 & 2,7 \\
\hline & 101 & & & 14 & 44 & & 13 & & $1,6 \%$ & 12 & 441 & \\
\hline 20 & 114 & & $1,4 \%$ & 11 & 455 & & 133 & & & 12 & 454 & \\
\hline 21/abr & 169 & 8468 & $0 \%$ & 9 & 464 & $2,0 \%$ & 131 & 8487 & $1,6 \%$ & 12 & 465 & $6 \%$ \\
\hline labr & 166 & 334 & $0 \%$ & 11 & 475 & $2,4 \%$ & 147 & 86 & $1,7 \%$ & 11 & 477 & \\
\hline labr & 171 & 305 & $0 \%$ & 17 & 492 & $3,6 \%$ & 14 & 0 & $1,6 \%$ & 11 & 487 & \\
\hline t/abr & 127 & 932 & $1,4 \%$ & 6 & 498 & $1,2 \%$ & 134 & 8910 & $1,5 \%$ & 11 & 498 & $2 \%$ \\
\hline 25/abr & 184 & 9116 & $2,1 \%$ & 11 & 509 & $2,2 \%$ & 123 & 0 & $1,4 \%$ & 1 & 509 & 200 \\
\hline $26 / a b r$ & 60 & & $0,7 \%$ & 10 & 519 & & 0 & & & 10 & 519 & \\
\hline /abr & 62 & 38 & $0,7 \%$ & 12 & 531 & 2,3 & -11 & 90 & $\%$ & & 527 & \\
\hline (1) & 90 & $\angle O$ & $1,0 \%$ & 0 & 540 & 1,7 & -2 & I & & & 535 & \\
\hline /abr & -635 & 8693 & $-6,8 \%$ & 7 & 47 & 1,3 & -45 & 8963 & & 7 & 542 & \\
\hline /abr & 38 & 731 & $0.4 \%$ & 0 & 547 & 0.0 & -48 & 8914 & & 6 & 549 & 20 \\
\hline i & 38 & & 0,4 & 8 & 55 & & -54 & & & 5 & 554 & $1,0 \%$ \\
\hline & 3 & 8 & 0 & 2 & 7 & 0 & -64 & 87 & & 5 & 559 & \\
\hline & 33 & 0 & 4 & $c_{1}$ & & 1,1 & 30 & 88 & & 5 & 564 & \\
\hline & 22 & 0 & $2 \%$ & 6 & 569 & $1,1^{\circ}$ & 27 & 8853 & $0,3 \%$ & 6 & 569 & 1,07 \\
\hline mai & 22 & 8881 & $0,2 \%$ & 4 & 573 & $0,7 \%$ & 26 & 8879 & $0,3 \%$ & 5 & 574 & $0,8 \%$ \\
\hline mai & 20 & & $0,2 \%$ & 9 & 582 & 1,6 & 23 & 8902 & $0,3 \%$ & 5 & 579 & $00^{\circ}$ \\
\hline & 18 & 8 & $0,2^{\circ}$ & 4 & 586 & 0 & 21 & 8 & $0,2 \%$ & 4 & 583 & \\
\hline & 33 & ( & $0,4 \%$ & 2 & 88 & 0,3 & 20 & 89 & $0,2 \%$ & 3 & 586 & ; \\
\hline & 12 & 64 & 0 & 0 & 591 & 0,5 & 1 & 89 & $0,2 \%$ & 3 & 590 & \\
\hline ai & 17 & 8981 & $0,2 \%$ & 1 & 592 & 0,2 & 16 & 89 & $0,2 \%$ & 2 & 592 & $0,4^{\circ}$ \\
\hline Imai & 18 & & $02 \%$ & 1 & 593 & $0,2 \%$ & 16 & 8 & $0,2 \%$ & 2 & 594 & $0.4^{\circ}$ \\
\hline & 4 & & 0 & 2 & 595 & 0 & 12 & & & 2 & 596 & \\
\hline & 11 & 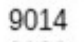 & $\%$ & 2 & 597 & 0,3 & -5 & 9 & $\%$ & 2 & 598 & \\
\hline & 16 & 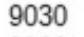 & $0,2 \%$ & 4 & 601 & 0,7 & 10 & 90 & $0,1 \%$ & 2 & 600 & 0 , \\
\hline & 0 & & & 0 & 601 & & & & & 2 & 602 & \\
\hline & 5 & & & 3 & & & & & & 2 & 603 & \\
\hline mai & 10 & & 0.10 & 2 & 6 & & & & & 1 & 605 & 020 \\
\hline & 5 & & & 1 & 607 & 0 , & 7 & & & 1 & 606 & \\
\hline & 2 & y & 0,0 & 0 & 607 & 0,0 & 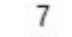 & 9 & $0,1 \%$ & 1 & 607 & 0 , \\
\hline & 9 & & & 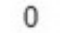 & 607 & 0,0 & 0 & & $0,1 \%$ & 1 & 608 & \\
\hline & 10 & & & 1 & 608 & 0,2 & 8 & & $0,1 \%$ & 1 & 609 & $0,2 \%$ \\
\hline & 7 & & & 1 & 609 & & & & & 0 & 609 & $00^{\circ}$ \\
\hline & 14 & & & 1 & & & 7 & & & 0 & 609 & \\
\hline & 7 & & & 3 & 613 & 0,5 & 7 & & $\%$ & 0 & 609 & \\
\hline & -26 & & $-0,3$ & -6 & 607 & $-1,0$ & 5 & & $0,1 \%$ & 0 & 609 & \\
\hline & 29 & & & 0 & 607 & & 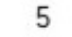 & & $0,1 \%$ & 0 & 609 & $0,0^{\circ}$ \\
\hline ai & 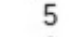 & & & 1 & 608 & 0,2 & 3 & & $0,0 \%$ & 0 & 609 & $0,0 \%$ \\
\hline & 2 & & & 0 & 608 & & 2 & & & -1 & 608 & \\
\hline & 2 & & & 0 & 608 & & & & & 0 & 608 & \\
\hline & 2 & & & 1 & 609 & & & & $0,0 \%$ & 0 & 609 & \\
\hline & -1 & & & 0 & 609 & & & & $0,0 \%$ & 0 & 609 & \\
\hline & 10 & & & 0 & 609 & $0,0 \%$ & 3 & 9120 & $0,0 \%$ & 0 & 609 & $0,0 \%$ \\
\hline & 1 & & & 0 & 609 & $0,0 \%$ & 4 & 913 & $0,0 \%$ & 0 & 609 & $0,0^{\circ}$ \\
\hline & 2 & & 0,0 & 0 & 609 & 0,0 & & & & & & \\
\hline & 2 & & $0,0^{\circ}$ & 0 & 60 & 0,0 & & & & & & \\
\hline & 12 & 9146 & $0,1 \%$ & 0 & 609 & $0,0 \%$ & & & & & & \\
\hline
\end{tabular}




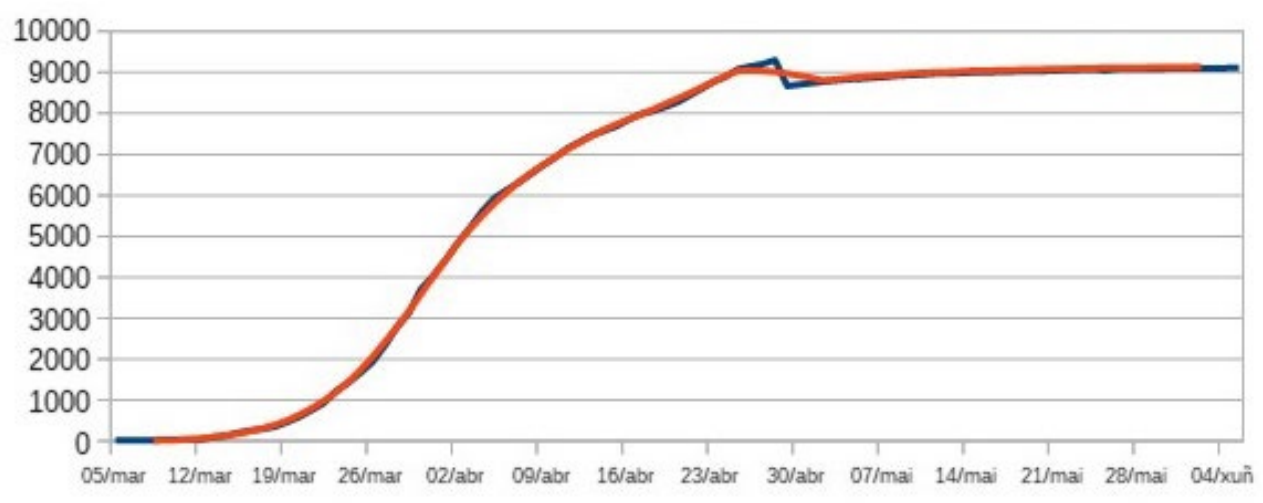

Figura 12. Total de infectados en Galicia.
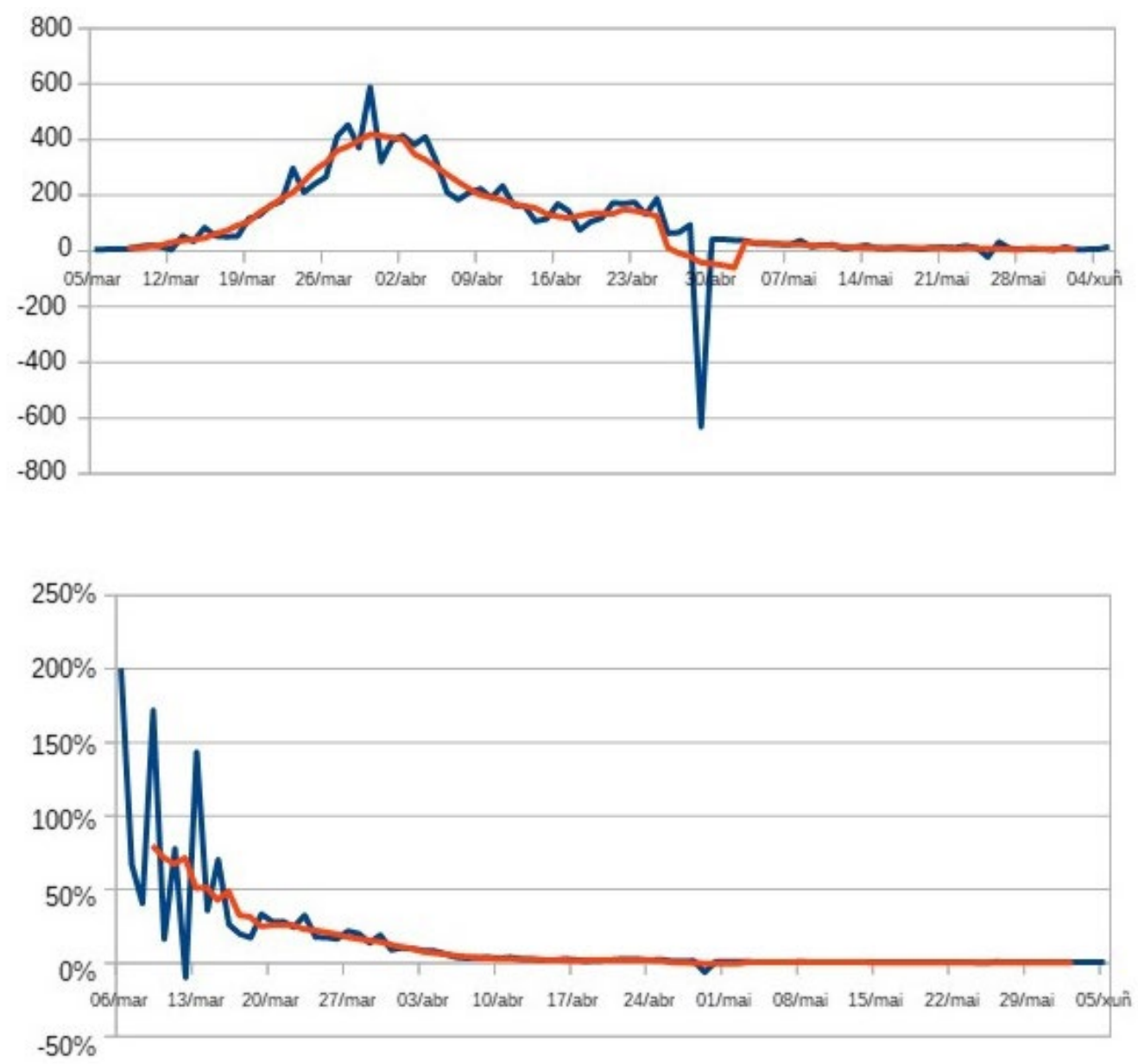

Figura 14. Incremento diario de infectados en Galicia. 


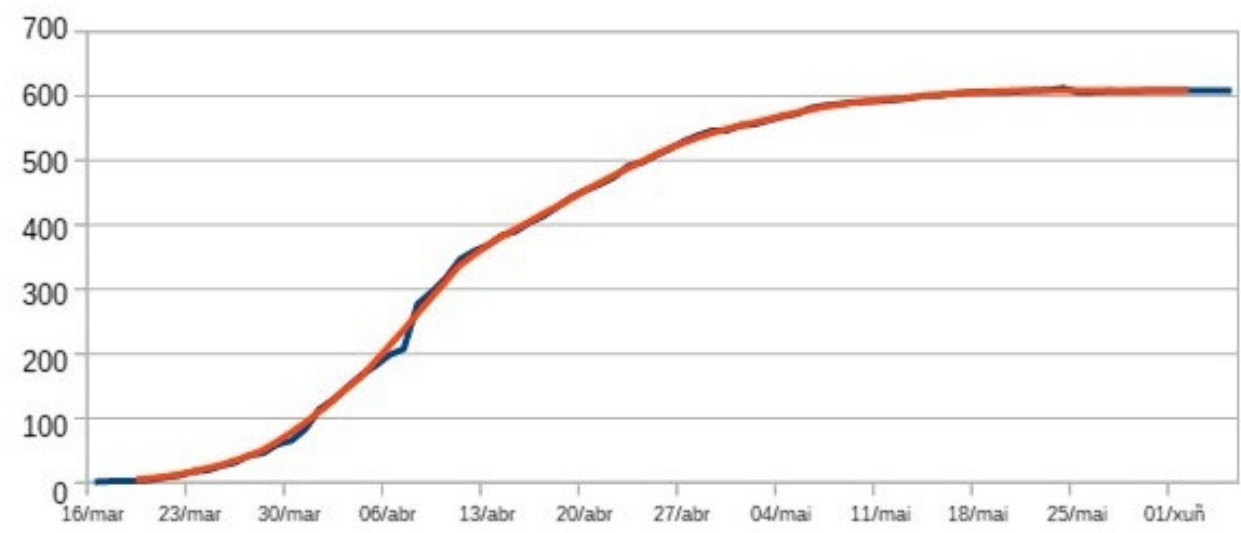

Figura 15. Mortos totais en Galicia.

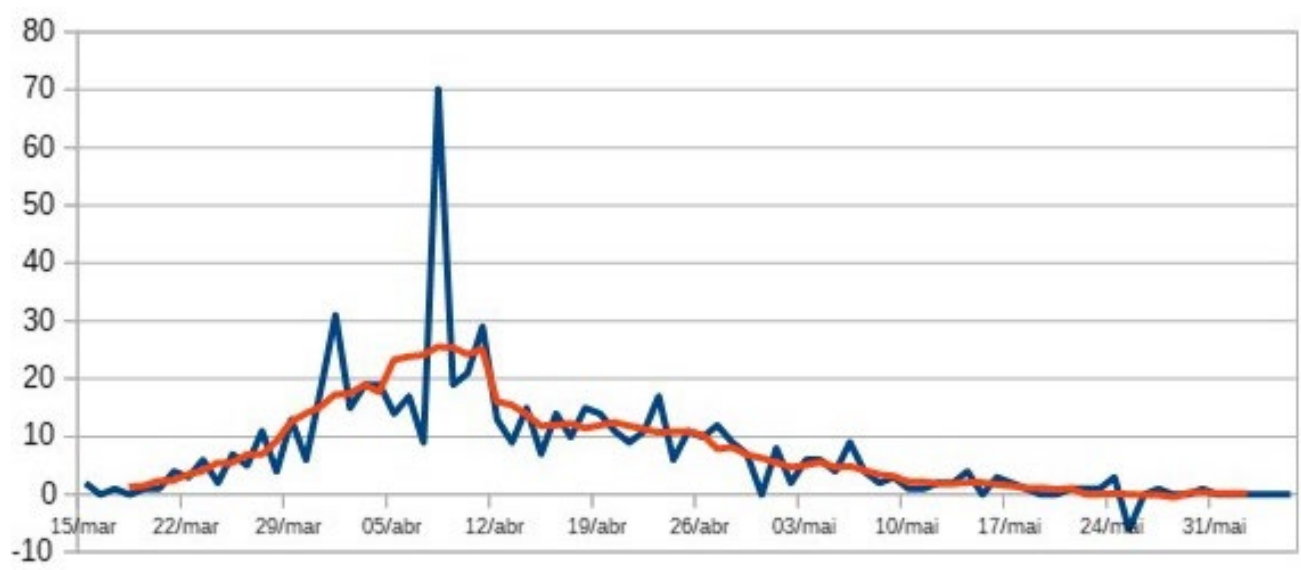

Figura 16. Mortos diarios en Galicia.

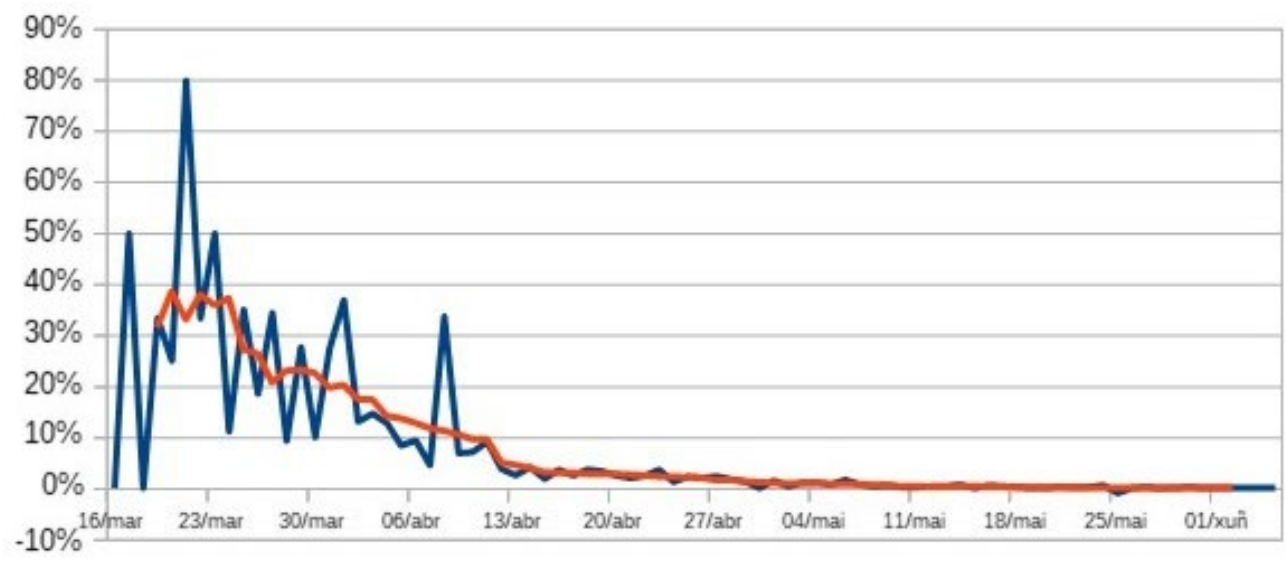

Figura 17. Incremento diario de mortos en Galicia. 


\section{0 FINAL DA SEGUNDA VAGA E A TERCEIRA EN FERROLTERRA E NAS CIDADES}

\section{1.- Ferrolterra}

Desde finais de novembro veño elaborando unhas táboas e gráficos sobre a situación da incidencia acumulada a 14 días $^{3}$ en Ferrolterra, termo non oficial ${ }^{4}$ que abarca os vinte concellos das comarcas do Eume, Ferrol e Ortegal, mais os de Miño e Vilarmaior. Os datos foron recollidos diariamente da páxina de información do coronavirus en Galicia ${ }^{5}$.

Nesa páxina recóllense, entre outra información, o número de casos novos nos últimos 14 días e a incidencia acumulada (IA) a 14 días de cada concello galego. Salientar que a IA vén dada por tramos: de 0 a 25 (baixa); de 25 a 50 (moderada); de 50 a 150 (media); de 150 a 250 (alta); e máis de 250 (extrema). A comezos de marzo prodúcense dúas novidades na información por concellos: desdóbrase o tramo de máis de 250 en dous -de 250 a 500, e máis de 500-, e infórmase dos casos novos e a IA nos últimos 7 días. Outra particularidade da información dada é que cando o número de casos novos é inferior a 10, non se dá o valor exacto senón que se di "entre 1 e 9 casos novos".

A intención era dar os datos exactos a partir da información dispoñible. No caso da IA, non supón maior problema sabendo o número de habitantes de cada concello6; simplemente é dividir os casos novos entre a poboación e multiplicar ese cociente por 100000 para obter a IA exacta (exemplo 1). Cando o número de casos novos é inferior a 10, ao non dispor do valor exacto, só se poden obter uns intervalos para a IA, e tamén restrinxir algo máis o intervalo [1,9] para o número de casos novos. Isto conséguese combinando os intervalos de casos novos e os de IA, mediante tenteo. Ás veces, é posible dar os valores exactos (exemplo 2).

Nun primeiro momento, dábanse na táboa estes intervalos que acoutaban os valores exactos. Mais esta maneira de expresar os datos en intervalos impedía facer gráficas nas que aparecesen os concellos cuxos datos viñan expresados por intervalos, razón pola cal só se facían gráficos para os cinco concellos máis poboados. Para salvar este atranco, a partir do primeiro de xaneiro, substituíronse os intervalos de IA polo valor central do intervalo (estes valores aparecen en cor vermella nas táboas), co cal xa era posible facer gráficas de todos os concellos (exemplo 3).

A modo de exemplo, propoño a continuación uns exercicios relacionados cos comentarios feitos:

Exemplo 1: o 5 de decembro de 2020 había en Ferrol 112 casos novos de infectados nos últimos 14 días. Calcular a IA a 14 días sabendo que o censo de Ferrol en 2019 era de 66065 habitantes.

Exemplo 2: segundo os datos facilitados polo Sergas, o 4 de decembro de 2020 había no concello de Ortigueira entre 1 e 9 casos novos nos últimos 14 días e unha IA entre 25 e 50 . Sabendo que o censo de Ortigueira en 2019 era de 5671 habitantes, calcular o número exacto de casos novos e o valor exacto da IA.

Exemplo 3: o 30 de decembro había en Ares entre 1 e 9 casos novos nos últimos 14 días, e unha IA entre 50 e 150. Sabendo que o censo de Ares en 2019 era de 5732 habitantes, dar senllos

\footnotetext{
${ }^{3}$ Defínese a incidencia acumulada a 14 días como o número de casos novos por cen mil habitantes aparecidos nos últimos 14 dias.
}

4Véxase a entrada Ferrolterra na Galipedia: https://gl.wikipedia.org/wiki/Ferrolterra

${ }^{5}$ https://coronavirus.sergas.gal/datos/\#/gl-ES/galicia

${ }^{6}$ Usouse o censo oficial de 2019, dispoñible na páxina web do Instituto Galego de Estatística:

https://www.ige.eu/igebdt/esq.jsp?paxina=002001\&ruta=nomenclator/nomenclator.jsp 
intervalos de amplitude mínima para os casos novos e a IA. Cal foi o valor medio do intervalo das IA?

Táboa 4. Casos novos nos últimos 14 días en Ferrolterra do 27 de novembro ao 8 de decembro de 2020 (os intervalos indican que o valor real está nese intervalo).

\begin{tabular}{|c|c|c|c|c|c|c|c|c|c|c|c|c|}
\hline CONCELLO & $27 / \mathrm{nov}$ & $28 /$ nov & $29 /$ nov & $30 /$ nov & $01 /$ dec & $02 / \mathrm{dec}$ & 03/dec & 04/dec & 05/dec & $06 / \mathrm{dec}$ & $07 / \mathrm{dec}$ & 08/dec \\
\hline Ares & 9 & {$[3,8]$} & {$[3,8]$} & {$[3,8]$} & {$[3,8]$} & {$[3,8]$} & {$[3,8]$} & {$[3,8]$} & {$[3,8]$} & {$[3,8]$} & {$[3,8]$} & {$[3,8]$} \\
\hline Cabanas & {$[2,4]$} & {$[2,4]$} & {$[5,8]$} & {$[5,8]$} & {$[5,8]$} & {$[5,8]$} & {$[5,8]$} & {$[2,4]$} & {$[2,4]$} & {$[5,8]$} & {$[5,8]$} & {$[5,8]$} \\
\hline Capela, A & {$[2,3]$} & {$[2,3]$} & {$[2,3]$} & {$[2,3]$} & {$[2,3]$} & {$[2,3]$} & {$[2,3]$} & {$[2,3]$} & {$[2,3]$} & 0 & 0 & \\
\hline Cariño & {$[2,5]$} & {$[2,5]$} & {$[2,5]$} & {$[2,5]$} & {$[2,5]$} & {$[2,5]$} & {$[2,5]$} & {$[2,5]$} & {$[2,5]$} & {$[2,5]$} & {$[2,5]$} & \\
\hline Cedeira & {$[4,9]$} & {$[4,9]$} & {$[4,9]$} & {$[4,9]$} & {$[4,9]$} & {$[4,9]$} & {$[4,9]$} & {$[4,9]$} & {$[4,9]$} & {$[4,9]$} & {$[4,9]$} & \\
\hline Cerdido & 1 & 1 & 1 & 1 & 1 & 1 & 1 & 1 & 1 & 1 & 0 & \\
\hline Fene & 32 & 31 & 28 & 25 & 26 & 23 & 17 & 14 & 13 & 14 & 15 & \\
\hline Ferrol & 159 & 150 & 149 & 140 & 138 & 128 & 126 & 130 & 112 & 110 & 108 & \\
\hline Mañón & 0 & 0 & 0 & 0 & 0 & 0 & 0 & 0 & 0 & 0 & 0 & \\
\hline Miño & 10 & 10 & 10 & 10 & 11 & 11 & 11 & 10 & {$[4,9]$} & {$[4,9]$} & {$[4,9]$} & {$[4$,} \\
\hline Moeche & {$[4,9]$} & {$[4,9]$} & {$[4,9]$} & {$[4,9]$} & {$[4,9]$} & {$[4,9]$} & {$[4,9]$} & {$[4,9]$} & 1 & 1 & {$[4,9]$} & \\
\hline Monfero & 17 & 18 & 18 & 17 & 19 & 18 & 16 & 14 & 15 & 14 & 14 & \\
\hline Mugardos & {$[3,7]$} & {$[3,7]$} & {$[8,9]$} & {$[3,7]$} & {$[3,7]$} & {$[8,9]$} & {$[3,7]$} & {$[3,7]$} & {$[3,7]$} & {$[3,7]$} & {$[3,7]$} & {$[3$,} \\
\hline Narón & 135 & 138 & 136 & 129 & 126 & 118 & 112 & 114 & 104 & 97 & 91 & \\
\hline Neda & 13 & 12 & 10 & {$[8,9]$} & {$[8,9]$} & {$[8,9]$} & {$[3,7]$} & {$[3,7]$} & {$[8,9]$} & 11 & 11 & \\
\hline Ortigueira & 1 & 1 & 1 & 1 & 2 & 2 & 2 & 2 & {$[3,8]$} & {$[3,8]$} & {$[3,8]$} & {$[3$,} \\
\hline Pontedeume & 41 & 42 & 37 & 34 & 35 & 35 & 31 & 26 & 20 & 18 & 15 & \\
\hline Pontes, As & 58 & 61 & 70 & 73 & 79 & 90 & 93 & 99 & 97 & 98 & 98 & 10 \\
\hline San Sadurniño & 10 & 10 & {$[8,9]$} & {$[8,9]$} & 10 & 10 & {$[8,9]$} & {$[5,7]$} & {$[5,7]$} & {$[5,7]$} & {$[5,7]$} & {$[5$,} \\
\hline Somozas, As & 1 & 1 & 1 & 1 & 1 & 0 & 0 & 0 & 1 & 1 & 2 & {$[3$,} \\
\hline Valdoviño & 13 & 14 & 16 & 18 & 16 & 16 & 15 & 15 & 16 & 17 & 16 & \\
\hline \multirow[t]{6}{*}{ Vilarmaior } & 1 & 1 & 1 & 1 & 1 & 1 & 1 & 1 & 1 & 1 & 1 & \\
\hline & \multicolumn{5}{|c|}{ CENSOS (2019) } & \multicolumn{2}{|c|}{ Mugardos } & \multicolumn{2}{|c|}{5245 Pontes, As } & 10138 & & \\
\hline & Ares & \multicolumn{2}{|c|}{5732 Cedeira } & \multicolumn{2}{|c|}{6640 Mañón } & \multicolumn{2}{|c|}{1356 Narón } & \multicolumn{2}{|c|}{39090 S. Sadurniño } & 2822 & & \\
\hline & Cabanas & \multicolumn{2}{|c|}{3281 Cerdido } & \multicolumn{2}{|c|}{1113 Miño } & \multicolumn{2}{|c|}{$6200 \mathrm{Neda}$} & \multicolumn{2}{|c|}{5079 Somozas, As } & 1098 & & \\
\hline & Capela A & \multicolumn{2}{|c|}{1232 Fene } & \multicolumn{2}{|c|}{12944 Moeche } & \multicolumn{2}{|c|}{1226 Ortigueira } & \multicolumn{2}{|c|}{5671 Valdoviño } & 6563 & & \\
\hline & Carî̀o & \multicolumn{2}{|c|}{3838 Ferrol } & \multicolumn{2}{|c|}{66065 Monfero } & \multicolumn{2}{|c|}{1932 Pontedeume } & \multicolumn{2}{|c|}{7777 Vilarmaior } & 1226 & & \\
\hline
\end{tabular}

Táboa 5. Incidencia acumulada a 14 días en Ferrolterra do 27 de novembro ao 8 de decembro de 2020 (os intervalos indican que o valor real está nese intervalo).

\begin{tabular}{|c|c|c|c|c|c|c|c|c|c|c|c|c|}
\hline CONCELLO & $27 /$ nov & $28 /$ nov & $29 /$ nov & $30 /$ nov & $01 /$ dec & $02 / \mathrm{dec}$ & 03/dec & 04/dec & 05/dec & 06/dec & 07/dec & 08/de \\
\hline Ares & 157 & {$[52,140]$} & {$[52,140]$} & {$[52,140]$} & {$[52,140]$} & {$[52,140]$} & ] $[52,140]$ & {$[52,140]$} & {$[52,140]$} & {$[52,140]$} & {$[52,140]$} & {$[52,14$} \\
\hline Cabanas & {$[61,122]$} & {$[61,122]$} & {$[152,244]$} & {$[152,244]$} & {$[152,244]$} & {$[152,244]$} & ]$[152,244]$ & {$[61,122]$} & {$[61,122]$} & 244] & $2,244]$ & \\
\hline Capela, A & {$[162,244][$} & $162,244]$ & {$[162,244][$} & {$[62,244][$} & {$[162,244][$} & {$[162,244][$} & {$[162,244]$} & {$[162,244][$} & {$[162,244]$} & 0 & 0 & \\
\hline Cariño & {$[52,130]$} & {$[52,130]$} & {$[52,130]$} & {$[52,130]$} & {$[52,130]$} & {$[52,130]$} & {$[52,130]$} & {$[52,130]$} & {$[52,130]$} & {$[52,130]$} & {$[52,130]$} & \\
\hline Cedeira & {$[60,136]$} & {$[60,136]$} & {$[60,136]$} & {$[60,136]$} & {$[60,136]$} & {$[60,136]$} & {$[60,136]$} & {$[60,136]$} & {$[60,136]$} & {$[60,136]$} & {$[60,136]$} & \\
\hline Cerdido & 90 & 90 & 90 & 90 & 90 & 90 & 90 & 90 & 90 & 90 & 0 & \\
\hline Fene & 247 & 239 & 216 & 193 & 201 & 178 & 131 & 108 & 100 & 108 & 116 & \\
\hline Ferrol & 241 & 227 & 226 & 212 & 209 & 194 & 191 & 197 & 170 & 167 & 163 & \\
\hline on & 0 & 0 & 0 & 0 & 0 & 0 & 0 & 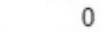 & 0 & 0 & 0 & \\
\hline Miño & 161 & 161 & 161 & 161 & 177 & 177 & 177 & 161 & {$[65,145]$} & {$[65,145]$} & {$[65,145]$} & {$[65,14$} \\
\hline Moeche & {$[326,734][$} & $326,734]$ & $326,734]$ & $326,734][$ & {$[326,734][$} & {$[326,734]$} & {$[326,734]$} & {$[326,734]$} & 82 & 82 & {$[326,734]$} & {$[326,73$} \\
\hline Monfero & $880^{\circ}$ & 932 & 932 & 880 & 983 & 932 & 828 & 725 & 776 & 725 & 725 & \\
\hline Mugardos & {$[57,133]$} & {$[57,133]$} & {$[153,172]$} & {$[57,133]$} & {$[57,133]$} & {$[153,172]$} & {$[57,133]$} & {$[57,133]$} & {$[57,133]$} & {$[57,133]$} & {$[57,133]$} & {$[57,13$} \\
\hline Narón & 345 & 353 & 348 & 330 & 322 & 302 & 287 & 292 & 266 & 248 & 233 & \\
\hline Neda & 256 & 236 & 197[ & $158,177][$ & {$[158,177][$} & {$[158,177]$} & {$[59,138]$} & {$[59,138]$} & {$[158,177]$} & 217 & 217 & \\
\hline Orti & 18 & 18 & 18 & 18 & 35 & 35 & 35 & 35 & {$[53,141]$} & {$[53,141]$} & {$[53,141]$} & {$[53,14$} \\
\hline eume & 527 & 540 & 476 & 437 & 450 & 450 & 399 & 334 & 257 & 231 & 193 & \\
\hline Pont & 572 & 602 & 690 & 720 & 779 & 888 & 917 & 977 & 957 & 967 & 967 & 10. \\
\hline San Sadurniño & 354 & 354 & {$[283,319]$} & {$[283,319]$} & 354 & 354 & {$[283,319]$} & {$[177,248]$} & {$[177,248]$} & {$[177,248]$} & {$[177,248]$} & {$[177,24$} \\
\hline Somozas, As & 91 & 91 & 91 & 91 & 91 & 0 & 0 & 0 & 91 & 91 & 182 [ & {$[273,82$} \\
\hline Valdoviño & 198 & 213 & 244 & 274 & 244 & 244 & 229 & 229 & 244 & 259 & 244 & \\
\hline Vilarmaior & 82 & 82 & 82 & 82 & 82 & 82 & 82 & 82 & 82 & 82 & 82 & \\
\hline
\end{tabular}


Táboa 6. Casos novos en Ferrolterra do 9 ao 21 de decembro de 2020.

\begin{tabular}{|c|c|c|c|c|c|c|c|c|c|c|c|c|}
\hline 09/dec & $10 /$ dec & $11 / \mathrm{dec}$ & $12 / \mathrm{dec}$ & $13 / \mathrm{dec}$ & $14 / \mathrm{dec}$ & $15 / \mathrm{dec}$ & $16 / \mathrm{dec}$ & $17 / \mathrm{dec}$ & $18 / \mathrm{dec}$ & $19 / \mathrm{dec}$ & $20 / \mathrm{dec}$ & $21 / \mathrm{dec}$ \\
\hline$[3,8]$ & {$[3,8]$} & {$[3,8]$} & {$[3,8]$} & {$[1,2]$} & {$[3,8]$} & {$[3,8]$} & {$[3,8]$} & {$[3,8]$} & 2 & 2 & 2 & \\
\hline$[2,4]$ & {$[2,4]$} & {$[5,8]$} & {$[5,8]$} & {$[5,8]$} & {$[5,8]$} & {$[5,8]$} & {$[5,8]$} & {$[5,8]$} & {$[5,8]$} & {$[5,8]$} & {$[2,4]$} & {$[2,4]$} \\
\hline 0 & 0 & 0 & 0 & 0 & 0 & 0 & 0 & 0 & 0 & 0 & 0 & 0 \\
\hline 1 & 0 & 0 & 0 & 0 & 0 & 0 & 0 & 0 & 0 & 0 & 0 & 1 \\
\hline 10 & 11 & 14 & 17 & 18 & 18 & 17 & 17 & 18 & 17 & 17 & 13 & 13 \\
\hline 0 & 0 & 0 & 0 & 0 & 0 & 0 & 0 & 0 & 0 & 0 & 0 & 0 \\
\hline 12 & 11 & 10 & 10 & 13 & 14 & 14 & 15 & 18 & 18 & 18 & 17 & 16 \\
\hline 119 & 118 & 111 & 115 & 115 & 115 & 115 & 115 & 120 & 115 & 113 & 108 & 103 \\
\hline 0 & 0 & 0 & 0 & 0 & 0 & 0 & 0 & 0 & 0 & 0 & 0 & 0 \\
\hline$[2,3]$ & {$[2,3]$} & {$[2,3]$} & {$[2,3]$} & {$[2,3]$} & {$[2,3]$} & {$[2,3]$} & {$[2,3]$} & {$[2,3]$} & {$[2,3]$} & {$[2,3]$} & 1 & 1 \\
\hline$[4,9]$ & {$[4,9]$} & {$[4,9]$} & {$[4,9]$} & {$[4,9]$} & {$[4,9]$} & {$[2,3]$} & {$[2,3]$} & {$[4,9]$} & {$[4,9]$} & {$[4,9]$} & {$[4,9]$} & {$[4,9]$} \\
\hline 11 & {$[5,9]$} & {$[5,9]$} & {$[5,9]$} & {$[5,9]$} & {$[5,9]$} & {$[5,9]$} & {$[3,4]$} & {$[3,4]$} & {$[3,4]$} & {$[3,4]$} & {$[3,4]$} & {$[3,4]$} \\
\hline$[3,7]$ & {$[3,7]$} & {$[3,7]$} & {$[3,7]$} & 2 & 2 & 2 & 0 & 1 & 1 & 1 & 1 & 1 \\
\hline 95 & 86 & 79 & 74 & 74 & 73 & 75 & 73 & 72 & 60 & 62 & 61 & 65 \\
\hline 12 & 11 & 11 & 11 & 12 & 13 & 13 & 14 & 14 & 13 & {$[8,9]$} & {$[3,7]$} & {$[3,7]$} \\
\hline$[3,8]$ & {$[3,8]$} & {$[3,8]$} & {$[3,8]$} & {$[3,8]$} & {$[3,8]$} & {$[3,8]$} & {$[3,8]$} & {$[3,8]$} & {$[3,8]$} & {$[3,8]$} & 2 & 2 \\
\hline 15 & 15 & 12 & 12 & 16 & 17 & 19 & 20 & 22 & 25 & 24 & 24 & 25 \\
\hline 108 & 107 & 109 & 112 & 125 & 131 & 137 & 134 & 134 & 128 & 124 & 114 & 110 \\
\hline & {$[2,4]$} & {$[5,7]$} & {$[8,9]$} & {$[8,9]$} & {$[8,9]$} & {$[8,9]$} & {$[8,9]$} & {$[8,9]$} & {$[8,9]$} & {$[8,9]$} & {$[8,9]$} & {$[8,9]$} \\
\hline$[3,9]$ & {$[3,9]$} & {$[3,9]$} & {$[3,9]$} & {$[3,9]$} & {$[3,9]$} & {$[3,9]$} & {$[3,9]$} & {$[3,9]$} & {$[3,9]$} & {$[3,9]$} & {$[3,9]$} & {$[3,9]$} \\
\hline 16 & 13 & 12 & 11 & 10 & {$[4,9]$} & {$[4,9]$} & {$[4,9]$} & {$[4,9]$} & {$[4,9]$} & {$[4,9]$} & {$[4,9]$} & {$[4,9]$} \\
\hline 1 & 10 & 12 & 4 & 20 & 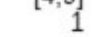 & 1 & 0 & 0 & 0 & 0 & 0 & 7 \\
\hline
\end{tabular}

Táboa 7. Incidencia acumulada en Ferrolterra do 9 ao 21 de decembro de 2020.

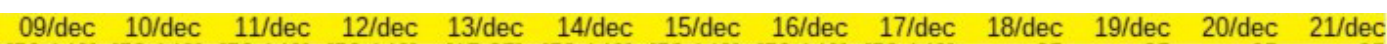

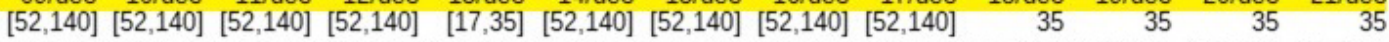
$[61,122][61,122][152,244][152,244][152,244][152,244][152,244][152,244][152,244][152,244][152,244][61,122][61,122]$

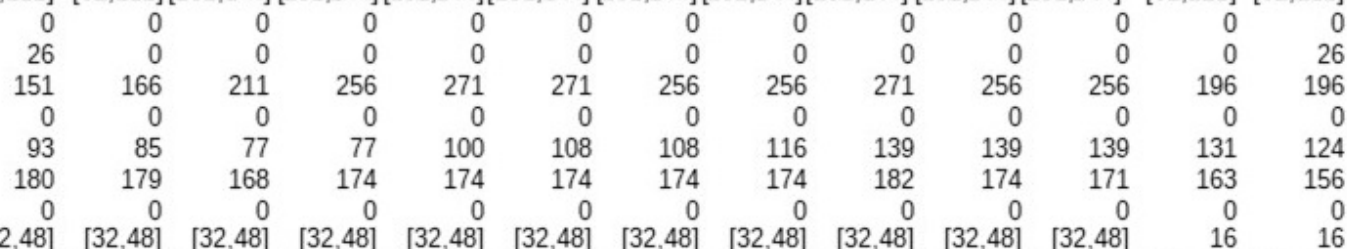
$[326,734][326,734][326,734][326,734][326,734][326,734][163,245][163,245][326,734][326,734][326,734][326,734][326,734]$ $569[258,466][258,466][258,466][258,466][258,466][258,466][155,207][155,207][155,207][155,207][155,207][155,207]$

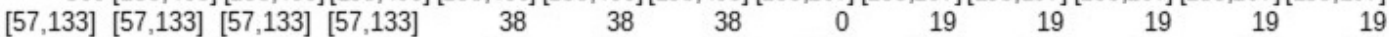

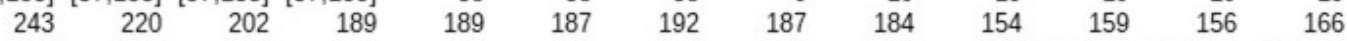

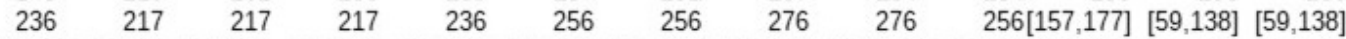
$[53,141][53,141][53,141][53,141][53,141][53,141][53,141][53,141][53,141][53,141][53,141] \quad 35 \quad 35$

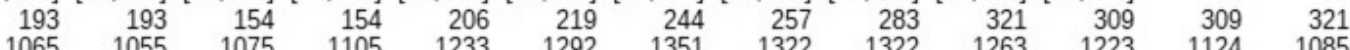
$\begin{array}{lllllll}35 & {[71,142][177,248][283,319]} & 283,319][283,319][283,319] & 283,319][283,319][283,319] & 283,319][283,319][283,319]\end{array}$ $[273,820][273,820][273,820][273,820][273,820][273,820][273,820][273,820][273,820][273,820][273,820][273,820][273,820]$ $\begin{array}{llllll}244 & 198 & 183 & 168 & 152[61,137][61,137][61,137][61,137][61,137][61,137][61,137][61,137]\end{array}$

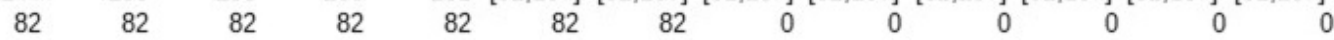


Táboa 8. Casos novos en Ferrolterra do 22 de decembro de 2020 ao 4 de xaneiro de 2021.

\begin{tabular}{|c|c|c|c|c|c|c|c|c|c|c|c|c|c|}
\hline $22 / \mathrm{dec}$ & $23 / \mathrm{dec}$ & $24 / \mathrm{dec}$ & $25 / \mathrm{dec}$ & $26 / \mathrm{dec}$ & $27 / \mathrm{dec}$ & $28 / \mathrm{dec}$ & $29 / \mathrm{dec}$ & $30 / \mathrm{dec}$ & $31 / \mathrm{dec}$ & 01/xan & $02 /$ xan & 03/xan & 04/xan \\
\hline & & {$[3,8]$} & {$[3,8]$} & {$[3,8]$} & {$[3,8]$} & {$[3,8]$} & {$[3,8]$} & {$[3,8]$} & {$[3,8]$} & {$[3,8]$} & {$[3,8]$} & 9 & \\
\hline$[2,4]$ & {$[2,4]$} & {$[2,4]$} & 0 & 1 & 1 & {$[2,4]$} & {$[2,4]$} & {$[5,8]$} & {$[5,8]$} & {$[5,8]$} & {$[5,8]$} & {$[5,8]$} & {$[5,8]$} \\
\hline 0 & 0 & 0 & 0 & 0 & 0 & 0 & 0 & 0 & 0 & 0 & 0 & 0 & 0 \\
\hline 1 & {$[6,9]$} & {$[6,9]$} & {$[6,9]$} & {$[6,9]$} & {$[6,9]$} & {$[6,9]$} & {$[6,9]$} & {$[6,9]$} & {$[6,9]$} & {$[6,9]$} & 10 & 11 & 10 \\
\hline 11 & 14 & 13 & 11 & 10 & 10 & 12 & 12 & 12 & 11 & 11 & 11 & 11 & 11 \\
\hline $2 \pi$ & 0 & 0 & 4 & 0 & 20 & 0 & $2 L$ & & 0 & 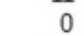 & 0 & 0 & 0 \\
\hline 18 & 18 & 20 & 19 & 18 & 16 & 16 & 15 & 13 & 12 & 14 & 13 & 20 & 23 \\
\hline 97 & 91 & 90 & 92 & 87 & 83 & 89 & 89 & 103 & 105 & 115 & 115 & 125 & 130 \\
\hline 0 & 0 & 0 & 0 & {$[1,2]$} & 2 & 3 & 3 & 3 & 3 & 3 & 3 & {$[4,9]$} & {$[4,9]$} \\
\hline 1 & {$[2,3]$} & {$[2,3]$} & {$[2,3]$} & {$[2$,} & 1 & 0 & 0 & 0 & 0 & 0 & 0 & {$[2,3]$} & {$[2,3]$} \\
\hline$[4,9]$ & {$[4,9]$} & {$[4,9]$} & {$[4,9]$} & {$[4,9]$} & {$[4,9]$} & {$[4,9]$} & {$[4,9]$} & {$[4,9]$} & {$[4,9]$} & {$[4,9]$} & {$[4,9]$} & {$[4,9]$} & {$[4,9]$} \\
\hline$[1,2]$ & {$[1,2]$} & {$[1,2]$} & {$[1,2]$} & {$[1,2]$} & {$[1,2]$} & {$[1,2]$} & {$[1,2]$} & {$[1,2]$} & {$[1,2]$} & {$[1,2]$} & {$[1,2]$} & {$[1,2]$} & {$[1,2]$} \\
\hline 1 & 1 & 2 & 2 & 2 & 2 & 2 & 2 & 2 & 2 & 2 & 2 & 2 & 2 \\
\hline 54 & 54 & 52 & 48 & 46 & 44 & 48 & 43 & 46 & 44 & 46 & 41 & $4 \overline{5}$ & 47 \\
\hline$[3,7]$ & {$[3,7]$} & {$[3,7]$} & {$[3,7]$} & {$[3,7]$} & {$[3,7]$} & {$[3,7]$} & {$[3,7]$} & {$[3,7]$} & {$[3,7]$} & {$[3,7]$} & {$[3,7]$} & {$[3,7]$} & {$[3,7]$} \\
\hline 2 & 2 & 2 & 1 & 1 & 1 & , & 2 & 2 & 2 & 2 & {$[3,8]$} & {$[3,8]$} & {$[3,8]$} \\
\hline 23 & 23 & 23 & 24 & 23 & 19 & 21 & 16 & 14 & 11 & {$[4,9]$} & {$[4,9]$} & 20 & 20 \\
\hline 100 & 91 & 84 & 78 & 70 & 48 & 38 & 25 & 16 & 10 & {$[6,9]$} & {$[3,5]$} & {$[3,5]$} & {$[3,5]$} \\
\hline$[8,9]$ & {$[8,9]$} & {$[5,7]$} & {$[2,4]$} & 1 & 0 & 0 & 1 & 1 & 1 & 1 & 1 & 1 & 1 \\
\hline & & & & 2 & 2 & 1 & 1 & 1 & 0 & 0 & 0 & 0 & 0 \\
\hline$[4,9]$ & {$[4,9]$} & {$[4,9]$} & {$[4,9]$} & {$[4,9]$} & {$[4,9]$} & {$[4,9]$} & {$[4,9]$} & {$[4,9]$} & {$\left[\begin{array}{l}{[4,9]} \\
22,3]\end{array}\right.$} & $\begin{array}{l}{[4,9]} \\
{[2,3]}\end{array}$ & $\left.\begin{array}{l}{[4,9]} \\
12\end{array}\right]$ & $\begin{array}{l}{[4,9]} \\
2,3]\end{array}$ & $\begin{array}{l}{[4,9]} \\
{[2,3]}\end{array}$ \\
\hline
\end{tabular}

Táboa 9. Incidencia acumulada a 14 días en Ferrolterra do 22 de decembro de 2020 ao 4 de xaneiro de 2021.

\begin{tabular}{|c|c|c|c|c|c|c|c|c|c|c|c|c|c|}
\hline IA14 días & & & & & & & & & & & & $\mid \mathrm{A} 1$ & 4 días \\
\hline $22 / \mathrm{dec}$ & 23/dec & $24 / \mathrm{dec}$ & $25 / \mathrm{dec}$ & $26 / \mathrm{dec}$ & $27 / \mathrm{dec}$ & $28 / \mathrm{dec}$ & $29 / \mathrm{dec}$ & $30 / \mathrm{dec}$ & $31 / \mathrm{dec}$ & 01/xan & $02 /$ xan & 03/xan & 4/xan \\
\hline 35 & & {$[52,140]$} & {$[52,140]$} & {$[52,140]$} & {$[52,140]$} & {$[52,140]$} & {$[52,140]$} & {$[52,140]$} & {$[52,140]$} & 96 & 96 & 157 & 157 \\
\hline$[61,122]$ & {$[61,122]$} & {$[61,122]$} & $\begin{array}{l}0 \\
0\end{array}$ & $\begin{array}{r}30 \\
0\end{array}$ & $\begin{array}{r}30 \\
0\end{array}$ & {$[61,122]$} & {$[61,122][0$} & $152,244][$ & $152,244]$ & $\begin{array}{r}198 \\
0\end{array}$ & $\begin{array}{r}198 \\
0\end{array}$ & $\begin{array}{r}198 \\
0\end{array}$ & $\begin{array}{r}198 \\
0\end{array}$ \\
\hline 26[] & {$[156,234]$} & {$[156,234][$} & {$[156,234]$} & {$[156,234][$} & {$[156,234][$} & $156,234][$ & $156,234][$ & $156,234][1$ & $156,234]$ & 195 & 261 & 287 & 261 \\
\hline $166^{\circ}$ & 211 & 196 & 166 & 151 & 151 & 181 & 181 & 181 & 166 & 166 & 166 & 166 & 166 \\
\hline 0 & 0 & 0 & 0 & 0 & 0 & 0 & 0 & 0 & 0 & 0 & 0 & 0 & 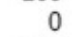 \\
\hline 139 & 139 & 155 & 147 & 139 & 124 & 124 & 116 & 100 & 93 & 108 & 100 & 155 & 178 \\
\hline 147 & 138 & 136 & 139 & 132 & 126 & 13 & 135 & 1 & 9 & 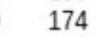 & 174 & 189 & 197 \\
\hline 0 & & & & {$[74,147]$} & 221 & 221 & 221 & 221 & 221 & 221 & 221 & 480 & 480 \\
\hline 16 & {$[32,48]$} & {$[32,48]$} & {$[32,48]$} & {$[32,48]$} & 16 & 0 & 0 & 0 & 0 & 0 & 0 & 40 & 40 \\
\hline 326,734$][$ & {$[326,734]$} & {$[326,734]$} & {$[326,734][$} & {$[326,734][$} & {$[326,734]$} & $326,734][3$ & $326,734][$ & $326,734][3$ & $326,734]$ & 530 & 530 & 530 & 530 \\
\hline 04] & {$[52,104]$} & {$[52,104]$} & {$[52,104]$} & {$[52$,} & & & {$[5$} & {$[5$} & & 78 & 78 & 78 & 78 \\
\hline 19 & 19 & 38 & 38 & 38 & 38 & 38 & 38 & 38 & 38 & 38 & 38 & 38 & 38 \\
\hline 138 & 138 & 133 & 123 & 118 & 113 & 123 & 110 & 118 & 113 & 118 & 105 & 115 & 120 \\
\hline$[59,138]$ & {$[59,138]$} & {$[59,138]$} & {$[59,138]$} & {$[59,138]$} & {$[59,138]$} & {$[59,138]$} & {$[59,138]$} & {$[59,138]$} & {$[59,138]$} & 99 & 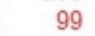 & 99 & 99 \\
\hline 35 & 35 & 35 & 18 & 18 & 18 & 35 & 35 & 35 & 35 & 35 & 97 & 97 & 97 \\
\hline 296 & 296 & 296 & 309 & 296 & 24 & 27 & 20 & 100 & 141 & & & $25 /$ & 257 \\
\hline 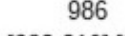 & 89 & 829 & 9 & . & 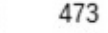 & 75 & 24 & 158 & 99 & & 40 & 40 & 0 \\
\hline 283,319$][$ & B3,319] & $77,248]$ & {$[71,142]$} & 35 & 0 & 0 & 35 & 35 & 35 & 35 & 35 & 35 & 35 \\
\hline 182 & 182 & 182 & 182 & 182 & 182 & 91 & 91 & 91 & 0 & 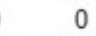 & 0 & 0 & \\
\hline$[61,137]$ & {$[61,137]$} & {$[61,137]$} & {$[61,137]$} & {$[61,137]$} & {$[61,137]$} & {$[61,137]$} & {$[61,137]$} & {$[61,137]$} & & 99 & 99 & 99 & 99 \\
\hline & & & & & & & 82 & 02 & & 204 & 204 & 204 & 204 \\
\hline
\end{tabular}


Táboa 10. Casos novos en Ferrolterra do 5 de xaneiro ao 20 de xaneiro de 2021.

Casos novos

Casos novos

05/xan 06/xan 07/xan 08/xan 09/xan 10/xan 11/xan 12/xan 13/xan 14/xan 15/xan 16/xan 17/xan 18/xan 19/xan 20/xan

$\begin{array}{rrrrrrrrrrrrrrrr}10 & 11 & 9 & 9 & 9 & 9 & {[3,8]} & {[3,8]} & {[3,8]} & 9 & 12 & 13 & 15 & 17 & 17 & 23 \\ 10 & 11 & 12 & 15 & 19 & 23 & 26 & 28 & 27 & 29 & 31 & 32 & 32 & 33 & 34 & 34 \\ 0 & 1 & 1 & 1 & 1 & 1 & 1 & 1 & 1 & 1 & 1 & 1 & {[2,3]} & {[2,3]} & {[2,3]} & {[2,3]} \\ 10 & {[6,9]} & {[6,9]} & {[6,9]} & 13 & 13 & 13 & 14 & 17 & 17 & 24 & 24 & 23 & 23 & 24 & 24 \\ 13 & 11 & 13 & 16 & 17 & 19 & 17 & 22 & 23 & 26 & 29 & 36 & 41 & 46 & 48 & 46 \\ 1 & 1 & 1 & 1 & 1 & 1 & 1 & 2 & 2 & 2 & {[3,9]} & {[3,9]} & 10 & 11 & 11 & 13 \\ 26 & 33 & 40 & 41 & 52 & 57 & 63 & 72 & 78 & 83 & 96 & 102 & 102 & 116 & 122 & 125 \\ 140 & 138 & 144 & 151 & 164 & 191 & 203 & 219 & 224 & 230 & 251 & 268 & 275 & 293 & 293 & 323 \\ {[4,9]} & {[4,9]} & {[4,9]} & {[4,9]} & {[4,9]} & {[4,9]} & {[4,9]} & {[4,9]} & 14 & 23 & 34 & 38 & 41 & 47 & 48 & 52 \\ {[2,3]} & {[2,3]} & {[2,3]} & {[2,3]} & {[2,3]} & {[2,3]} & 1 & {[4,9]} & {[4,9]} & {[4,9]} & {[4,9]} & {[4,9]} & {[4,9]} & {[4,9]} & 10 & 12 \\ {[2,3]} & {[2,3]} & {[2,3]} & {[2,3]} & {[2,3]} & {[2,3]} & {[2,3]} & {[4,9]} & {[4,9]} & 10 & 12 & 15 & 20 & 22 & 24 & 36 \\ {[1,2]} & {[1,2]} & {[1,2]} & {[1,2]} & {[3,4]} & {[3,4]} & {[3,4]} & {[1,2]} & {[3,4]} & {[3,4]} & {[3,4]} & {[1,2]} & {[1,2]} & {[1,2]} & {[3,4]} & {[3,4]} \\ 2 & 2 & {[3,7]} & {[3,7]} & {[3,7]} & 10 & 10 & 11 & 12 & 16 & 21 & 23 & 26 & 32 & 39 & 44 \\ 58 & 60 & 69 & 73 & 86 & 99 & 103 & 113 & 114 & 135 & 150 & 157 & 170 & 177 & 182 & 210 \\ {[3,7]} & {[3,7]} & 2 & 2 & 2 & 2 & {[3,7]} & {[8,9]} & 14 & 22 & 25 & 27 & 27 & 32 & 34 & 37 \\ {[3,8]} & 10 & 16 & 21 & 26 & 36 & 36 & 39 & 46 & 50 & 62 & 68 & 70 & 77 & 81 & 89 \\ 26 & 27 & 28 & 26 & 29 & 33 & 32 & 35 & 38 & 46 & 56 & 70 & 64 & 66 & 63 & 69 \\ {[3,5]} & {[3,5]} & {[6,9]} & {[3,5]} & {[3,5]} & {[6,9]} & {[6,9]} & {[6,9]} & {[6,9]} & 12 & 13 & 16 & 19 & 21 & 20 & 23 \\ 1 & {[2,4]} & {[2,4]} & {[5,7]} & {[5,7]} & {[5,7]} & {[5,7]} & {[5,7]} & {[5,7]} & 13 & 16 & 16 & 16 & 17 & 22 & 24 \\ 0 & 0 & 0 & 0 & 0 & 0 & 1 & 2 & 2 & {[3,9]} & {[3,9]} & {[3,9]} & {[3,9]} & {[3,9]} & 11 & 12 \\ {[4,9]} & {[4,9]} & {[4,9]} & {[4,9]} & {[4,9]} & {[4,9]} & {[4,9]} & 10 & 13 & 14 & 21 & 20 & 24 & 25 & 28 & 30 \\ {[2,3]} & {[2,3]} & {[2,3]} & {[2,3]} & {[2,3]} & {[2,3]} & {[2,3]} & {[2,3]} & {[2,3]} & {[2,3]} & 1 & 1 & {[2,3]} & {[2,3]} & {[2,3]} & {[4,9]}\end{array}$

Táboa 11. Incidencia acumulada a 14 días en Ferrolterra do 5 de xaneiro ao 20 de xaneiro de 2021.

IA14 días

IA14 días

05/xan 06/xan 07/xan 08/xan 09/xan 10/xan 11/xan 12/xan 13/xan 14/xan 15/xan 16/xan 17/xan 18/xan 19/xan 20/xan

$\begin{array}{rrrrrrrrrrrrrrrr}174 & 192 & 157 & 157 & 157 & 157 & 96 & 96 & 96 & 157 & 209 & 227 & 262 & 297 & 297 & 401 \\ 305 & 335 & 366 & 457 & 579 & 701 & 792 & 853 & 823 & 884 & 945 & 975 & 975 & 1006 & 1036 & 1036 \\ 0 & 81 & 81 & 81 & 81 & 81 & 81 & 81 & 81 & 81 & 81 & 81 & 203 & 203 & 203 & 203 \\ 261 & 195 & 195 & 195 & 339 & 339 & 339 & 365 & 443 & 443 & 625 & 625 & 599 & 599 & 625 & 625 \\ 196 & 166 & 196 & 241 & 256 & 286 & 256 & 331 & 346 & 392 & 437 & 542 & 617 & 693 & 723 & 693 \\ 90 & 90 & 90 & 90 & 90 & 90 & 90 & 180 & 180 & 180 & 540 & 540 & 898 & 988 & 988 & 1168 \\ 201 & 255 & 309 & 317 & 402 & 440 & 487 & 556 & 603 & 641 & 742 & 788 & 788 & 896 & 943 & 966 \\ 212 & 209 & 218 & 229 & 248 & 289 & 307 & 331 & 339 & 348 & 380 & 406 & 416 & 444 & 444 & 489 \\ 480 & 480 & 480 & 480 & 480 & 480 & 480 & 480 & 1032 & 1696 & 2507 & 2802 & 3024 & 3466 & 3540 & 3835 \\ 40 & 40 & 40 & 40 & 40 & 40 & 16 & 105 & 105 & 105 & 105 & 105 & 105 & 105 & 161 & 194 \\ 204 & 204 & 204 & 204 & 204 & 204 & 204 & 530 & 530 & 816 & 979 & 1223 & 1631 & 1794 & 1958 & 2936 \\ 78 & 78 & 78 & 78 & 181 & 181 & 181 & 78 & 181 & 181 & 181 & 78 & 78 & 78 & 181 & 181 \\ 38 & 38 & 95 & 95 & 95 & 191 & 191 & 210 & 229 & 305 & 400 & 439 & 496 & 610 & 744 & 839 \\ 148 & 154 & 177 & 187 & 220 & 253 & 264 & 289 & 292 & 345 & 384 & 402 & 435 & 453 & 466 & 537 \\ 99 & 99 & 39 & 39 & 39 & 39 & 99 & 167 & 276 & 433 & 492 & 532 & 532 & 630 & 669 & 728 \\ 97 & 176 & 282 & 370 & 458 & 635 & 635 & 688 & 811 & 882 & 1093 & 1199 & 1234 & 1358 & 1428 & 1569 \\ 334 & 347 & 360 & 334 & 373 & 424 & 411 & 450 & 489 & 591 & 720 & 900 & 823 & 849 & 810 & 887 \\ 40 & 40 & 74 & 40 & 40 & 74 & 74 & 74 & 74 & 118 & 128 & 158 & 187 & 207 & 197 & 227 \\ 35 & 107 & 107 & 213 & 213 & 213 & 213 & 213 & 213 & 461 & 567 & 567 & 567 & 602 & 780 & 850 \\ 0 & 0 & 0 & 0 & 0 & 0 & 91 & 182 & 182 & 547 & 547 & 547 & 547 & 547 & 1002 & 1093 \\ 99 & 99 & 99 & 99 & 99 & 99 & 99 & 152 & 198 & 213 & 320 & 305 & 366 & 381 & 427 & 457 \\ 204 & 204 & 204 & 204 & 204 & 204 & 204 & 204 & 204 & 204 & 82 & 82 & 204 & 204 & 204 & 530\end{array}$


Táboa 12. Casos novos en Ferrolterra do 21 de xaneiro ao 5 de febreiro de 2021.

Casos novos

Casos novos

21/xan 22/xan 23/xan 24/xan 25/xan 26/xan 27/xan 28/xan 29/xan 30/xan 31/xan 01/feb 02/feb 03/feb 04/feb 05/feb

\begin{tabular}{|c|c|c|c|c|c|c|c|c|c|c|c|c|c|c|c|}
\hline 22 & 24 & 28 & 29 & 29 & 35 & 37 & 40 & 45 & 48 & 48 & 53 & 52 & 49 & 54 & 58 \\
\hline 38 & 38 & 36 & 32 & 29 & 27 & 40 & 42 & 42 & 43 & 45 & 44 & 74 & 74 & 70 & 80 \\
\hline$[2,3]$ & {$[2,3]$} & {$[2,3]$} & {$[2,3]$} & {$[2,3]$} & {$[4,9]$} & {$[4,9]$} & {$[4,9]$} & {$[4,9]$} & {$[4,9]$} & {$[4,9]$} & {$[4,9]$} & {$[4,9]$} & 10 & 10 & 10 \\
\hline 24 & 22 & 18 & 19 & 18 & 19 & 18 & 17 & {$[6,9]$} & {$[6,9]$} & {$[6,9]$} & 11 & 11 & {$[6,9]$} & 10 & 12 \\
\hline 48 & 57 & 63 & 70 & 75 & 83 & 86 & 85 & 91 & 87 & 85 & 84 & 84 & 90 & 89 & 81 \\
\hline 13 & 14 & 14 & 15 & 15 & 15 & 15 & 15 & 13 & 11 & 13 & 13 & 12 & 10 & 11 & 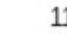 \\
\hline 140 & 152 & 147 & 147 & 149 & 147 & 149 & 154 & 141 & 140 & 146 & 135 & 128 & 120 & 104 & 96 \\
\hline 332 & 374 & 386 & 382 & 395 & 399 & 403 & 426 & 430 & 442 & 441 & 434 & 442 & 441 & 440 & 419 \\
\hline 53 & 52 & 50 & 51 & 51 & 48 & 44 & 37 & 26 & 24 & 23 & 17 & 17 & 14 & 13 & 14 \\
\hline 16 & 24 & 27 & 28 & 32 & 31 & 33 & 33 & 39 & 39 & 39 & 40 & 40 & 38 & 37 & 32 \\
\hline 38 & 43 & 47 & 50 & 62 & 62 & 64 & 60 & 71 & 70 & 67 & 69 & 67 & 56 & 58 & 57 \\
\hline$[5,9]$ & {$[5,9]$} & {$[5,9]$} & {$[5,9]$} & {$[5,9]$} & {$[5,9]$} & {$[5,9]$} & 11 & 11 & 11 & 12 & 12 & 11 & 12 & 12 & 17 \\
\hline 52 & 56 & 61 & 57 & 59 & 60 & 62 & 63 & 65 & 67 & 66 & 66 & 61 & 62 & 56 & 55 \\
\hline 223 & 245 & 250 & 251 & 261 & 268 & 278 & 285 & 295 & 301 & 297 & 315 & 312 & 296 & 288 & 270 \\
\hline 39 & 41 & 42 & 43 & 43 & 41 & 40 & 33 & 31 & 30 & 30 & 25 & 23 & 21 & 20 & 18 \\
\hline 90 & 93 & 94 & 93 & 100 & 100 & 102 & 101 & 89 & 88 & 93 & 91 & 87 & 82 & 76 & 69 \\
\hline 78 & 84 & 86 & 88 & 90 & 91 & 92 & 96 & 92 & 82 & 80 & 80 & 76 & 74 & 71 & 66 \\
\hline 29 & 32 & 35 & 40 & 45 & 46 & 53 & 57 & 61 & 61 & 66 & 70 & 71 & 71 & 68 & 67 \\
\hline 27 & 28 & 34 & 35 & 38 & 37 & 43 & 38 & 38 & 42 & 42 & 47 & 45 & 44 & 51 & 50 \\
\hline 12 & 14 & 17 & 17 & 16 & 15 & 15 & 11 & 11 & 10 & 11 & 12 & 12 & 11 & 11 & {$[3,9]$} \\
\hline $\begin{array}{r}32 \\
{[4,9]}\end{array}$ & $\begin{array}{r}34 \\
{[4,9]}\end{array}$ & $\begin{array}{r}37 \\
{[4,9]}\end{array}$ & $\begin{array}{r}40 \\
{[4,9]}\end{array}$ & $\begin{array}{r}39 \\
{[4,9]}\end{array}$ & $\begin{array}{r}38 \\
{[4,9]}\end{array}$ & $\begin{array}{r}39 \\
{[4,9]}\end{array}$ & $\begin{array}{r}41 \\
{[4,9]}\end{array}$ & $\begin{array}{r}43 \\
{[4,9]}\end{array}$ & $\begin{array}{l}45 \\
10\end{array}$ & $\begin{array}{r}43 \\
{[4,9]}\end{array}$ & $\begin{array}{r}46 \\
{[4,9]}\end{array}$ & $\begin{array}{l}47 \\
10\end{array}$ & $\begin{array}{r}48 \\
{[4,9]}\end{array}$ & $\begin{array}{r}49 \\
{[4,9]}\end{array}$ & $\begin{array}{r}49 \\
{[4,9}\end{array}$ \\
\hline
\end{tabular}

Táboa 13. Incidencia acumulada a 14 días en Ferrolterra do 21 de xaneiro ao 5 de febreiro de 2021.

IA14 días

IA14 días

21/xan 22/xan 23/xan 24/xan 25/xan 26/xan 27/xan 28/xan 29/xan 30/xan 31/xan 01/feb 02/feb 03/feb 04/feb 05/feb

$\begin{array}{rrrrrrrrrrrrrrrr}384 & 419 & 488 & 506 & 506 & 611 & 645 & 698 & 785 & 837 & 837 & 925 & 907 & 855 & 942 & 1012 \\ 1158 & 1158 & 1097 & 975 & 884 & 823 & 1219 & 1280 & 1280 & 1311 & 1372 & 1341 & 2255 & 2255 & 2133 & 2438 \\ 203 & 203 & 203 & 203 & 203 & 528 & 528 & 528 & 528 & 528 & 528 & 528 & 528 & 812 & 812 & 812 \\ 625 & 573 & 469 & 495 & 469 & 495 & 469 & 443 & 195 & 195 & 195 & 287 & 287 & 195 & 261 & 313 \\ 723 & 858 & 949 & 1054 & 1130 & 1250 & 1295 & 1280 & 1370 & 1310 & 1280 & 1265 & 1265 & 1355 & 1340 & 1220 \\ 1168 & 1258 & 1258 & 1348 & 1348 & 1348 & 1348 & 1348 & 1168 & 988 & 1168 & 1168 & 1078 & 898 & 988 & 988 \\ 1082 & 1174 & 1136 & 1136 & 1151 & 1136 & 1151 & 1190 & 1089 & 1082 & 1128 & 1043 & 989 & 927 & 803 & 742 \\ 503 & 566 & 584 & 578 & 598 & 604 & 610 & 645 & 651 & 669 & 668 & 657 & 669 & 668 & 666 & 634 \\ 3909 & 3835 & 3687 & 3761 & 3761 & 3540 & 3245 & 2729 & 1917 & 1770 & 1696 & 1254 & 1254 & 1032 & 959 & 1032 \\ 258 & 387 & 435 & 452 & 516 & 500 & 532 & 532 & 629 & 629 & 629 & 645 & 645 & 613 & 597 & 516 \\ 3100 & 3507 & 3834 & 4078 & 5057 & 5057 & 5220 & 4894 & 5791 & 5710 & 5465 & 5628 & 5465 & 4568 & 4731 & 4649 \\ 363 & 363 & 363 & 363 & 363 & 363 & 363 & 569 & 569 & 569 & 621 & 621 & 569 & 621 & 621 & 880 \\ 991 & 1068 & 1163 & 1087 & 1125 & 1144 & 1182 & 1201 & 1239 & 1277 & 1258 & 1258 & 1163 & 1182 & 1068 & 1049 \\ 571 & 627 & 640 & 642 & 668 & 686 & 711 & 729 & 755 & 770 & 760 & 806 & 798 & 757 & 737 & 691 \\ 768 & 807 & 827 & 847 & 847 & 807 & 788 & 650 & 610 & 591 & 591 & 492 & 453 & 413 & 394 & 354 \\ 1587 & 1640 & 1658 & 1640 & 1763 & 1763 & 1799 & 1781 & 1569 & 1552 & 1640 & 1605 & 1534 & 1446 & 1340 & 1217 \\ 1003 & 1080 & 1106 & 1132 & 1157 & 1170 & 1183 & 1234 & 1183 & 1054 & 1029 & 1029 & 977 & 952 & 913 & 849 \\ 286 & 316 & 345 & 395 & 444 & 454 & 523 & 562 & 602 & 602 & 651 & 690 & 700 & 700 & 671 & 661 \\ 957 & 992 & 1205 & 1240 & 1347 & 1311 & 1524 & 1347 & 1347 & 1488 & 1488 & 1665 & 1595 & 1559 & 1807 & 1772 \\ 1093 & 1275 & 1548 & 1548 & 1457 & 1366 & 1366 & 1002 & 1002 & 911 & 1002 & 1093 & 1093 & 1002 & 1002 & 547 \\ 488 & 518 & 564 & 609 & 594 & 579 & 594 & 625 & 655 & 686 & 655 & 701 & 716 & 731 & 747 & 747 \\ 530 & 530 & 530 & 530 & 530 & 530 & 530 & 530 & 530 & 816 & 530 & 530 & 816 & 530 & 530 & 530\end{array}$


Táboa 14. Casos novos en Ferrolterra do 6 de febreiro ao 21 de febreiro de 2021.

Casos novos

Casos novos

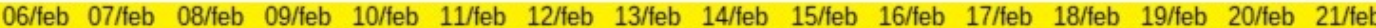

$\begin{array}{rrrrrrrrrrrrrrrr}54 & 55 & 59 & 55 & 54 & 51 & 46 & 44 & 41 & 34 & 33 & 30 & 25 & 20 & 20 & 19 \\ 77 & 76 & 76 & 88 & 74 & 72 & 71 & 69 & 67 & 67 & 33 & 32 & 37 & 25 & 24 & 30 \\ 10 & 10 & 10 & {[4,9]} & {[4,9]} & {[4,9]} & {[4,9]} & {[4,9]} & {[4,9]} & {[2,3]} & {[2,3]} & 0 & 0 & 0 & 0 & 0 \\ 12 & 12 & 12 & 12 & 11 & 11 & 11 & 11 & 13 & 11 & 10 & 10 & 10 & {[6,9]} & {[6,9]} & {[6,9]} \\ 72 & 63 & 60 & 51 & 47 & 50 & 47 & 47 & 47 & 43 & 40 & 35 & 32 & 28 & 27 & 26 \\ 11 & 10 & 10 & {[3,9]} & {[3,9]} & {[3,9]} & {[3,9]} & {[3,9]} & {[3,9]} & 2 & 2 & {[3,9]} & 2 & 2 & 2 & 2 \\ 94 & 90 & 84 & 78 & 73 & 63 & 63 & 59 & 47 & 46 & 45 & 45 & 38 & 33 & 30 & 29 \\ 422 & 420 & 405 & 400 & 406 & 386 & 365 & 351 & 340 & 330 & 316 & 286 & 278 & 265 & 252 & 241 \\ 13 & 13 & 13 & 12 & 12 & 10 & 10 & {[4,9]} & {[4,9]} & {[4,9]} & {[4,9]} & 3 & 3 & {[1,2]} & {[4,9]} & 3 \\ 30 & 31 & 27 & 33 & 34 & 34 & 28 & 29 & 28 & 26 & 23 & 23 & 21 & 18 & 18 & 16 \\ 54 & 51 & 38 & 38 & 38 & 37 & 26 & 26 & 25 & 23 & 23 & 23 & 19 & 15 & 14 & 14 \\ 15 & 15 & 14 & 14 & 13 & 11 & 11 & 11 & 10 & 10 & 10 & {[5,9]} & {[5,9]} & {[1,2]} & {[1,2]} & {[1,2]} \\ 52 & 50 & 47 & 46 & 43 & 39 & 32 & 30 & 27 & 21 & 22 & 15 & 13 & 12 & 10 & 10 \\ 263 & 257 & 242 & 228 & 218 & 201 & 182 & 182 & 172 & 148 & 143 & 136 & 129 & 126 & 122 & 113 \\ 19 & 15 & 14 & 14 & 11 & 11 & 11 & 14 & 14 & 15 & 15 & 18 & 19 & 20 & 18 & 18 \\ 65 & 55 & 48 & 45 & 36 & 32 & 32 & 26 & 18 & 13 & 10 & 9 & {[3,8]} & {[3,8]} & 1 & 1 \\ 62 & 58 & 55 & 51 & 47 & 36 & 28 & 26 & 23 & 22 & 24 & 22 & 18 & 19 & 18 & 20 \\ 65 & 59 & 55 & 56 & 50 & 48 & 44 & 45 & 37 & 31 & 33 & 34 & 32 & 30 & 31 & 33 \\ 45 & 43 & 40 & 41 & 34 & 35 & 33 & 29 & 30 & 25 & 22 & 21 & 12 & 13 & 12 & 12 \\ {[3,9]} & {[3,9]} & {[3,9]} & {[3,9]} & {[3,9]} & {[3,9]} & {[3,9]} & {[3,9]} & {[3,9]} & {[3,9]} & 2 & 2 & 2 & 2 & 2 & 2 \\ 46 & 43 & 43 & 41 & 38 & 34 & 26 & 25 & 23 & 18 & 14 & 12 & {[4,9]} & {[4,9]} & {[4,9]} & {[4,9]} \\ {[4,9]} & {[4,9]} & {[4,9]} & {[4,9]} & {[4,9]} & {[4,9]} & {[4,9]} & {[4,9]} & {[4,9]} & {[4,9]} & {[4,9]} & {[4,9]} & {[2,3]} & {[4,9]} & {[4,9]} & {[4,9]}\end{array}$

Táboa 15. Incidencia acumulada a 14 días en Ferrolterra do 6 de febreiro ao 21 de febreiro de 2021.

IA 14 días

IA14 días

06/feb $07 / \mathrm{feb}$ 08/feb $09 / \mathrm{feb} \quad 10 / \mathrm{feb} \quad 11 / \mathrm{feb} \quad 12 / \mathrm{feb} \quad 13 / \mathrm{feb} \quad 14 / \mathrm{feb} \quad 15 / \mathrm{feb} \quad 16 / \mathrm{feb} \quad 17 / \mathrm{feb} \quad 18 / \mathrm{feb} \quad 19 / \mathrm{feb} \quad 20 / \mathrm{feb} \quad 21 / \mathrm{feb}$

\begin{tabular}{|c|c|c|c|c|c|c|c|c|c|c|c|c|c|c|c|}
\hline 942 & 960 & 1029 & 960 & 942 & 890 & 803 & 768 & 715 & 593 & 576 & 523 & 436 & 349 & 349 & 331 \\
\hline 2347 & 2316 & 2316 & 2682 & 2255 & 2194 & 2164 & 2103 & 2042 & 2042 & 1006 & 975 & 1128 & 762 & 731 & 914 \\
\hline 812 & 812 & 812 & 528 & 528 & 528 & 528 & 528 & 528 & 203 & 203 & 0 & 0 & 0 & 0 & 0 \\
\hline 313 & 313 & 313 & 313 & 287 & 287 & 287 & 287 & 339 & 287 & 261 & 261 & 261 & 195 & 195 & 195 \\
\hline 1084 & 949 & 904 & 768 & 708 & 753 & 708 & 708 & 708 & 648 & 602 & 527 & 482 & 422 & 407 & 392 \\
\hline 988 & 898 & 898 & 540 & 540 & 540 & 540 & 540 & 540 & 180 & 180 & 540 & 180 & 180 & 180 & 180 \\
\hline 726 & 695 & 649 & 603 & 564 & 487 & 487 & 456 & 363 & 355 & 348 & 348 & 294 & 255 & 232 & 224 \\
\hline 639 & 636 & 613 & 605 & 615 & 584 & 552 & 531 & 515 & 500 & 478 & 433 & 421 & 401 & 381 & 365 \\
\hline 959 & 959 & 959 & 885 & 885 & 737 & 737 & 480 & 480 & 480 & 480 & 221 & 221 & 111 & 480 & 221 \\
\hline 484 & 500 & 435 & 532 & 548 & 548 & 452 & 468 & 452 & 419 & 371 & 371 & 339 & 290 & 290 & 258 \\
\hline 4405 & 4160 & 3100 & 3100 & 3100 & 3018 & 2121 & 2121 & 2039 & 187 & 1876 & 1876 & 1550 & 1223 & 1142 & 1142 \\
\hline 776 & 776 & 725 & 725 & 673 & 569 & 569 & 569 & 518 & 518 & 518 & 363 & 363 & 78 & 78 & 78 \\
\hline 991 & 953 & 896 & 877 & 820 & 744 & 610 & 572 & 515 & 400 & 419 & 286 & 248 & 229 & 191 & 191 \\
\hline 673 & 658 & 619 & 583 & 558 & 514 & 466 & 466 & 440 & 37 & 366 & 348 & 330 & 322 & 312 & 289 \\
\hline 374 & 295 & 276 & 276 & 217 & 217 & 217 & 276 & 276 & 29 & 295 & 354 & 374 & 394 & 354 & 354 \\
\hline 1146 & 970 & 846 & 794 & 635 & 564 & 564 & 458 & 317 & 22 & 176 & 159 & 97 & 97 & 18 & 18 \\
\hline 797 & 746 & 707 & 656 & 604 & 463 & 360 & 334 & 296 & 283 & 30 & 283 & 231 & 244 & 231 & 257 \\
\hline 641 & 582 & 543 & 552 & 493 & 473 & 434 & 444 & 365 & 306 & 326 & 335 & 316 & 296 & 306 & 326 \\
\hline 1595 & 1524 & 1417 & 1453 & 1205 & 1240 & 1169 & 1028 & 1063 & 886 & 780 & 744 & 425 & 461 & 425 & 425 \\
\hline 547 & 547 & 547 & 547 & 547 & 547 & 547 & 547 & 547 & 54 & 182 & 182 & 182 & 182 & 182 & 182 \\
\hline $\begin{array}{l}701 \\
530\end{array}$ & $\begin{array}{l}655 \\
530\end{array}$ & $\begin{array}{l}655 \\
530\end{array}$ & $\begin{array}{l}625 \\
530\end{array}$ & $\begin{array}{l}579 \\
530\end{array}$ & $\begin{array}{l}518 \\
530\end{array}$ & $\begin{array}{l}396 \\
530\end{array}$ & $\begin{array}{l}381 \\
530\end{array}$ & $\begin{array}{l}350 \\
530\end{array}$ & $\begin{array}{l}274 \\
530\end{array}$ & $\begin{array}{l}213 \\
530\end{array}$ & $\begin{array}{l}183 \\
530\end{array}$ & $\begin{array}{r}99 \\
204\end{array}$ & $\begin{array}{r}99 \\
530\end{array}$ & $\begin{array}{r}99 \\
530\end{array}$ & $\begin{array}{r}99 \\
530\end{array}$ \\
\hline
\end{tabular}


Táboa 16. Casos novos en Ferrolterra do 22 de febreiro ao 9 de marzo de 2021.

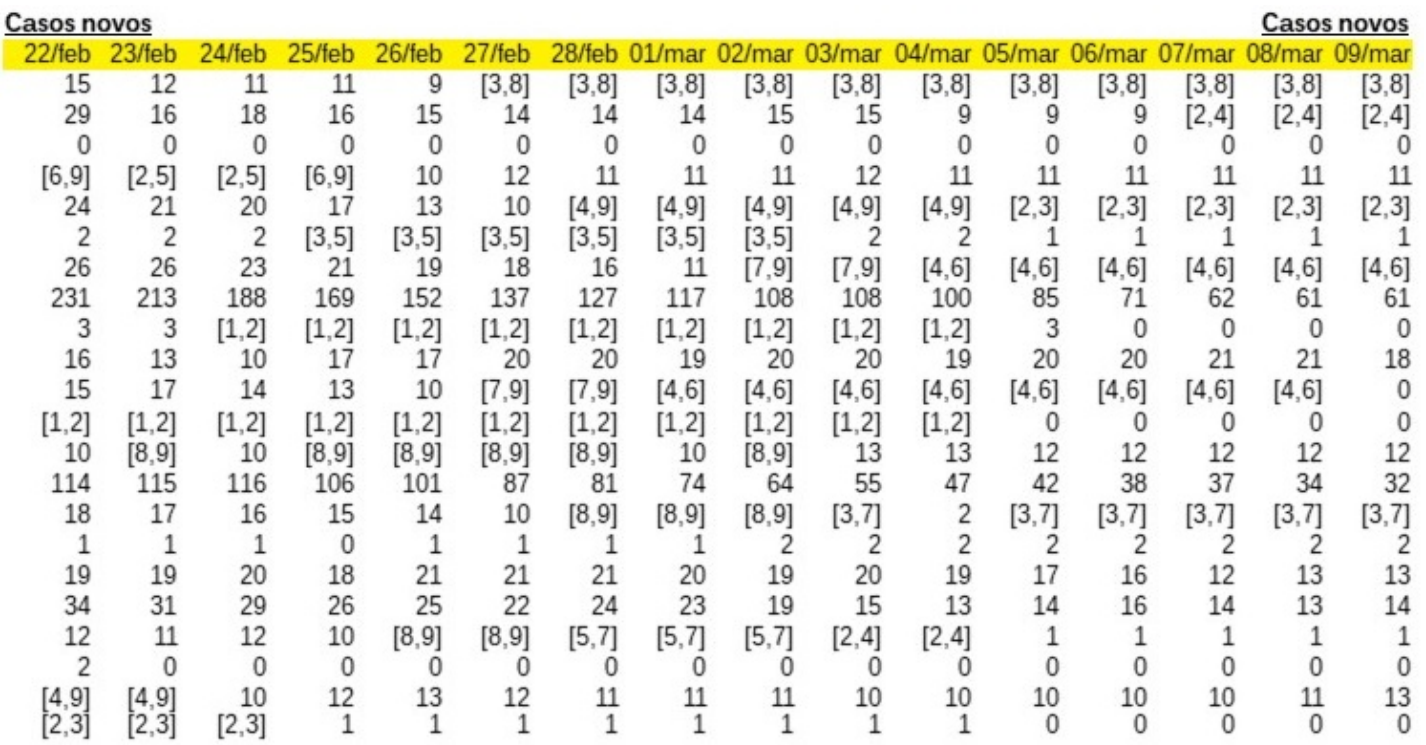

Táboa 17. Incidencia acumulada a 14 días e número de concellos por tramo de incidencia en Ferrolterra do 22 de febreiro ao 9 de marzo de 2021.

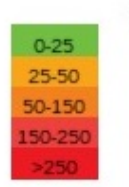

número de concellos en cada tramo

$\begin{array}{lllll}4 & 5 & 5 & 5 & 6 \\ 4 & 4 & 4 & 4 & 4 \\ 6 & 5 & 7 & 7 & 7 \\ 4 & 4 & 3 & 3 & 3 \\ 4 & 4 & 3 & 3 & 2\end{array}$

\begin{tabular}{|c|c|c|c|c|c|c|c|c|c|c|c|c|c|c|c|}
\hline A14 día & & & & & & & & & & & & & & & días \\
\hline $22 / \mathrm{feb}$ & 23/feb & 24/feb & $25 /$ feb & 26/feb & 27/feb & 28/feb & 01/mar & $02 /$ mar & 03/mar & 04/mar & 05/mar & 06/mar & 07/mar & & 9/mar \\
\hline 262 & 209 & 192 & 192 & 157 & 96 & 96 & 96 & 96 & 96 & 96 & 96 & 96 & 96 & 96 & 96 \\
\hline 884 & 488 & 549 & 488 & 457 & 427 & 427 & 427 & 457 & 457 & 274 & 274 & 274 & 92 & 92 & 92 \\
\hline 0 & 0 & 0 & 0 & 0 & 0 & 0 & 0 & 0 & 0 & 0 & 0 & 0 & 0 & 0 & 0 \\
\hline 195 & 91 & 91 & 195 & 261 & 313 & 287 & 287 & 287 & 313 & 287 & 287 & 287 & 287 & 287 & 287 \\
\hline 361 & 316 & 301 & 256 & 196 & 151 & 98 & 98 & 98 & 98 & 98 & 38 & 38 & 38 & 38 & 38 \\
\hline 180 & 180 & 180 & 360 & 360 & 360 & 360 & 360 & 360 & 180 & 180 & 90 & 90 & 90 & 90 & 90 \\
\hline 201 & 201 & 178 & 162 & 147 & 139 & 124 & 85 & 62 & 62 & 39 & 39 & 39 & 39 & 39 & 39 \\
\hline 350 & 322 & 285 & 256 & 230 & 207 & 192 & 177 & 163 & 163 & 151 & 129 & 107 & 94 & 92 & 92 \\
\hline 221 & 221 & 111 & 111 & 111 & 111 & 111 & 111 & 111 & 111 & 111 & 221 & 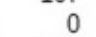 & 0 & 0 & 0 \\
\hline 258 & 210 & 161 & 274 & 274 & 323 & 323 & 306 & 323 & 323 & 306 & 323 & 323 & 339 & 339 & 290 \\
\hline 1223 & 1387 & 1142 & 1060 & 816 & 653 & 653 & 408 & 408 & 408 & 408 & 408 & 408 & 408 & 408 & 0 \\
\hline 78 & 78 & 78 & 78 & 78 & 78 & 78 & 78 & 78 & 78 & 78 & 0 & 0 & 0 & 0 & 0 \\
\hline 191 & 163 & 191 & 163 & 163 & 163 & 163 & 191 & 163 & 248 & 248 & 229 & 229 & 229 & 229 & 229 \\
\hline 292 & 294 & 297 & 271 & 258 & 223 & 207 & 189 & 164 & 141 & 120 & 107 & 97 & 95 & 87 & 82 \\
\hline 354 & 335 & 315 & 295 & 276 & 197 & 167 & 167 & 167 & 99 & 39 & 99 & 99 & 99 & 99 & 99 \\
\hline 18 & 18 & 18 & 0 & 18 & 18 & 18 & 18 & 35 & 35 & 35 & 35 & 35 & 35 & 35 & 35 \\
\hline 244 & 244 & 257 & 231 & 270 & 270 & 270 & 257 & 244 & 257 & 244 & 219 & 206 & 154 & 167 & 167 \\
\hline 335 & 306 & 286 & 256 & 247 & 217 & 237 & 227 & 187 & 148 & 128 & 138 & 158 & 138 & 128 & 138 \\
\hline 425 & 390 & 425 & 354 & 301 & 301 & 213 & 213 & 213 & 107 & 107 & 35 & 35 & 35 & 35 & 35 \\
\hline 182 & 0 & 0 & 0 & 0 & 0 & 0 & 0 & 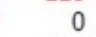 & 0 & 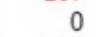 & 0 & 0 & 0 & 0 & 0 \\
\hline 99 & 99 & 152 & 183 & 198 & 183 & 168 & 168 & 168 & 152 & 152 & 152 & 152 & 152 & 168 & 198 \\
\hline 204 & 204 & 204 & 82 & 82 & 82 & 82 & 82 & 82 & 82 & 82 & 0 & 0 & 0 & 0 & 0 \\
\hline
\end{tabular}


Táboa 18. Casos novos en Ferrolterra do 10 ao 25 de marzo de 2021.

Casos novos

Casos novos

$10 /$ mar $11 /$ mar $12 /$ mar $13 /$ mar $14 /$ mar $15 /$ mar $16 /$ mar $17 /$ mar $18 /$ mar $19 /$ mar $20 /$ mar $21 /$ mar $22 /$ mar $23 /$ mar $24 /$ mar $25 /$ mar

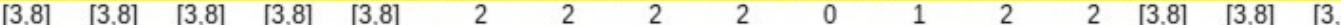

$\begin{array}{rrrrrrrrrrrrrrrr}{[2,4]} & {[2,4]} & {[2,4]} & {[2,4]} & {[2,4]} & {[2,4]} & {[2,4]} & {[2,4]} & {[2,4]} & {[2,4]} & {[2,4]} & {[2,4]} & {[2,4]} & {[2,4]} & 0 & 0 \\ 0 & 0 & 0 & 0 & 0 & 0 & 0 & 0 & 0 & 0 & 0 & 0 & 0 & 0 & 0 & 0 \\ {[6,9]} & {[6,9]} & {[2,5]} & {[2,5]} & {[2,5]} & {[2,5]} & {[2,5]} & {[2,5]} & {[2,5]} & {[2,5]} & {[2,5]} & {[2,5]} & {[2,5]} & {[2,5]} & {[2,5]} & {[2,5]}\end{array}$

2,4] $\quad 0 \quad 0$

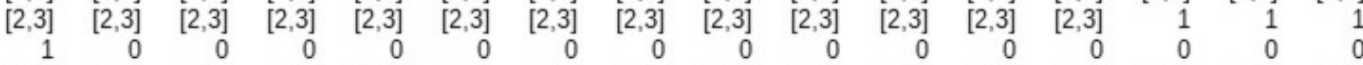

$\begin{array}{rrrrrrrrrrrrrrrr}{[4,6]} & {[4,6]} & {[4,6]} & {[4,6]} & {[4,6]} & {[4,6]} & {[4,6]} & {[4,6]} & {[7,9]} & {[7,9]} & {[7,9]} & {[7,9]} & {[4,6]} & {[4,6]} & {[4,6]} & {[4,6]}\end{array}$

$\begin{array}{rrrrrrrrrrrrrrrr}56 & 56 & 73 & 72 & 74 & 75 & 72 & 76 & 76 & 72 & 68 & 64 & 60 & 60 & 65 & 64 \\ 0 & 0 & 0 & 0 & 0 & 0 & 0 & 0 & 0 & 0 & 0 & 0 & 0 & 0 & 0 & 0 \\ 18 & 12 & 15 & {[4,9]} & {[4,9]} & {[4,9]} & {[4,9]} & 10 & 10 & {[4,9]} & {[4,9]} & {[4,9]} & {[4,9]} & {[4,9]} & {[4,9]} & {[4,9]}\end{array}$

$\begin{array}{rrrrrrrrrrrrrrrr}18 & 12 & 15 & {[4,9]} & {[4,9]} & {[4,9]} & {[4,9]} & 10 & 10 & {[4,9]} & {[4,9]} & {[4,9]} & {[4,9]} & {[4,9]} & {[4,9]} & {[4,9]} \\ 0 & 0 & 0 & 0 & 0 & 0 & 0 & 0 & 0 & 0 & 0 & 0 & 0 & 0 & 1 & 1\end{array}$

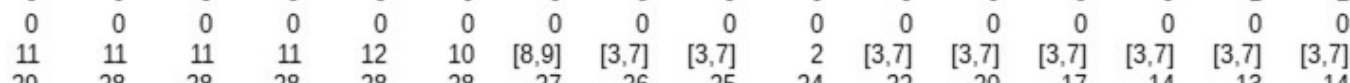

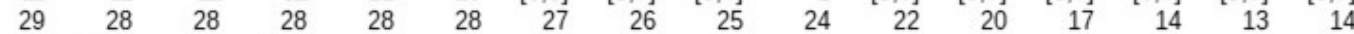

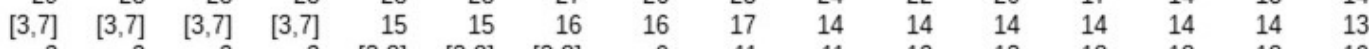

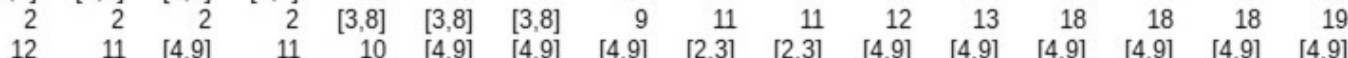

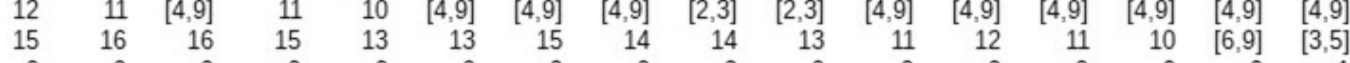

$\begin{array}{llllllllllllllll}0 & 0 & 0 & 0 & 0 & 0 & 0 & 0 & 0 & 0 & 0 & 0 & 0 & 0 & 0 & 1 \\ 0 & 0 & 0 & 0 & 0 & 0 & 0 & 0 & 0 & 0 & 0 & 0 & 0 & 0 & 0 & 0\end{array}$

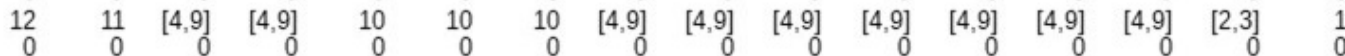

Táboa 19. Incidencia acumulada a 14 días e número de concellos por tramo de incidencia en Ferrolterra do 10 ao 25 de marzo de 2021.

número de concellos en cada tramo

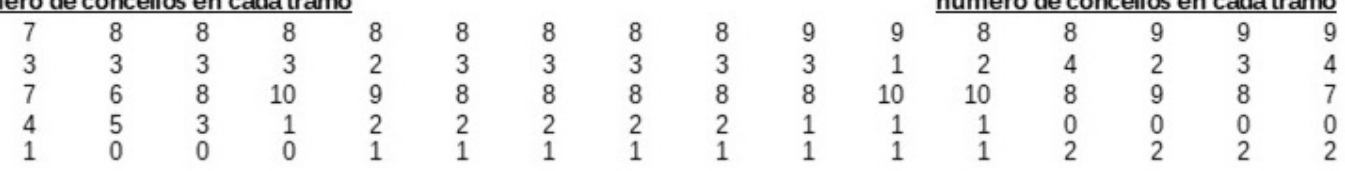

IA14 días

\begin{tabular}{|c|c|c|c|c|c|c|c|c|c|c|c|c|c|c|c|}
\hline nar & Imar & mar & mar & mar & mar & ma & ma & Imar & /mar & /mar & /mar & mar & $/ \mathrm{ma}$ & $\mathrm{m}$ & \\
\hline 96 & 96 & 96 & 96 & 96 & 35 & 35 & 35 & 35 & 0 & 17 & 35 & 35 & 96 & 96 & 96 \\
\hline 92 & 92 & 92 & 92 & 92 & 92 & 92 & 92 & 92 & 92 & 92 & 92 & 92 & 92 & 0 & 0 \\
\hline 0 & 0 & 0 & 0 & 0 & 0 & 0 & 0 & 0 & 0 & 0 & 0 & 0 & 0 & 0 & 0 \\
\hline 195 & 195 & 91 & 91 & 91 & 91 & 91 & 91 & 91 & 91 & 91 & 91 & 91 & 91 & 91 & 91 \\
\hline 38 & 38 & 38 & 38 & 38 & 38 & 38 & 38 & 38 & 38 & 38 & 38 & 38 & 15 & 15 & 15 \\
\hline 90 & 0 & 0 & 0 & 0 & 0 & 0 & 0 & 0 & 0 & 0 & 0 & 0 & 0 & 0 & \\
\hline 39 & 39 & 39 & 39 & 39 & 39 & 39 & 39 & 62 & 62 & 62 & 62 & 39 & 39 & 39 & 39 \\
\hline 85 & 85 & 110 & 109 & 112 & 114 & 109 & 115 & 115 & 109 & 103 & 97 & 91 & 91 & 98 & 97 \\
\hline 0 & 0 & 0 & 0 & 0 & 0 & 0 & 0 & 0 & 0 & 0 & 0 & 0 & 0 & 0 & \\
\hline 290 & 194 & 242 & 105 & 105 & 105 & 105 & 161 & 161 & 105 & 105 & 105 & 105 & 105 & 105 & 105 \\
\hline 0 & 0 & 0 & 0 & 0 & 0 & 0 & 0 & 0 & 0 & 0 & 0 & 0 & 0 & 82 & 82 \\
\hline 0 & 0 & 0 & 0 & 0 & 0 & 0 & 0 & 0 & 0 & 0 & 0 & 0 & 0 & 0 & \\
\hline 210 & 210 & 210 & 210 & 229 & 191 & 163 & 95 & 95 & 38 & 95 & 95 & 95 & 95 & 95 & 95 \\
\hline 74 & 72 & 72 & 72 & 72 & 72 & 69 & 67 & 64 & 61 & 56 & 51 & 44 & 36 & 33 & \\
\hline 99 & 99 & 99 & 99 & 295 & 295 & 315 & 315 & 335 & 276 & 276 & 276 & 276 & 276 & 276 & 256 \\
\hline 35 & 35 & 35 & 35 & 97 & 97 & 97 & 159 & 194 & 194 & 212 & 229 & 317 & 317 & 317 & 335 \\
\hline 154 & 141 & 84 & 141 & 129 & 84 & 84 & 84 & 33 & 33 & 84 & 84 & 84 & 84 & 84 & 84 \\
\hline 148 & 158 & 158 & 148 & 128 & 128 & 148 & 138 & 138 & 128 & 109 & 118 & 109 & 99 & 74 & \\
\hline 0 & 0 & 0 & 0 & 0 & 0 & 0 & 0 & 0 & 0 & 0 & 0 & 0 & 0 & 0 & \\
\hline 0 & 0 & 0 & 0 & 0 & 0 & 0 & 0 & 0 & 0 & 0 & 0 & 0 & 0 & 0 & \\
\hline 183 & 168 & 99 & 99 & 152 & 152 & 152 & 99 & 99 & 99 & 99 & 99 & 99 & 99 & 38 & \\
\hline 0 & 0 & 0 & 0 & 0 & 0 & 0 & 0 & 0 & 0 & 0 & 0 & 0 & 0 & 0 & \\
\hline
\end{tabular}


Táboa 20. Casos novos en Ferrolterra do 26 ao 31 de marzo de 2021.

\begin{tabular}{|c|c|c|c|c|c|}
\hline \multicolumn{2}{|c|}{ Casos novos } & & & & Casos novos \\
\hline $26 /$ mar & $27 /$ mar & 28/mar & 29/mar & $30 /$ mar & 31/mar CONCELO \\
\hline$[3,8]$ & {$[3,8]$} & {$[3,8]$} & {$[3,8]$} & {$[3,8]$} & {$[3,8]_{\text {Ares }}$} \\
\hline 0 & 0 & 0 & 0 & 0 & 0 Cabanas \\
\hline 0 & 0 & 0 & 0 & 0 & OCapela A \\
\hline$[2,5]$ & {$[2,5]$} & 1 & 1 & 0 & 0 Cariño \\
\hline 1 & 1 & 1 & 1 & 1 & 1 Cedeira \\
\hline 0 & 0 & 0 & 0 & 0 & 0 Cerdido \\
\hline$[4,6]$ & {$[4,6]$} & {$[4,6]$} & {$[4,6]$} & {$[4,6]$} & {$[1,3]$ Fene } \\
\hline 46 & 47 & 44 & 46 & 47 & 42 Ferrol \\
\hline 0 & 0 & 0 & 0 & 0 & 0Mañón \\
\hline$[4,9]$ & {$[4,9]$} & {$[4,9]$} & {$[4,9]$} & {$[2,3]$} & {$[2,3]^{\text {Miño }}$} \\
\hline 1 & 1 & 1 & 1 & 1 & 1 Moeche \\
\hline 0 & 0 & 0 & 0 & 0 & 0 Monfero \\
\hline$[3,7]$ & {$[3,7]$} & {$[3,7]$} & {$[3,7]$} & {$[3,7]$} & {$[3,7]^{\text {Mugardos }}$} \\
\hline 13 & 13 & 13 & 12 & 11 & $11^{\text {Narón }}$ \\
\hline 10 & {$[8,9]$} & 2 & 2 & 1 & $1^{\text {Neda }}$ \\
\hline 16 & 17 & 13 & 14 & 14 & 12 Ortigueira \\
\hline$[4,9]$ & {$[4,9]$} & {$[4,9]$} & {$[4,9]$} & {$[4,9]$} & {$[4,9]$ Pontedeume } \\
\hline$[3,5]$ & {$[3,5]$} & {$[3,5]$} & {$[3,5]$} & {$[3,5]$} & {$[3,5]$ Pontes, As } \\
\hline 1 & 1 & 1 & 1 & 1 & 1 S. Sadurniño \\
\hline 0 & 0 & 0 & 0 & 0 & 0 Somozas, As \\
\hline 1 & 1 & 0 & 0 & 0 & 0 Valdoviño \\
\hline 0 & 0 & 0 & 0 & 0 & 0 \\
\hline
\end{tabular}

Táboa 21. Incidencia acumulada a 14 días e número de concellos por tramo de incidencia en Ferrolterra do 26 ao 31 de marzo de 2021.

$\begin{array}{ccccc}\text { número de concellos en cada tramo } \\ & 9 & 9 & 9 & 11 \\ 4 & 4 & 6 & 6 & 5 \\ 7 & 7 & 6 & 6 & 5 \\ 1 & 1 & 1 & 1 & 1 \\ 1 & 1 & 0 & 0 & 0\end{array}$

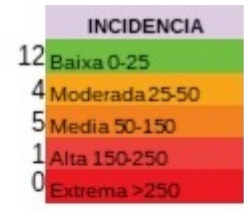

IA 14 días

\begin{tabular}{|c|c|c|c|c|c|}
\hline $26 / \mathrm{mar}$ & $27 /$ mar & $28 / \mathrm{mar}$ & 29/mar & $30 /$ mar & $31 / \mathrm{mar}$ CONCEUO \\
\hline 96 & 96 & 96 & 96 & 96 & 96 Ares \\
\hline 0 & 0 & 0 & 0 & 0 & 0 Cabanas \\
\hline 0 & 0 & 0 & 0 & 0 & 0 Capela A \\
\hline 91 & 91 & 26 & 26 & 0 & 0 Cariño \\
\hline 15 & 15 & 15 & 15 & 15 & 15 Cedeira \\
\hline 0 & 0 & 0 & 0 & 0 & 0 Cerdido \\
\hline 39 & 39 & 39 & 39 & 39 & 16 Fene \\
\hline 70 & 71 & 67 & 70 & 71 & 64 Ferrol \\
\hline 0 & 0 & 0 & 0 & 0 & 0 Mañón \\
\hline 105 & 105 & 105 & 105 & 40 & 40 Miño \\
\hline 82 & 82 & 82 & 82 & 82 & 82 Moeche \\
\hline 0 & 0 & 0 & 0 & 0 & 0 Monfero \\
\hline 95 & 95 & 95 & 95 & 95 & $95^{\text {Mugardos }}$ \\
\hline 33 & 33 & 33 & 31 & 28 & 28 Narón \\
\hline 197 & 167 & 39 & 39 & 20 & 20 Neda \\
\hline 282 & 300 & 229 & 247 & 247 & 212 Ortigueira \\
\hline 84 & 84 & 84 & 84 & 84 & $84^{\text {Pontedeume }}$ \\
\hline 40 & 40 & 40 & 40 & 40 & 40 Pontes, As \\
\hline 35 & 35 & 35 & 35 & 35 & 35 S. Sadurniño \\
\hline 0 & 0 & 0 & 0 & 0 & 0 Somozas, As \\
\hline 15 & 15 & 0 & 0 & 0 & 0 Valdovino \\
\hline 0 & 0 & 0 & 0 & 0 & 0 \\
\hline
\end{tabular}




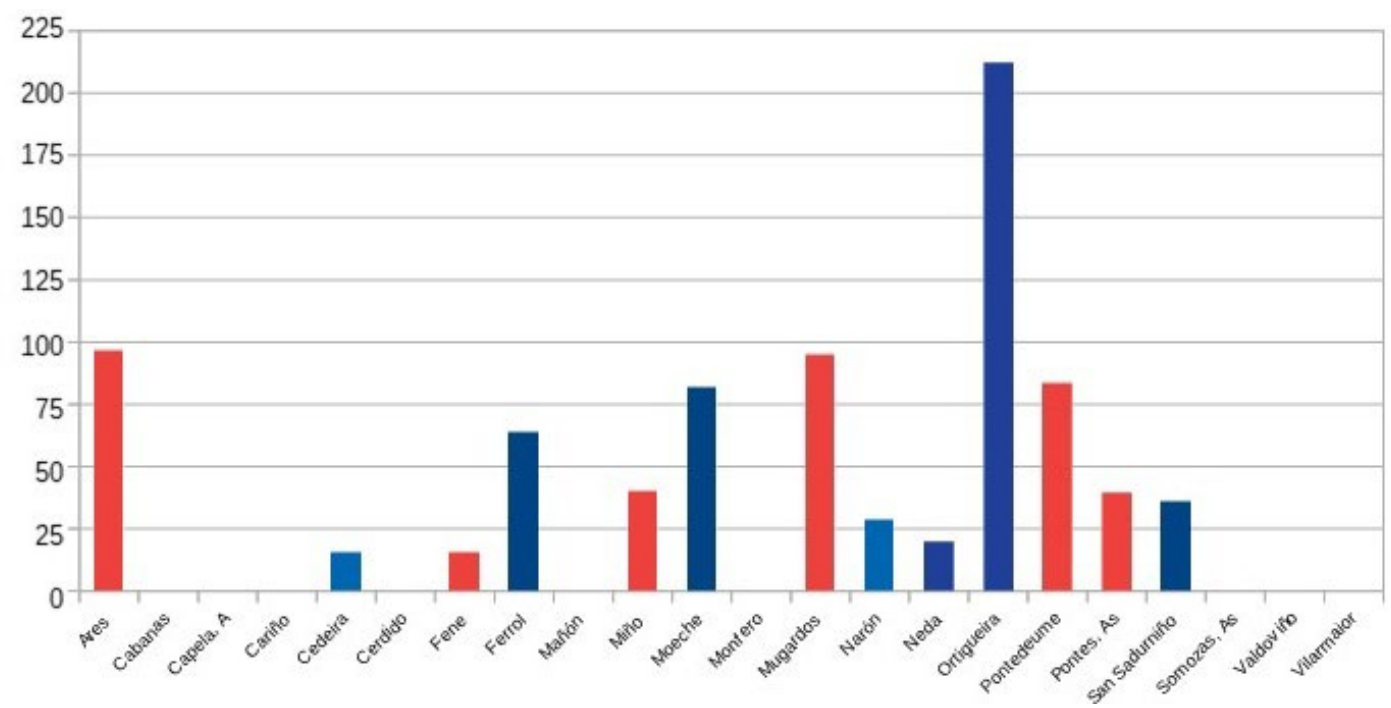

Figura 18. Incidencia acumulada o 31 de marzo dos concellos de Ferrolterra.

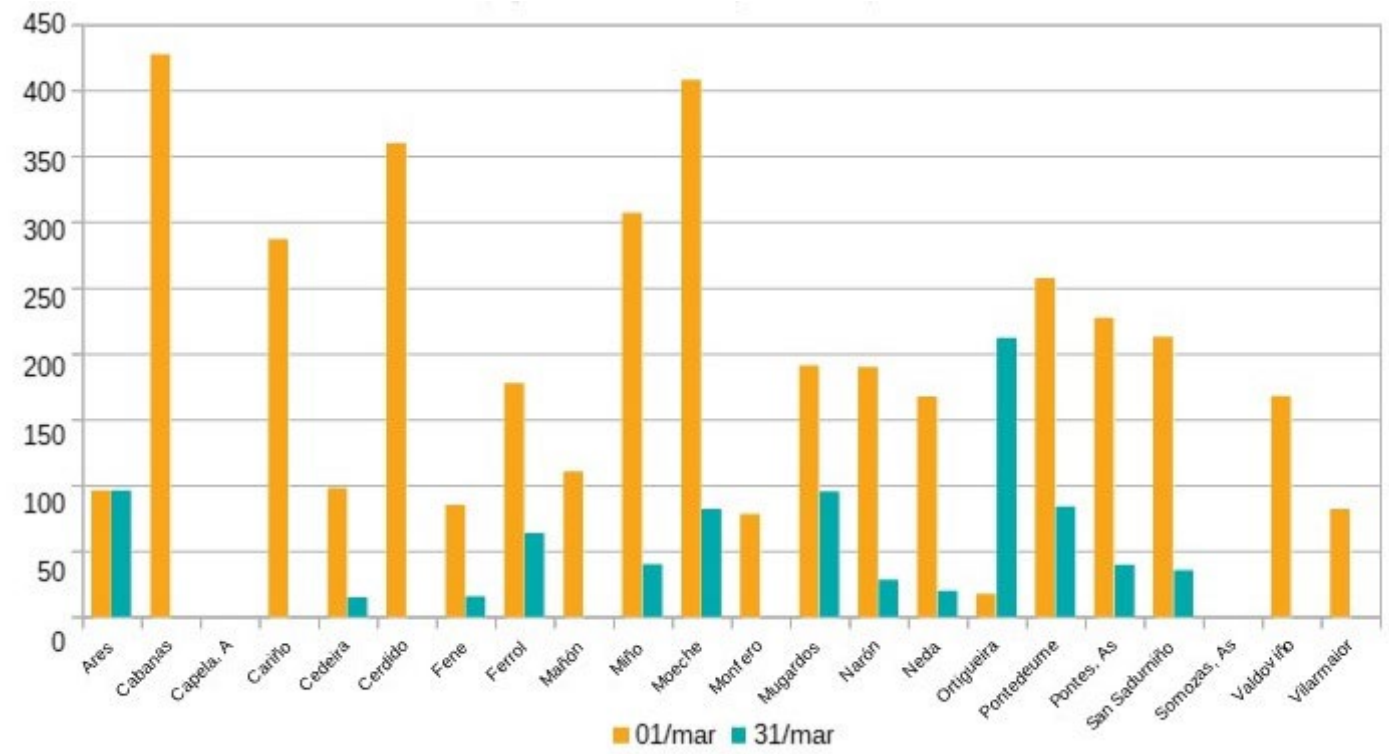

Figura 19. Comparativa dos valores de incidencia acumulada o 1 e o 31 de marzo dos concellos de Ferrolterra (algúns valores son aproximados). 


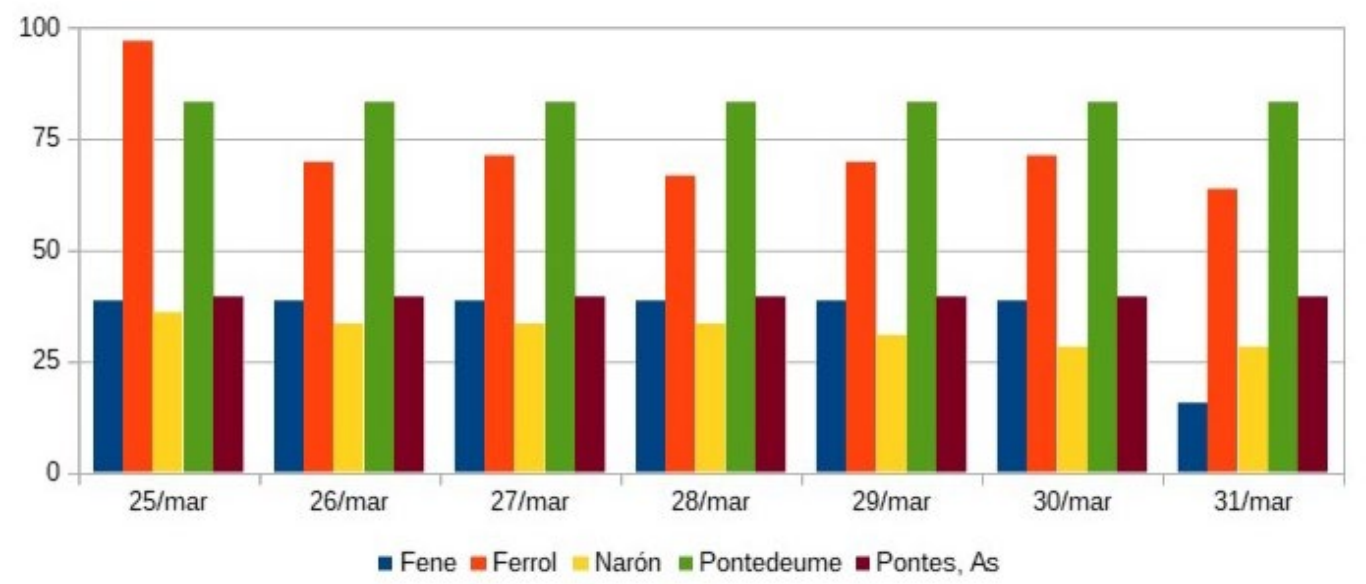

Figura 20. Incidencia acumulada nos últimos sete días de marzo de 2021 nos cinco concellos máis poboados de Ferrolterra.

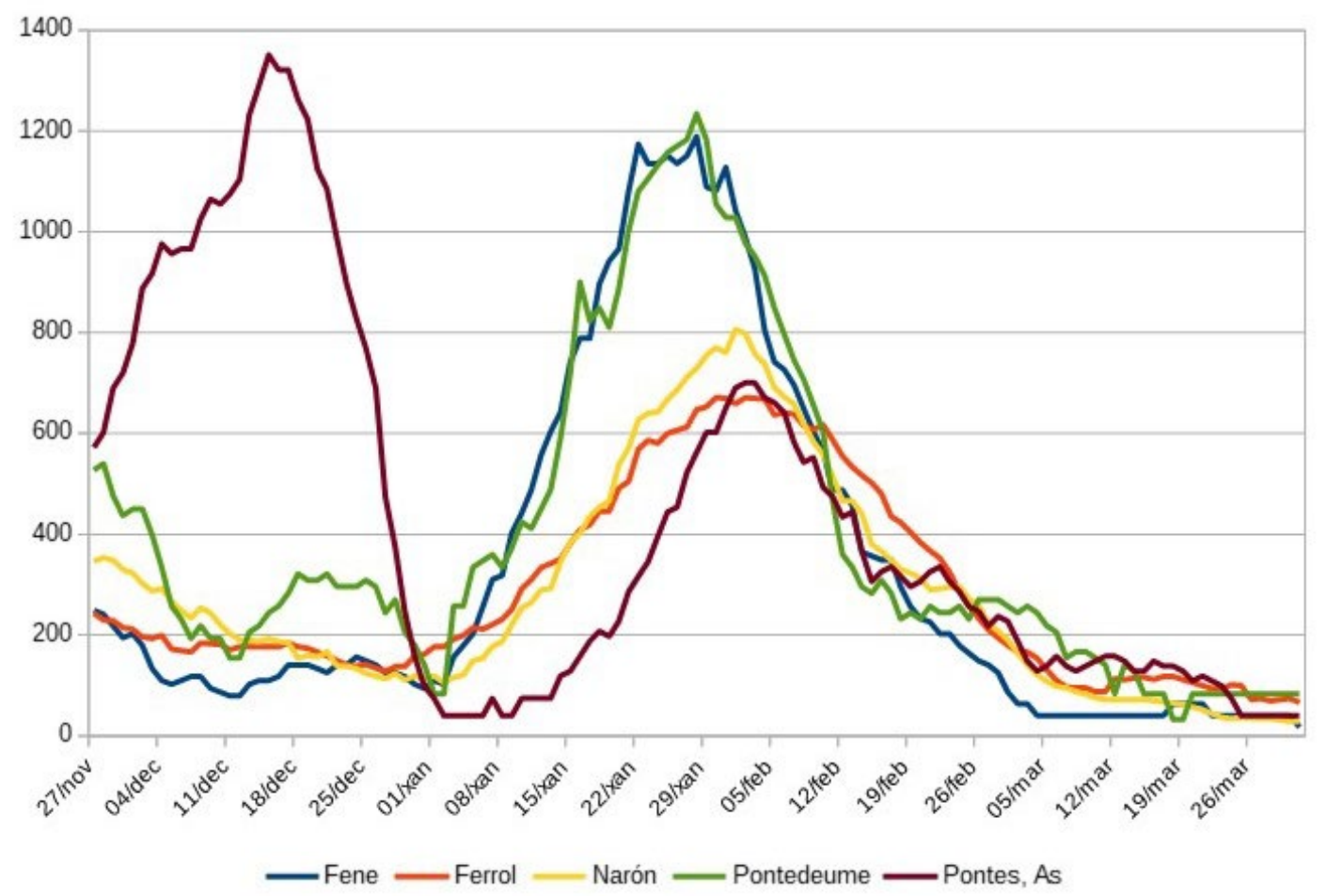

Figura 21. Evolución da incidencia acumulada desde o 27 de novembro de 2021 nos cinco concellos máis poboados de Ferrolterra. 


\subsection{As sete cidades galegas}

Usando a mesma metodoloxía ca en Ferrolterra, o 20 de decembro comecei a recompilar os datos dos casos novos e da incidencia acumulada a 14 días nas sete cidades galegas, tirados da citada páxina web do Sergas. A partir do primeiro de marzo, recóllense tamén os casos novos e as incidencias acumuladas a 7 días.

Os gráficos presentados son: un gráfico lineal da evolución da IA a 14 días desde o 20 de decembro ata o 31 de marzo no que se aprecian moi ben os picos da terceira vaga nas sete cidades (é interesante a forma case perfecta de campá de Gauss da gráfica de Ourense); dous gráficos de barras horizontais das IA nos últimos sete días de marzo no que cada barra amosa a IA total nun certo día das sete cidades (comparando as lonxitudes destas barras apréciase se a IA está aumentando ou diminuíndo no conxunto das cidades); un diagrama de rede coas IA a 7 e a 14 días do último día de marzo (o derradeiro con datos); e finalmente sete gráficos lineais para cada unha das cidades para as IA a 7 e a 14 días durante o mes de marzo.

Táboa 22. Casos novos nos últimos 14 días e incidencia acumulada a 14 días nas principais cidades galegas do 20 de decembro de 2020 ao 15 de xaneiro de 2021.

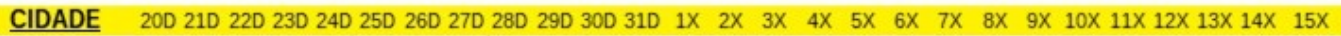

\begin{tabular}{|c|c|c|}
\hline & Casos novos nos últimos 14 días & lovos \\
\hline CORUÑA. & 289280289289302305302 & \\
\hline FERROL & $\begin{array}{llllllllll}108103 & 97 & 91 & 90 & 92 & 87 & 83 & 89 & 89103105115115125130140138144151164191203219224230\end{array}$ & 251 \\
\hline LUGO & 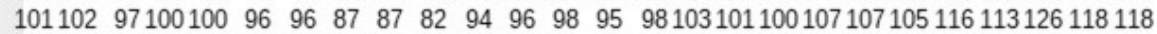 & 124 \\
\hline OURENSE & 151151155158157156142135140138151161162157168179192204221241272301335378422458 & 486 \\
\hline PONTEVEDRA & 167161152156167152149143129132127121113118128131133130119123124131146151162176 & 190 \\
\hline SANTIAGO & 1911932002122122102072011962152122112332272192262402402693033163213503 & 471 \\
\hline VIGO & 517507522573530549521519528507511530541545538536528532536590592624653712749767 & 837 \\
\hline CORUṄA, A & 118114118118123124123119123138158173192193198208231250263280298319 & 420 \\
\hline FERROL & 139132126135135156159174174189197212209218229248289307331339348 & \\
\hline LUGO & $10310499102102 \quad 98 \quad 98 \quad 898983 \quad 96 \quad 98100 \quad 97100105103102109109107118115128120120$ & 126 \\
\hline OURENSE & 143143147150149148135128133131143153154149160170182194210229258286318359401435 & \\
\hline PONTEVEDRA & 1831791721551591531461361421 & 229 \\
\hline SANTIAGO & 196198206218218216213207202221218217240233225232247247277312325330360374428459 & 484 \\
\hline VIGO & 175172177194179186176176179172173179183185182181179180181200200211221241254260 & \\
\hline
\end{tabular}

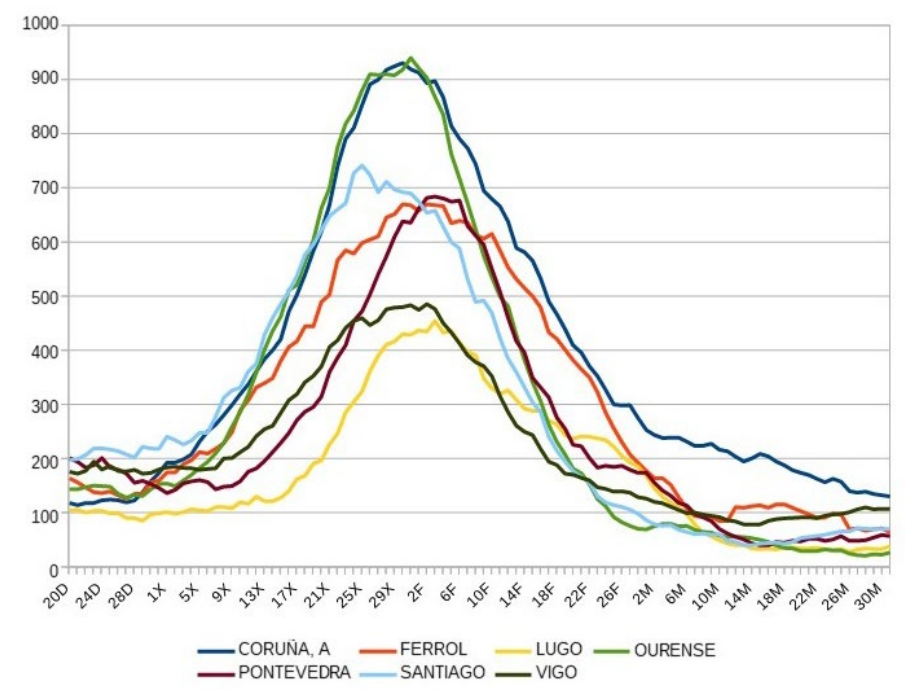

Figura 22. Evolución da incidencia acumulada a 14 días desde o 20 de decembro de 2020 ata o 31 de marzo de 2021 nas sete cidades galegas. 
Táboa 23. Casos novos nos últimos 14 días e incidencia acumulada a 14 días nas principais cidades galegas do 17 de xaneiro ao 8 de febreiro de 2021.

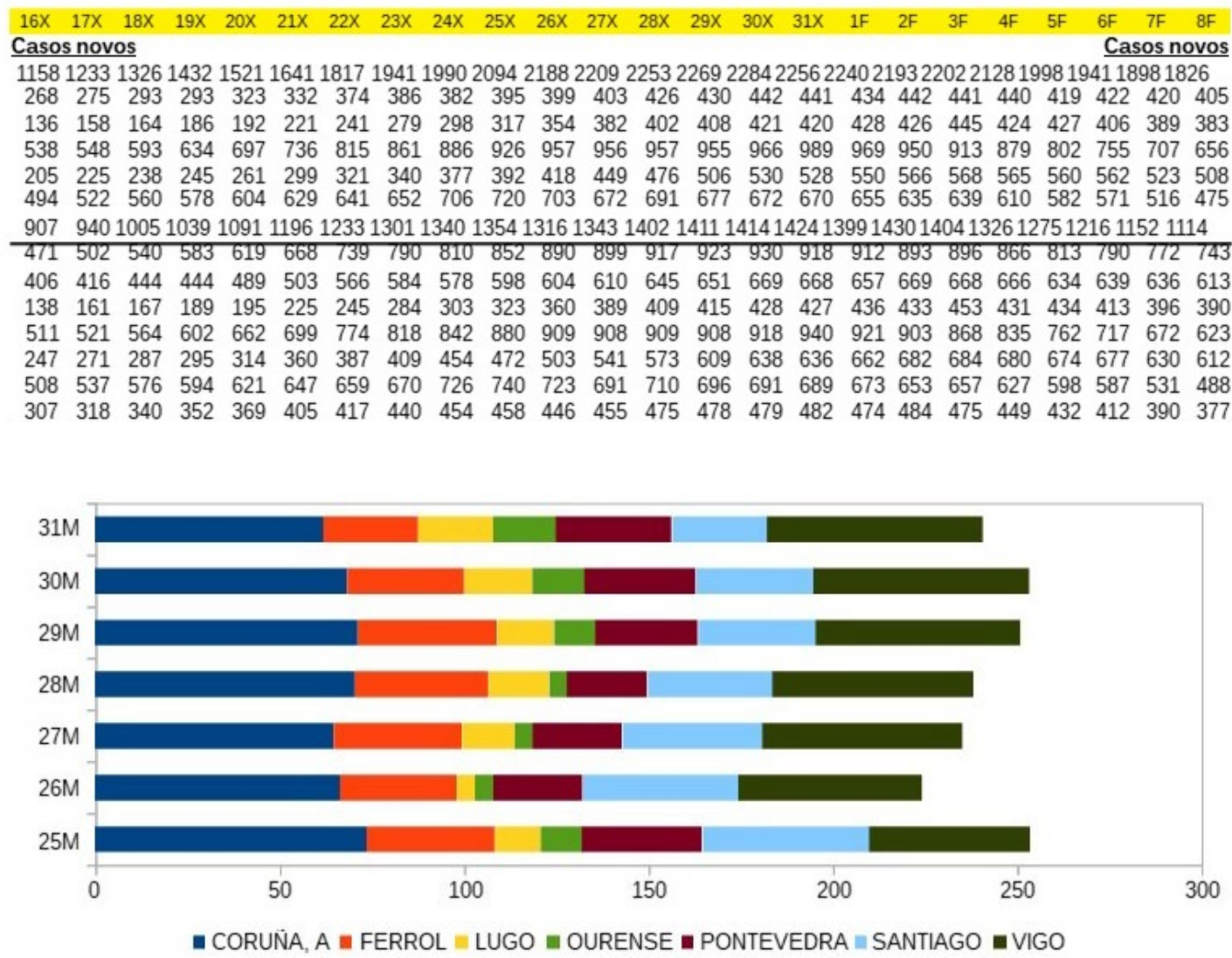

Figura 23. Incidencia acumulada a sete días nos últimos sete días de marzo de 2021 nas sete cidades galegas.

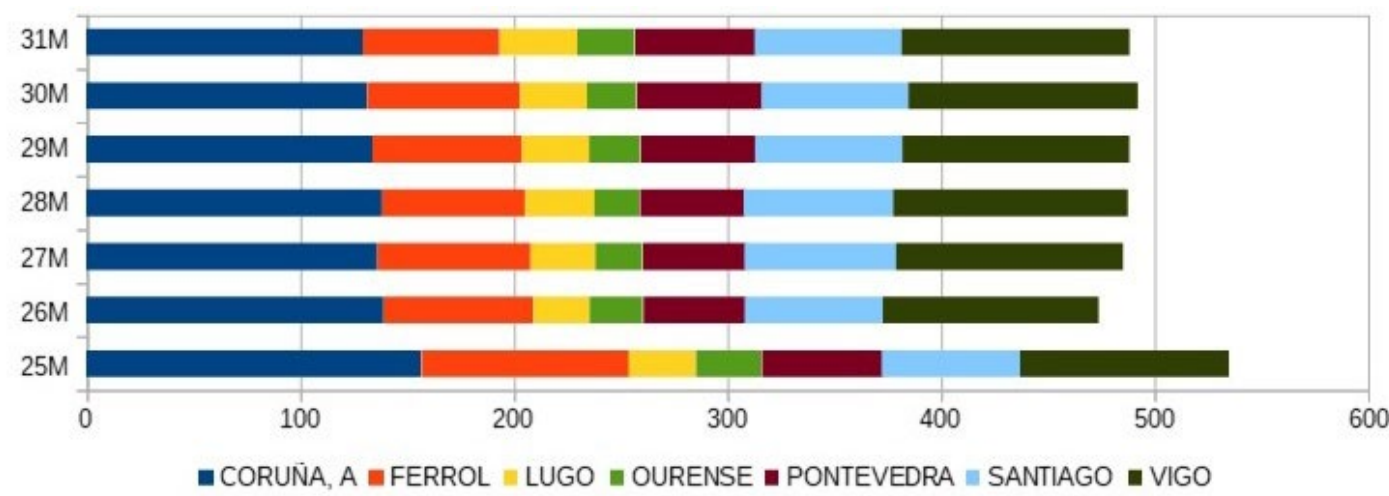

Figura 24. Incidencia acumulada a catorce días nos últimos sete días de marzo de 2021 nas sete cidades galegas. 
Táboa 24. Casos novos nos últimos 14 días e incidencia acumulada a 14 días nas principais cidades galegas do 9 de febreiro ao 6 de marzo de 2021.

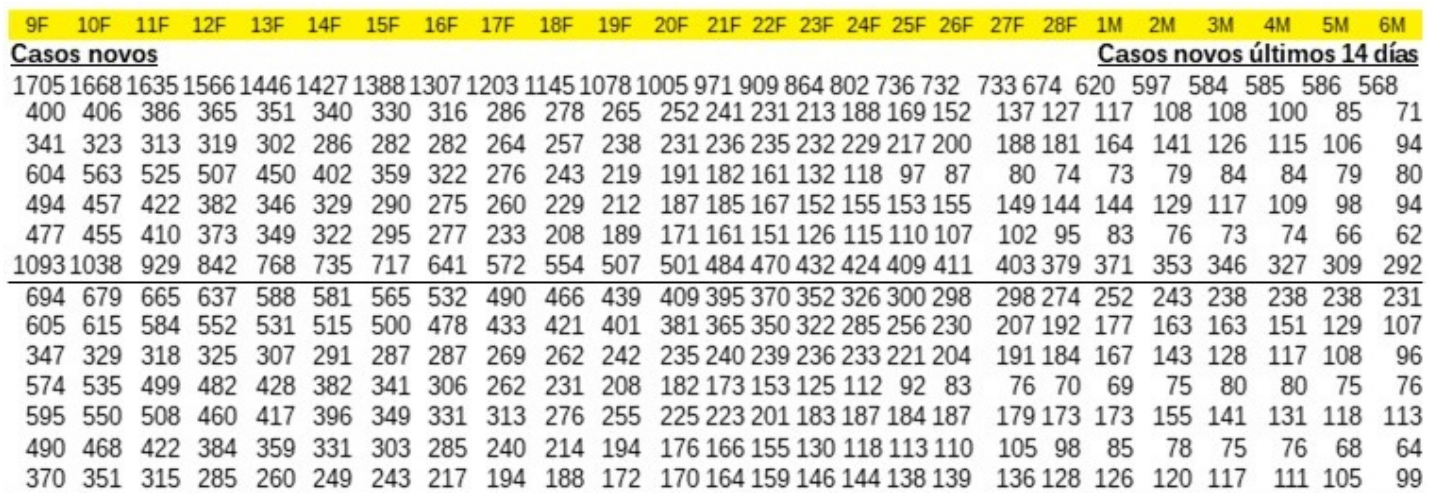

Táboa 25. Casos novos nos últimos 7 días e razón entre as IAs nas principais cidades galegas do 1 ao 6 de marzo de 2021.

\begin{tabular}{lrrrrrr} 
& $1 M$ & $2 M$ & $3 M$ & $4 M$ & $5 M$ & $6 M$ \\
AC & 267 & 261 & 261 & 269 & 255 & 242 \\
FE & 26 & 24 & 21 & 22 & 27 & 28 \\
LU & 46 & 39 & 29 & 26 & 21 & 23 \\
OU & 33 & 42 & 40 & 41 & 42 & 43 \\
PO & 64 & 53 & 41 & 34 & 26 & 23 \\
SA & 35 & 32 & 32 & 24 & 22 & 20 \\
VI & 164 & 158 & 151 & 148 & 138 & 122 \\
\hline AC & 109 & 106 & 106 & 109 & 104 & 98 \\
FE & 39 & 36 & 32 & 33 & 41 & 42 \\
LU & 47 & 40 & 30 & 26 & 21 & 23 \\
OU & 31 & 40 & 38 & 39 & 40 & 41 \\
PO & 77 & 64 & 49 & 41 & 31 & 28 \\
SA & 36 & 33 & 33 & 25 & 23 & 21 \\
VI & 56 & 53 & 51 & 50 & 47 & 41 \\
\hline AC & 0,43 & 0,44 & 0,45 & 0,46 & 0,44 & 0,43 \\
FE & 0,22 & 0,22 & 0,19 & 0,22 & 0,32 & 0,39 \\
LU & 0,28 & 0,28 & 0,23 & 0,23 & 0,20 & 0,24 \\
OU & 0,45 & 0,53 & 0,48 & 0,49 & 0,53 & 0,54 \\
PO & 0,44 & 0,41 & 0,35 & 0,31 & 0,27 & 0,24 \\
SA & 0,42 & 0,42 & 0,44 & 0,32 & 0,33 & 0,32 \\
VI & 0,44 & 0,45 & 0,44 & 0,45 & 0,45 & 0,42
\end{tabular}

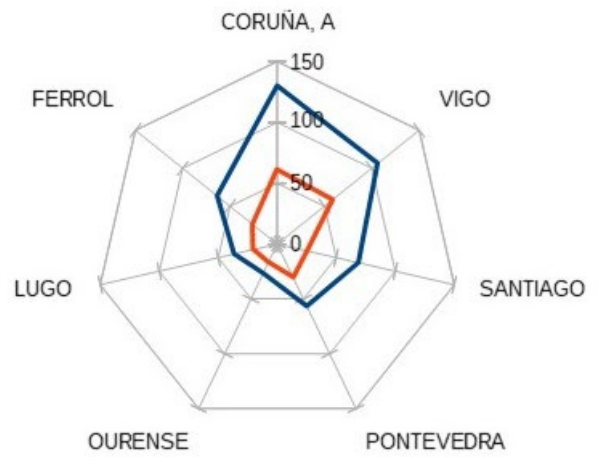

Figura 25. Incidencia acumulada a catorce días para o 31 de marzo de 2021 nas sete cidades galegas. 
Táboa 26. Casos novos nos últimos 14 e 7 días e razón entre as IAs nas principais cidades galegas do 7 ao 31 de marzo de 2021. Os valores en vermello da IA a 7 días son a media do intervalo no que se acha o valor real. Este dato úsase para calcular a razón entre ambas IA, polo que estas tamén aparecen en vermello.

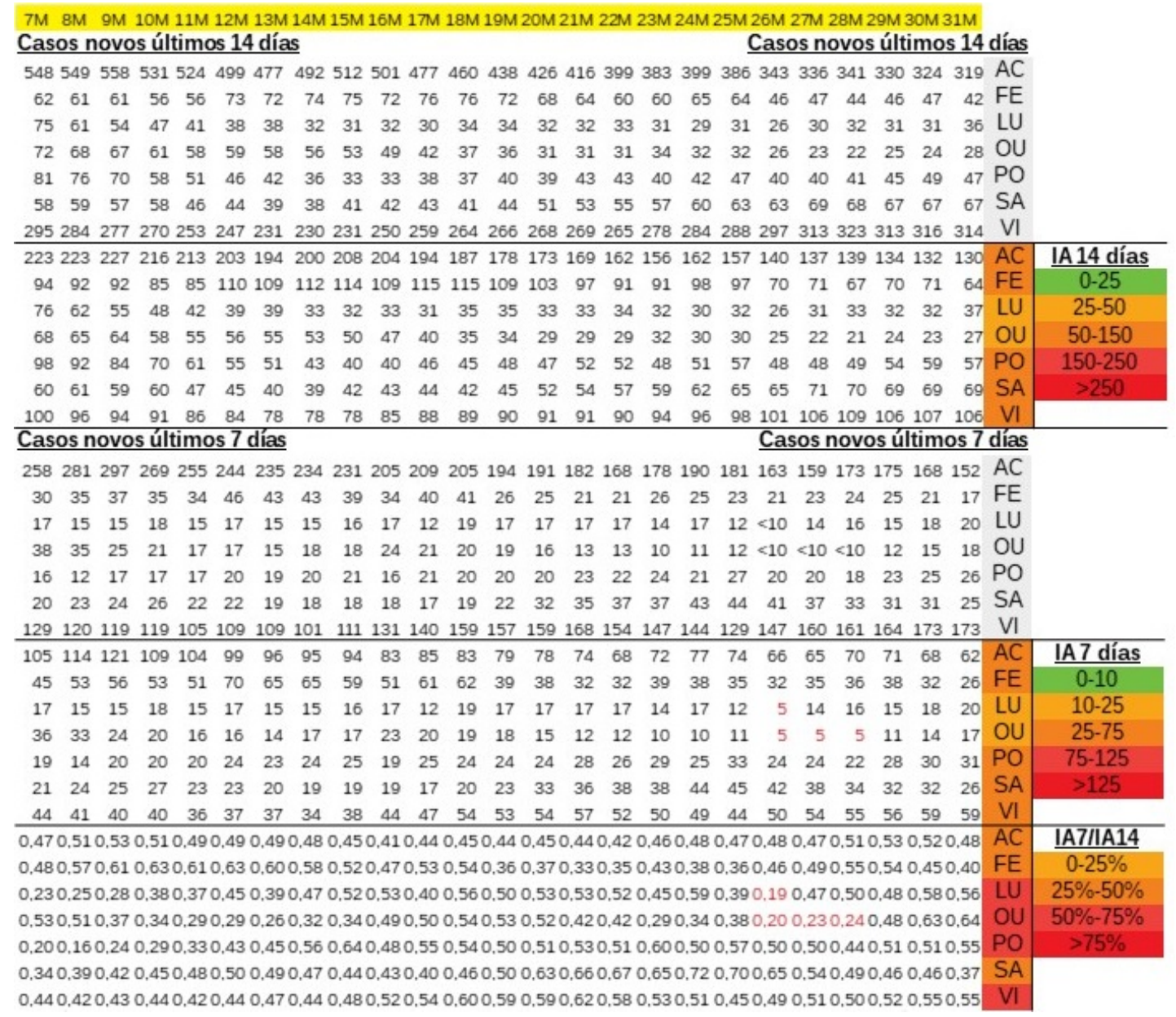




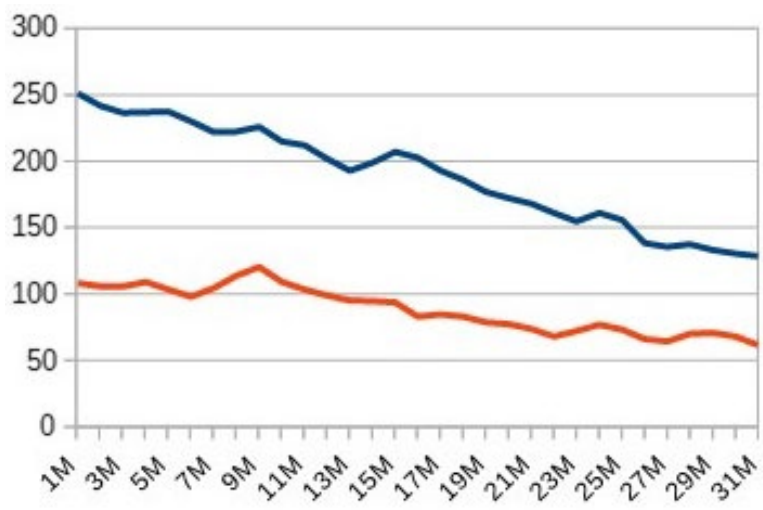

Figura 26. Incidencia acumulada a 7 e 14 días para a cidade de A Coruña do 1 ao 31 de marzo de 2021.

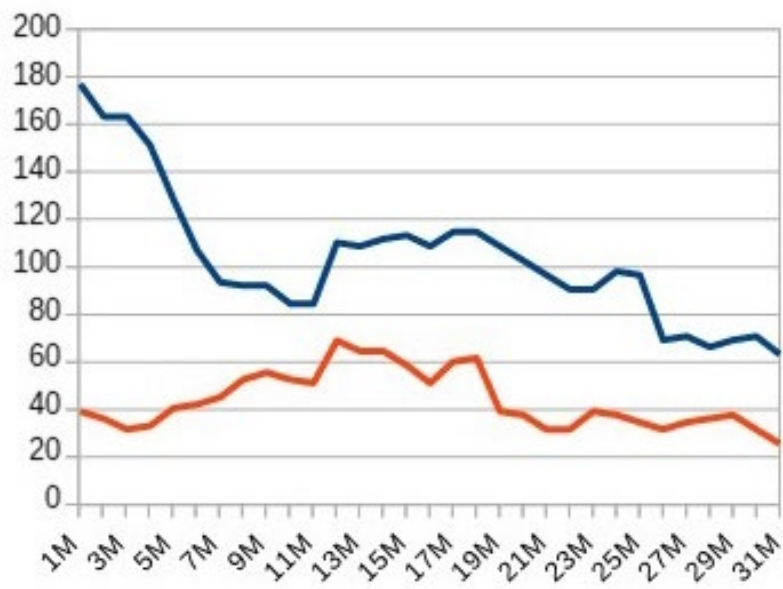

Figura 27. Incidencia acumulada a 7 e 14 días para a cidade de Ferrol do 1 ao 31 de marzo de 2021.

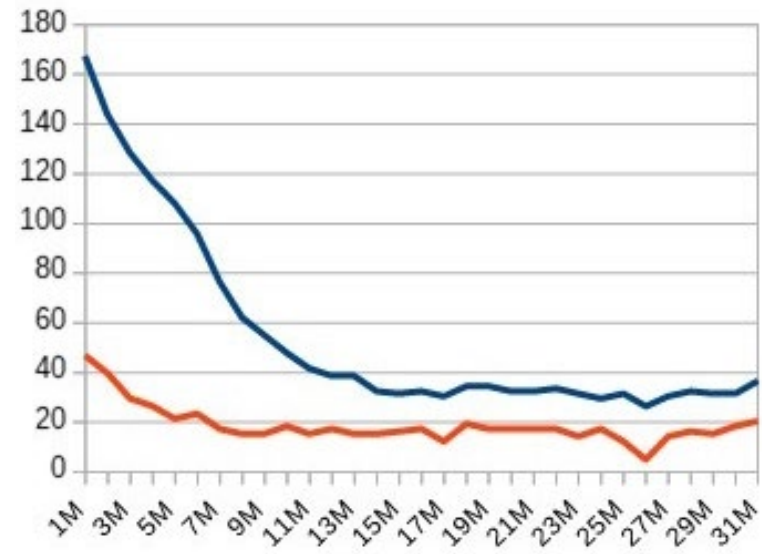

Figura 28. Incidencia acumulada a 7 e 14 días para a cidade de Lugo do 1 ao 31 de marzo de 2021. 


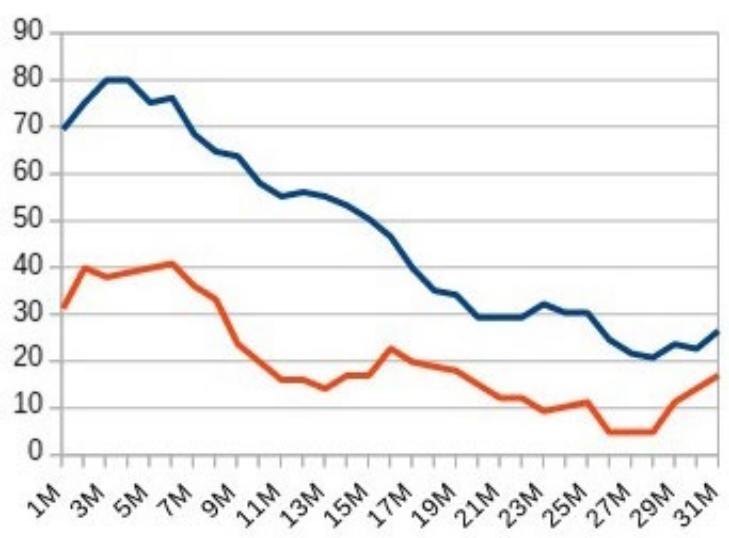

Figura 29. Incidencia acumulada a 7 e 14 días para a cidade de Ourense do 1 ao 31 de marzo de 2021.

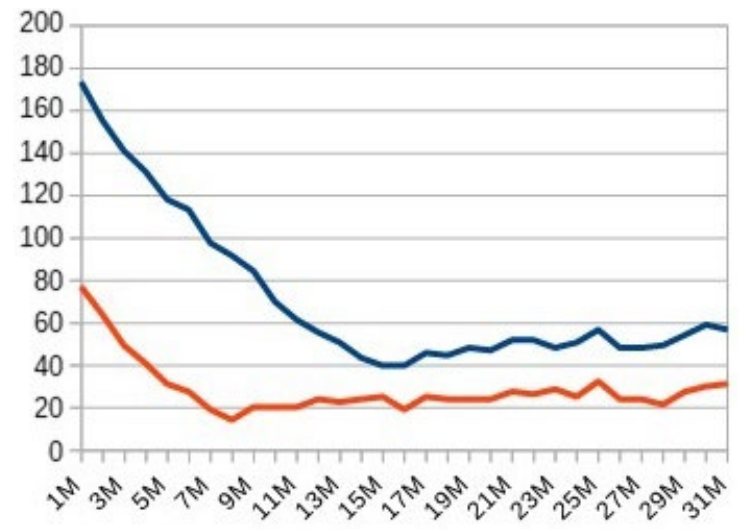

Figura 30. Incidencia acumulada a 7 e 14 días para a cidade de Pontevedra do 1 ao 31 de marzo de 2021.

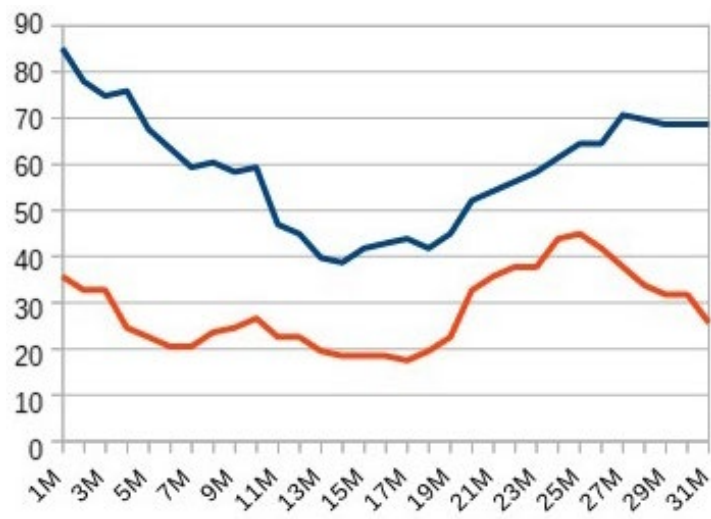

Figura 31. Incidencia acumulada a 7 e 14 días para a cidade de Santiago de Compostela do 1 ao 31 de marzo de 2021. 


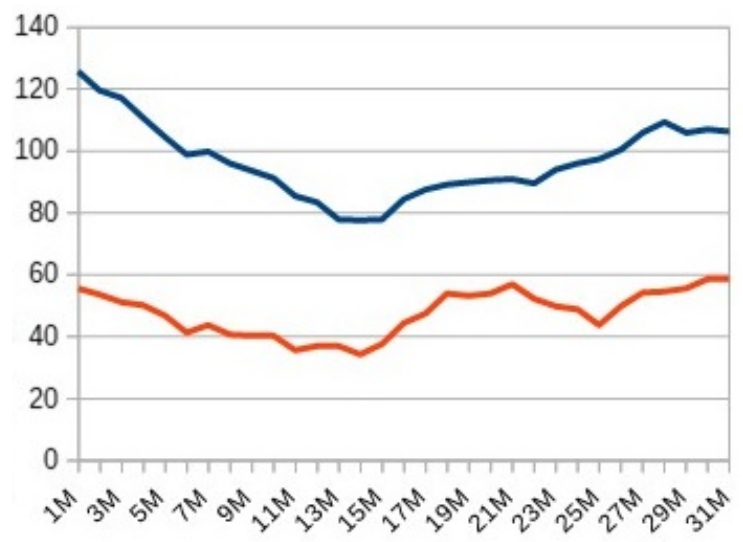

Figura 32. Incidencia acumulada a 7 e 14 días para a cidade de Vigo do 1 ao 31 de marzo de 2021. 